\title{
Learning in internships : what and how students learn from experience
}

Citation for published version (APA):

Wagenaar, A. (2008). Learning in internships : what and how students learn from experience. [Doctoral Thesis, Maastricht University]. Datawyse / Universitaire Pers Maastricht.

https://doi.org/10.26481/dis.20081218aw

Document status and date:

Published: 01/01/2008

DOI:

10.26481/dis.20081218aw

Document Version:

Publisher's PDF, also known as Version of record

\section{Please check the document version of this publication:}

- A submitted manuscript is the version of the article upon submission and before peer-review. There can be important differences between the submitted version and the official published version of record.

People interested in the research are advised to contact the author for the final version of the publication, or visit the DOI to the publisher's website.

- The final author version and the galley proof are versions of the publication after peer review.

- The final published version features the final layout of the paper including the volume, issue and page numbers.

Link to publication

\footnotetext{
General rights rights.

- You may freely distribute the URL identifying the publication in the public portal. please follow below link for the End User Agreement:

www.umlib.nl/taverne-license

Take down policy

If you believe that this document breaches copyright please contact us at:

repository@maastrichtuniversity.nl

providing details and we will investigate your claim.
}

Copyright and moral rights for the publications made accessible in the public portal are retained by the authors and/or other copyright owners and it is a condition of accessing publications that users recognise and abide by the legal requirements associated with these

- Users may download and print one copy of any publication from the public portal for the purpose of private study or research.

- You may not further distribute the material or use it for any profit-making activity or commercial gain

If the publication is distributed under the terms of Article $25 \mathrm{fa}$ of the Dutch Copyright Act, indicated by the "Taverne" license above, 


\title{
Learning in internships
}

\author{
What and how students learn \\ from experience
}

Agnes Wagenaar 


$\begin{array}{ll}\text { Druk } & \text { Datawyse Maastricht } \\ & \text { www.datawyse.nl } \\ \text { Uitgever } & \text { Universitaire Pers Maastricht } \\ \text { Omslag } & \text { Gerben Bosch }\end{array}$

ISBN: 978-90-5278-772-5

(C) Agnes Wagenaar, Maastricht, 2008 


\title{
Learning in internships
}

\section{What and how students learn from experience}

\author{
proefschrift \\ ter verkrijging van de graad van doctor aan de Universiteit Maastricht op gezag \\ van de Rector Magnificus Prof. mr. G.P.M.F. Mols, \\ volgens het besluit van het College van Decanen, \\ in het openbaar te verdedigen op donderdag 18 december om 16.00 uur
}

door

Agnes Wagenaar

geboren op 6 september 1973 te Burgum

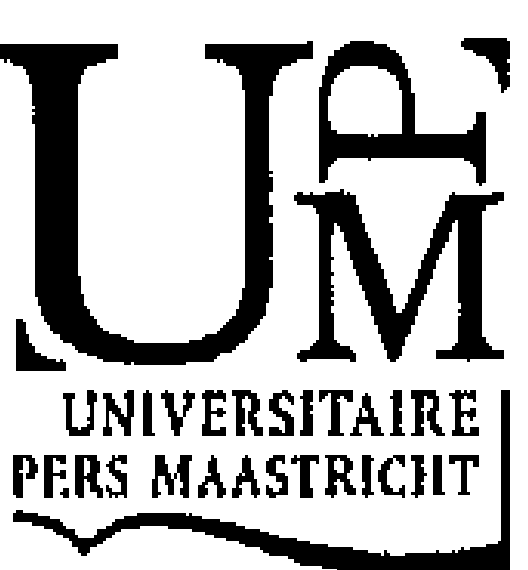




\section{Promotores}

Prof. dr. H.P.A. Boshuizen

Prof. dr. A.J.J.A. Scherpbier

Prof. dr. C.P.M. van der Vleuten

Leden beoordelingscommissie:

Prof. dr. L.W.T. Schuwirth (voorzitter)

Dr. J. van Dalen

Prof. dr. H. Gruber, Universiteit Regensburg

Prof. dr. R. Koopmans

Prof. dr. R.P. Zwierstra, Rijksuniversiteit Groningen 


\section{Dankwoord}

Hierbij wil ik graag een aantal mensen bedanken die voor mij erg belangrijk zijn geweest bij het tot stand komen van dit proefschrift. Vaak heb ik met plezier aan dit proefschrift gewerkt, vaak ook met minder plezier. In zijn totaliteit kijk ik echter terug op een zeer waardevolle en leerzame tijd.

Allereerst Cees van der Vleuten, Els Boshuizen en Albert Scherpbier, jullie waren voor mij de beste promotoren die ik me kon wensen. Jullie hebben me alle vrijheid gegeven om van het onderzoek mijn onderzoek te maken. Ieder plan werd, nadat het voorzien was van kritische noten en er goed over gediscussieerd was, door jullie van harte ondersteund.

Els, dank je wel voor al je tijd, kennis en kritische feedback. Zelfs in je vakanties nam je nog de tijd om uitgebreid mijn artikelen met mij door te nemen. Jouw altijd kritische, maar zeer opbouwende commentaar en onze gesprekken waren zeer waardevol voor mij. Dank je wel voor de prettige samenwerking.

Cees, jouw positieve houding en jouw vertrouwen in mij heeft me goed gedaan.

Albert, dank je voor je optimisme en enthousiasme. Als het nodig was, was je altijd bereid me ergens bij te helpen of iets te doen.

Naast mijn promotoren zijn mijn collega-aio's van onschatbare waarde geweest tijdens mijn promotietraject. Dank je wel Dineke, Astrid, Theo en Susan. Ik heb genoten van onze lunches, pauzes, borrels bij Thembi, gesprekken al dan niet over het onderzoek en vriendschap.

Alle andere collega's van O\&O dank ik voor de fantastische werksfeer. Hoe lastig ook het onderzoek af en toe was, mede door jullie ben ik zelden met tegenzin naar mijn werk gekomen. Mijn speciale dank gaat uit naar Mascha (voor je belangstelling en de etentjes), Mereke (voor het corrigeren van mijn engelse teksten en het submitten van mijn artikelen. Je hebt me zoveel werk uit handen genomen), en Arno (voor je onmisbare hulp bij de loglineaire analyse en natuurlijk voor het mooie plaatje). En niet helemaal van O\&O, maar wel belangrijk, Susan Bögels. Dank je voor de enthousiaste manier waarop je hebt meegedacht over mijn expertise onderzoek.

Ook dank aan alle studenten en expert-psychotherapeuten die hebben meegewerkt aan de verschillende onderzoeken. Ik ben me ervan bewust dat ik soms een forse tijdsinvestering vroeg. Zonder jullie had ik de studies niet kunnen doen. Dit geldt ook voor de stagiaires en student-assistenten: Kathelijne, Crista, Liselotte, Leonore en Lisette. 
En dan mijn collega's bij De Hoop, Accare-UCKJP, en Verslavingszorg Noord Nederland. In de loop van de jaren zijn er veel collega's geweest wiens betrokkenheid en gezelschap ik zeer heb gewaardeerd. Zonder anderen tekort te willen doen, wil ik een aantal mensen hier met name noemen. Het diagnostiekteam: ik had me geen betere start kunnen wensen bij Accare, dank jullie wel voor de fijne samenwerking en de leuke dingen die we buiten werktijd deden. Marjan: voor de prettige supervisie en je belangstelling. Kristel: dank voor alle uurtjes intervisie en je wijze raad. Ellen en Annelies: voor jullie vriendschap en steun. Marion van Zonneveld: voor de gezellige samenwerking en je vriendschap. Esther Verbeek: voor de leuke 'intaketijd' en vriendschap. Helma Festen: voor onze super-sova. Irene Kruithof: voor de gezelligheid en natuurlijk het mooie voorkantje.

Verder wil ik mijn vrienden heel hartelijk bedanken. Jullie zijn ontzettend belangrijk.

Dineke, ik heb genoten van onze (uiteindelijk bijna dagelijkse) avondwandelingen in het Savels Bos en later in Leiden en Friesland. Jouw vriendschap is erg waardevol voor mij. Dank je voor je wijze raad.

Carin, we zien elkaar minder door onze opleidingen en drukke werk, maar ik geniet van de keren dat we elkaar spreken.

Christian en Mariska, dank jullie wel voor jullie vriendschap en jullie gastvrijheid. Werken in Dordrecht werd nog leuker doordat ik bijna iedere week bij jullie kon blijven slapen. Dan leek het weer een beetje alsof jullie nog steeds maar twee straten verderop woonden. Op het moment ben $\mathrm{ik}$ erg blij met onze gesprekken via skype.

Dirk en Ellen, jullie vriendschap en nooit aflatende steun tijdens moeilijke periodes in Maastricht hebben mij er op veel momenten doorheen gesleept. Ik heb genoten van de gesprekken met jullie, van alle gezellige maaltijden en kopjes thee en van nog veel meer. Ook Tim, Matthias en David, ik heb met erg veel plezier spelletjes met jullie gedaan, koekjes met jullie gebakken of andere leuke dingen gedaan. Jullie zijn de leukste oppaskinderen die ik ken (al zijn jullie inmiddels wat te groot geworden voor oppas).

Nanette, onze gezellige weekendjes in Nijmegen en Maastricht zorgden zeker voor de broodnodige afleiding.

Jack, Patricia, Laura en Rebecca, dank jullie wel voor jullie gastvrijheid, vriendschap en belangstelling.

Franciska en Jorrit, dank jullie wel dat jullie er zijn. Jullie hebben mijn verhuizing van Maastricht naar Drachten een stukje makkelijker gemaakt. Francisca bedankt ook voor de muzikale afleiding.

Tot slot bedank ik mijn familie voor de belangstelling en steun. Dank je wel Mem, Monique, Remco, Els, Tim, David, Thabor en Stijnie. 


\section{Content}

Dankwoord (Acknowledgements in Dutch)

1 Introduction

2 The importance of active involvement in learning: A qualitative study on learning results and learning processes in different internships

Published in Advances in Health Sciences Education, 8, 201-212, 2003. Wagenaar, A., Scherpbier, A.J.J.A., Boshuizen, H.P.A., \& Van der Vleuten, C.P.M.

3 Are students self-directed learners during internships? A qualitative exploration

Wagenaar, A., Boshuizen, H..P.A., Van der Vleuten, C.P.M., Scherpbier, A.J.J.A. (subm.)

4 How do medical and mental health sciences students cope with stressful situations in their internships and how does stress influence learning? An in-depth interview study

Wagenaar, A., Scherpbier, A.J.J.A., Boshuizen, H.P.A., \& Van der Vleuten, C.P.M. (subm.)

5 Differences in cognitive processes between beginning and experienced counsellors during a diagnostic interview

Wagenaar, A., Boshuizen, H.PA., Muijtiens, A.M.M., Bögels, S.M., Dik, K., Scherpbier, A.J.J.A., \& Van der Vleuten, C.P.M. (subm.)

6 The first contact with a client in mental health care: Differences in diagnostic reasoning and knowledge structure between beginning and experienced counsellors

Wagenaar, A., Boshuizen, H.P.A., Van der Vleuten, C.P.M., \& Scherpbier, A.J.J.A. (subm.)

7 General discussion

Appendix

Summary

Samenvatting

Curriculum vitae 


\section{1 \\ Introduction}

\section{Problem definition}

Professional practice is the most authentic and powerful learning environment thinkable. Most academic educational programs include an internship period in which students work on a research project or in a professional setting. Internships aim at various educational goals, including learning from experience, learning to apply and enrich theoretical knowledge and skills in practice, and tuning knowledge and skills to practice. Learning in internships differs in many respects from learning in classroom settings. Internships provide students with a rich learning environment in which they can have many and varied contacts with professional practice, professionals, clients, products, et cetera, and in which they can observe and perform the work of the profession. Teaching is mainly indirect and includes activities such as supervision, modelling, feedback, reflection, and observation of students by professionals in the workplace.

The workplace learning environment, which is new for students and not specifically designed for learning, requires a new learning attitude from students. For many students, internships may be the first time they have to take so much responsibility for their own learning. They have to (at least partly) choose their own learning experiences, set their own learning goals, seek out coaching and support, and apply self-directed learning skills such as reflection to learn from their experiences.

Published studies on learning in academic internships mainly concern internships in medical education and focus on specific aspects that influence learning in these internships. Research has been done on such diverse aspects as the clinical teacher, stress level, the learning environment and formulating learning goals, influencing learning in a practical learning environment (e.g., Dornan, 2006; Erstad, Armstrong, Callahan, \& Keller, 1997; Irby \& Rakestraw, 1981; Irby, Ramsey, Gillmore, \& Schaad, 1991; Kilminster \& Jolly, 2000; Kilminster, Jolly, \& Van der Vleuten, 2002; Metcalfe \& Matharu, 1995; Niemantsverdriet, 2007; Niemi, 1997; Niemi \& Vainiomaki, 1999; Price, Miflin, Mudge, \& Jackson, 1994; Prince, 2006; Rotem, Bloomfield, \& Southon, 1996). However, paradoxically, it is not very clear how and what students learn during their internships. Learning in practice is difficult to study, because practice is a complex learning environment and the learning processes that occur are often implicit, spontaneous, and context 
Introduction

dependent. Exploration of what and how students learn in internships is the central focus of this thesis. More specifically, we focus on how and what individual students learn in the context of their internships. The context of our research into internships is students in undergraduate mental health sciences and medical training programmes of Maastricht University.

\section{Theoretical framework}

Various theories form the background to the studies in this thesis. These theories all emphasise different facets of learning in practice, although they are not specifically designed for learning in internships. Here these theories will be described briefly, with emphasis on aspects that are relevant to the studies in this thesis.

\section{Experiential learning theories}

Experiential learning theories see experience as the starting point for learning (Boud, Cohen, \& Walker, 1993; Kolb, 1984; Kolb \& Fry, 1975; Schön, 1983, 1990). Kolb (1984) described a cyclic learning process, consisting of four phases. These phases concern a concrete experience, observation of and reflection on this experience, the creation of abstract concepts that integrate the observations into a theory, and testing the theory in decision making and problem solving. Kolb's experiential learning cycle suggests that experiences are necessary but not sufficient conditions for learning to take place. More is needed: the learner must transform the episode into ideas or theories, examine these and integrate the new, more refined ideas into his belief system.

Reflection on experiences is a central element in the experiential learning theories. According to Schön (1990) reflection is so important because it stimulates new learning, it helps students to adopt new behaviour, and it helps students to generalise from their experiences. Schön (1983, 1990) distinguishes between reflection in action and reflection on action. Reflection in action is a form of metacognition in situations in which unexpected things happen and conscious thinking about actions is necessary. Reflection on action refers to thinking about experiences afterwards. Supervisors play an important role in guiding students in these reflections, although, according to Schön, supervisors should only coach students, not teach them. Supervisors should stimulate and guide students' own reflections.

Experiential learning theories argue that the learning process can be facilitated by supervisors. A supervisor cannot teach students what they need to know, they just can coach students towards self-understanding. The most important tasks for the supervisor are modelling of self-reflection and stimulating and teaching students to reflect on their experiences.

\section{Self-directed learning theories}

Theories of self-directed learning define learning as an active and constructive process and describe how learning should take place and what students should do 
to direct their learning (Candy, 1991; Simons, 2000; Simons, Van der Linden, \& Duffy, 2000; Zimmerman, 2002; Zimmerman \& Schunk, 2001). Zimmerman (2002) described eight characteristics that are needed for students to be able to regulate their own learning: students have to set learning goals, choose learning strategies for attaining these goals, monitor their performance, restructure their learning environment to make it compatible with their goals, manage their time effectively, selfevaluate their methods, attribute results to causation, and think about what they should do differently in the future. However, Zimmerman also observed that not all students meet the requirements for fully self-directed learning.

\section{Workplace learning theories}

Another class of theories go under the heading of 'workplace learning'. They are more diverse than experiential learning and self-directed learning theories and show little coherence (Streumer \& Kho, 2006). Theories of workplace learning incorporate various theories from different disciplines, such as experiential learning theories, self-directed learning theories, theories about social learning, communities of practice, and theories about adult learning. Theories about communities of practice (Lave \& Wenger, 1991; Wenger, 2000) differ from the other theories in that they take into consideration the stage of (candidate) learners. Dependent on someone's status in the community, s/he is allowed to learn and/or is supported by the community. These theories describe careers of learners.

Van der Klink and Streumer (2004) suggest that workplace learning can be defined along five dimensions. The first dimension is intentionality. Learning can be more or less intentional, with on the one side of the dimension intentional learning and on the other side incidental learning. Incidental learning occurs as a by-product of working activities, such as task performance, learning from mistakes, learning from conversations with colleagues, learning from trial and error, or formalisation of the learning process (Marsick, 2006). The second dimension is formalisation, with formal learning on the one side and informal learning on the other side. Formal learning is typically institution-sponsored, classroom based, and highly structured (Marsick, 2006), while informal learning is mainly under the control of the learner and depends on his/her motivation and capabilities. The third dimension is the context in which learning takes place, which incorporates, amongst other things, the place of work, support and feedback, working pressure and autonomy of task performance. The fourth dimension concerns the various forms of learning, such as individual learning, group or social learning, and organisational learning. The final dimension is control of the learning, which may lie in the hands of the learner, the environment, and interventions to direct and stimulate learning in the workplace.

Though much research has been done on workers who have an established position in their company, research on workplace learning is also informative about students and interns. Dornan (2006) developed a model of workplace - or in his words 'experience-based' - learning that is about the progression from medical student to doctor through participation in clinical practice. He suggests that supported 
participation in practice is central to becoming a doctor. Important in becoming a doctor is that students participate in practice in a way that is appropriate to their stage of education. By participating in practice students develop various competences. They develop emotional competences (such as a sense of identity, confidence, motivation, and a sense of reward) and they develop knowledge and skills (such as study skills and clinical skills). These two competences influence each other. Greater competence in knowledge and skills leads to more positive emotions and vice versa. Furthermore, developing positive emotions and competence makes it increasingly easier for learners to participate in practice. However, the ability to participate in practice is strongly moderated by the behaviour of people the learner meets in the workplace (patients, doctors, nurses, peers). Learning mainly occurs in relation with doctors, patients, nurses, and peers. Practitioners have considerable power to further or hinder workplace participation and thus the learning processes that bring students closer to becoming a doctor. An effective workplace teacher is someone who can simultaneously support students and make demands of them in a way that bolsters their emotional and technical competence.

\section{Theories of expertise development}

The first steps in building expertise in the work domain are taken during internships. Expertise theories describe the process of expertise development in a particular area.

Dreyfus and Dreyfus (1986) formulated a five-phase model of skills development. During skills acquisition and the development of expertise in these skills, qualitative changes occur in perception of the task and in the mode of decisionmaking. The first stage, the novice stage, is characterised by the learning of and rigid adherence to context free rules or plans. In the second stage, the advanced beginner starts to apply theoretical knowledge in practice. However, because practice is such a complex environment, the advanced beginner has difficulties finding out when to apply which knowledge and skills. The development through the following stages of competence and proficiency is characterised by an increased capability to recognise and discriminate between features of a situation in which a skill should be performed. Furthermore, the ability to carry out routine tasks under pressure increases. In the fifth stage, people do not rely on rules and guidelines anymore, but are completely involved in the situation and have an intuitive grasp of the situation, which is based on a deep, thorough understanding of the situation. Analytical thinking only occurs in new situations or when problems occur. Experts have high levels of procedural knowledge and skills (knowing how) and declarative knowledge (knowing what), and know when and where to apply their knowledge and skills (contextual flexibility).

Ericsson and Smith (1991) and Feltovich, Prietula, and Ericsson (2006) emphasise the crucial role of deliberate practice of skills in gaining expertise. To attain expertise continually increased challenges are necessary that raise performance beyond its current level (Ericsson, 2003). Expert performers have to set 
clear goals, seek out teachers, engage in specially designed training activities for repetition and gradual refinement of their skills, and receive feedback on the quality of their attempts (Feltovich, Prietula, \& Ericsson, 2006). Deliberate practice is the engagement in these selected activities and involves anticipation, planning, and decision making. An amount of deliberate practice rather than simply experience is necessary in acquiring expertise (Ericsson, Krampe, \& Tesch-Römer, 1993). Ericsson and Lehmann (1996) suggested that ten years of consistent deliberate practice is necessary to develop the skills needed to reach the level of experts. According to this theory, guidance and instruction from teachers is necessary in addition to deliberate practice. However, future experts have to be able to monitor, control, and evaluate their own performance.

Expertise development in the medical domain is often described in relation to changes in the organisation of knowledge (Norman, Eva, Brooks, and Hamstra, 2006). Three broad types of knowledge can be distinguished: causal knowledge (essentially, understanding basic mechanisms), analytical knowledge (the formal relationship between diagnoses and features - signs and symptoms - of various conditions), and experiential knowledge (the accumulation of a storehouse of prior cases that comes with experience (Schmidt, Norman, and Boshuizen, 1990; Gruppen \& Frohna, 2002). Greater experience seems to result in greater reliance on exemplarbased knowledge and less on formal knowledge.

Boshuizen and Schmidt (2000) developed a theory of clinical reasoning expertise in medicine which describes changes in knowledge structures with increased levels of expertise in clinical reasoning. The first stage of expertise development is characterised by the acquisition of biomedical knowledge and reliance on detailed reasoning steps when diagnosing a patient. The second stage is characterised by the development of constantly enlarging knowledge structures and the abbreviation of reasoning steps. In stage three a process of knowledge encapsulation takes place. When detailed biomedical knowledge is repeatedly applied, direct links between patient findings and clinical concepts are built. Due to these encapsulations the reasoning steps become less and less detailed, because doctors no longer need to activate their detailed biomedical knowledge to understand the various diseases. They can use their biomedical knowledge, but when the patient findings are straightforward this is not necessary. The final step in gaining expertise in clinical reasoning is the formation of illness scripts. Illness scripts consist of three parts, namely the enabling conditions of the disease, the fault of the disease, and the consequences of the disease, and become activated as a whole when a doctor meets a patient who presents his/her complaints or symptoms.

\section{Theories on learning and emotions}

Theories on learning and emotions describe factors that impede learning. Feelings of stress, which may incorporate many different emotions, influence learning and information processing (Boekaerts \& Simons, 1993; Bolhuis, 1995; Christianson, 1992; Lazarus, 1993; Mandler, 1984; Wessel, 1997; Yuille \& Tollestrup, 1992). Laza- 
rus (1993) argued that negative emotions can hinder mental operations, while positive emotions have been associated with sublime performance. Frijda (1986), however, found that both positive and negative emotions always demand immediate attention, regardless of what one is doing at the moment and thus always hinder task performance.

The attention narrowing hypothesis explains why emotions hinder task performance and memory (Christianson, 1992). This hypothesis says that elevation of stress levels or emotions and the physiological arousal that accompanies this, influences the direction of attention. Attention will be directed towards the central or crucial aspects of the situation at the expense of peripheral and irrelevant aspects. A consequence is that memory for central information will not be affected, while peripheral and irrelevant information will not be remembered. Yuille and Tollestrup (1992) extended the attention narrowing hypothesis with the notion that attention can be directed internally, to the emotional response instead of the task at hand. When this happens, memory of both the central and the peripheral aspects of the situation will be hampered.

Mandler $(1984,1993)$ describes the mechanism that underlies the attentional narrowing hypothesis. In stressful situations there are two things that demand the individual's attention. These are the autonomous physical sensations and the worry about irrelevant aspects of the task, among which are the individual's own feelings, performance, and reactions. These two things use capacity in working memory, which leaves less free mental capacity for task relevant aspects. Less attention to the task will result in hampered memory and hence impaired learning.

Another theory that may explain the detrimental effect of stress and emotions on learning is the theory of ego depletion (Baumeister, Bratslavsky, Murraven, \& Tice, 1998). This theory assumes that people have a limited resource available for actions involving active volition. This resource is used by different, probably unrelated, acts of volition, such as self-control, making choices, taking initiatives, et cetera. Use of this resource for previous acts of volition leads to a temporary reduction in the self's capacity or willingness to engage in new volitional action. This is called the state of ego depletion. This may also occur in coping with stressful or emotional situations. Coping with stressful situations involves volitional actions. When the stress level is too high or the coping strategies used ineffective, coping may use up too much of the limited resource for acts of volition, which leaves not enough resources for learning, which also involves volition.

\section{Research questions}

The focus of the studies in this thesis is on learning results and learning processes during internships. Our overall research questions are: what do students learn during internships; how do students learn during internships and what factors contribute to or impede this learning? The starting point for the present thesis is Study 1 which focuses on the first two broad research questions. This is an exploratory study which is not aimed at testing a previously formulated hypothesis. 
The following studies focus on more specific factors that influence students' learning. For these studies a more solid theoretical framework was used.

Study 1 addresses the first two research questions, namely what and how students learn in their internships. Students were interviewed about important learning experiences in their internships and asked what was instructive, less instructive, or difficult and how they learned from these experiences.

The results showed that remarkably few students reported indications of selfdirected learning. This led us to go more deeply into how students learn during their internships. The results of Study 1 are the more striking, because the importance of self-directed learning is emphasised or implicit in most of the literature about learning discussed above. Therefore, Study 2 focussed more specifically on how students used self-directed learning skills during their internships. The selfdirected learning theories were used as theoretical background. The research questions were: 1) Do students use reflection in their learning, and, if so, in what way? 2) In what way do students learn from coaching and support and does this involve self-directed learning? 3) Do students formulate learning goals before starting their internships?

For Studies 1 and 2 a critical incidents interview method was used for data collection. Neutral questions were asked, because we were interested in students' perceptions and did not want to steer them in any direction during the interview. Furthermore, we did not want to trigger social desirability in the students' answers.

An unexpected result of Study 1, namely that medical students spontaneously reported a great deal of stress during their internships, gave rise to a more specific research question about the influence of stress and coping on learning (Study 3). The theories about learning and emotion were the background to this study. Stress includes a variety of emotions (Lazarus, 1993), which influence learning. Furthermore, the strategies students use to cope with stressful experiences are important in regulating feelings of stress and thus for learning. In order to obtain a detailed picture of the stressful situation and the coping process, we used a structured interviewing technique from rational emotive therapy (Ellis \& Grieger, 1977). In this interview students were asked to describe a stressful experience in a very lively and detailed way. Then they were asked about their thoughts, emotions, and behaviours in that particular situation and about the consequences of these thoughts, emotions, and behaviours. In this way a complete picture of the coping process and of the function of various coping strategies was obtained.

Studies 4 and 5 focus in detail on what mental health sciences students learn in their internships. These studies are grounded in theories of expertise development. The research question was how well mental health sciences students master important tasks, namely performing a diagnostic interview and making an initial diagnosis, before and after their internships. In this study, the performance of students was compared with how expert counsellors conduct such an interview and make a first diagnosis. Three groups of counsellors, namely students before entering internships, students during their internships, and experienced counsellors, interviewed a 
simulated client to arrive at a first diagnosis. Immediately after these interviews stimulated recall interviews were conducted in which the participants reported their thoughts during the interview. These cognitive processes were the subject of study.

The focus of Study 4 is on all cognitive processes during a diagnostic interview. To study how well students and interns mastered the skill of diagnostic interviewing, the following specific research questions were studied: What do counsellors think during a diagnostic interview and how do the cognitive processes of beginning and experienced counsellors differ? An additional research question was whether the three groups differed in diagnostic accuracy. Diagnostic accuracy can be seen as an important indicator of the quality of cognitive interviewing skills.

Study 5 aims to provide more specific insight into the quality of diagnostic reasoning during the diagnostic interview and into quality differences between the three groups. A second aim was to find indications for knowledge restructuring with increased experience. Using the theory of development of diagnostic reasoning in medicine (Boshuizen, \& Schmidt, 2000; Schmidt, Norman, \& Boshuizen, 1990) we looked for possible indications for knowledge restructuring.

This thesis is based on five articles about the above described studies. Because each chapter was written to be read independently some overlap between chapters was inevitable.

\section{References}

Baumeister, R. F., Bratslavsky, E., Murraven, M., \& Tice, D. M. (1998). Ego-depletion: Is the active self a limited resource? Joumal of Personality and Social Psychology, 74, 5, 1252-1265.

Boekaerts, M., \& Simons, P. R. J. (1993). Leren en instructie: Psychologie van de leerling en het leerproces [Learning and instruction: Psychology of the learner and the learning process]. Assen: Dekker \& Van de Vegt.

Bolhuis, S. (1995). Leren en veranderen bij volwassenen. Een nieuwe benadering [Learning and changing in adults. A nezw approach]. Bussum: Coutinho.

Bolhuis, S. M., \& Simons, P. R. J. (1999). Leren en werken [Learning and working]. Deventer: Kluwer.

Boshuizen, H.P.A., \& Schmidt, H.G. (2000). The development of clinical reasoning expertise. In J. Higgs \& M. Jones (Eds.), Clinical reasoning in the health professions. Oxford: Butterworth Heinemann.

Boud, D., Cohen, R., \& Walker, D. (1993). Using experience for learning. Buckingham: The Society for Research into Higher Education \& Open University Press.

Candy, P. C. (1991). Self-direction for lifelong learning. A comprehensive guide to theory and practice. San Francisco: Jossey-Bass.

Christianson, S. A. (1992). Emotional stress and eyewitness memory: A critical review. Psychological Bulletin, 112, 284-309.

Dornan, T. (2006). Experienced based learning. Learning clinical medicine in workplaces. Maastricht: Universitaire Pers.

Dreyfus, H. L., \& Dreyfus, S. E. (1986). Mind over machine: The power of humtan intuition and expertise in the era of the computer. New York: Free Press.

Ellis, A., \& Grieger, R. (1977). Handbook of rational-emotive therapy. Berlin: Springer.

Ericsson, K.A., \& Smith, J. (1991). Toward a general theory of expertise prospects and linits. Cambridge: Cambridge University Press.

Ericsson, K. A., Krampe, R. T., \& Tesch-Römer, C. (1993). The role of deliberate practice in the acquisition of expert performance. Psychological Review, 100, 3, 363-406. 
Ericsson, K. A., \& Lehmann, A. C. (1996). Expert and exceptional performance: Evidence of maximal adaptation to task constraints. Annual Review of Psychology, 47, 273-305.

Ericsson, K. A. (2003). The search for general abilities and basic capacities: Theoretical implications from the modifiability and complexity of mechanisms mediating expert performance. In: R.J. Sternberg \& Grigorenko, E.L. (Eds.). The psychology of abilities, competencies, and expertise. Cambridge: Cambridge University Press.

Erstad, B. L., Armstrong, E. P., Callahan, P., \& Keller, J. (1997). Evaluation of practice site learning experience for entry-level doctor of pharmacy students. American Journal of Pharmaceutical Education, 61, 87-90.

Feltovich, P. J., Prietula, M. J., \& Ericsson, K. A. (2006). Studies of expertise from psychological perspectives. In: K. A. Ericsson, N. Charness, P. J. Feltovich, \& R. R. Hoffman (2006). The Cambridge handbook of expertise en expert performance (pp. 41-67). Cambridge: Cambridge University Press.

Frijda, N.H. (1986). The emotions. Cambridge: Cambridge University Press.

Gruppen, L. D., \& Frohna, A. Z. (2002). Clinical reasoning. In: G. R. Norman, D. I. Newble, \& C. P. M. van der Vleuten (Eds.) International handbook of research in medical education (pp. 205-230). Dordrecht: Kluwer.

Irby, D., \& Rakestraw, P. (1981). Evaluating clinical teaching in medicine. Journal of Medical Education, 56, 181-186.

Irby, D. M., Ramsey, P. G., Gillmore, G. M., \& Schaad, D. (1991). Characteristics of effective clinical teachers of ambulatory care medicine. Academic Medicine, 66, 1, 54-55.

Kilminster, S., \& Jolly, B. (2000). Effective supervision in clinical practice settings: A literature review. Medical Education, 34, 827-840.

Kilminster, S., Jolly, B., \& Van der Vleuten, C. P. M. (2002). A framework for effective training for supervisors. Medical Teacher, 24, 4, 385-389.

Kolb, D. A. (1984). Experiential learning. Experience as the source of learning and development. Englewood Cliffs: Prentice-Hall.

Kolb, D. A., \& Fry, R. (1975). Towards an applied theory of experiential learning. In C. L. Cooper (Ed.), Theories of group processes (pp. 33-58). London: John-Wiley.

Lave, J., \& Wenger, E. (1991). Situated learning: legitimate peripheral participation. Cambridge: University Press.

Lazarus, R. S. (1993). From psychological stress to the emotions: A history of changing outlooks Annual Review of Psychology, 44, 1-21.

Mandler, G. (1984). Mind and body. Psychology of emotion and stress. New York: Norton \& company.

Mandler, G. (1993). Thought, memory, and learning: Effects of emotional stress. In L. Coldberger \& S. Breznitz (Eds.), Handbook of stress. Theoretical and clinical aspects (pp. 40-55). New York: The Free Press.

Marsick, V. (2006). Informal strategic learning in the workplace. In: J. N. Streumer (Ed.). Work-related learning (pp. 51-69). The Netherlands: Springer.

Metcalfe, D. H., \& Matharu, M. (1995). Students' perceptions of good and bad teaching: Report of a critical incident study. Medical Education, 29, 193-197.

Niemantsverdriet, S. (2007). Learning from international internships. A reconstruction in the medical domain. Maastricht: Datawyse / Univesitaire Pers.

Niemi, P. M. (1997). Medical students' professional identity: self-reflection during the preclinical years. Medical Education, 31, 408-415.

Niemi, P. M., \& Vainiomaki, P. T. (1999). Medical students' academic distress, coping and achievement strategies during the preclinical years. Tenching and Learning in Medicine, 11, 3, 125-134.

Norman, G., Eva, K., Brooks, L, \& Hamstra, S. (2006). Expertise in medicine and surgery. In: K. A. Ericsson, N. Charness, P. J. Feltovich, \& R. R. Hoffman (Eds.). The Cambridge handbook of expertise and expert performance (pp. 339-353). Cambridge: Cambridge University Press.

Price, D. A., Miflin, B. M., Mudge, P. R., \& Jackson, C. L. (1994). The quality of teaching and learning in rural settings: The learner's perspective. Medical Education, 28, 239-251.

Prince, K.J.A.H. (2006). Problem-based learning as a preparation for professional practice. Maastricht: Universitaire Pers

Rotem, A., Bloomfield, L., \& Southon, G. (1996). The clinical learning environment. Israel Journal of Medical Sciences, 32, 705-710. 
Introduction

Schmidt, H. G., Norman, G. R., \& Boshuizen, H. P. A. (1990). A cognitive perspective on medical expertise: Theory and implications. Academic Medicine, 65, 611-621.

Schön, D. A. (1983). The reflective practitioner: How professionals think in action. London: Temple Smith. Schön, D. A. (1990). Educating the reflective practitioner. San Francisco: Jossey-Bass Publishers.

Simons, P. R. J. (2000). Towards a constructivistic theory of self-directed learning. In G. Straka (Ed.), Self-learning (pp. 1-12). Munster/New York: Waxman.

Simons, P. R. J., Van der Linden, J., \& Duffy, T. (2000). New learning: Three ways to learn in a new balance. In P. R. J. Simons, J. Van der Linden \& T. Duffy (Eds.), New Learning (pp. 1-20). Dordrecht: Kluwer Academic Publishers.

Streumer, J. N., \& Kho, M. (2006). The world of work-related learning. In J. streumer (Ed.), Workrelated learning (pp. 3-49). The Netherlands: Springer.

Van der Klink, M., \& Streumer, J. (2004). De werkplek als leersituatie (The workplacce as learning environment). In: J. Streumer, \& M. Van der Klink (Eds.) Leren op de werkplek (Learning at the workplace]. Den Bosch: Reed Business Information.

Wenger, E. (2000). Communities of practice and social learning systems. Organization, 7, 2, 225-246.

Wessel, I. (1997). Attentional narrowing as a model for partial amnesia. The Maastricht University, Maastricht.

Yuille, J. C., \& Tollestrup, P. A. (1992). A model of the diverse effects of emotion on eyewitness memory. In S. A. Christianson (Ed.), Handbook of memory and emotion: Theory, research and practice (pp. 201-215). NJ: Erlbaum.

Zimmerman, B. J. (2002). Becoming a self-regulated learner: An overview. Theory into Practice, 21, 2, 64-70.

Zimmerman, B. J., \& Schunk, D. H. (2001). Self-regulated learning and acndemic achievement: Theoretical perspectives. Mahwah/NJ: Erlbaum. 


\title{
2
}

\section{The importance of active involvement in learning: A qualitative study on learning results and learning processes in different internships ${ }^{1}$}

\begin{abstract}
Introduction: In order to gain more insight into learning in different traineeships we sought students' opinions on their experiences.

Method: 24 students of Maastricht University, the Netherlands, were interviewed: 8 medical students and 16 students in the mental health science programme of the Faculty of Health Sciences (8 research trainees (MHS-res.) and 8 trainees in mental health care practice (MHS-prac.). Students' perceptions about instructive, difficult and less instructive learning experiences were recorded on audiotape. The literal transcripts of the interviews were analysed and categorised.

Results: The most frequently mentioned learning process was "learning by doing" followed by "actively overcoming gaps in knowledge and skills". These processes occurred with instructive and difficult experiences. Other processes were "learning by seeing things in practice" and "preparation and evaluation". Learning outcomes were categorised as learning about: working, professional competences and personal growth. Most frequently mentioned - in most cases with difficult experiences - were "professional knowledge and skills", "learning about personal growth" and "learning about working". The latter was mentioned most often by MHS-res. students. Medical students' responses suggested that they occasionally perceived the clerkship environment as stressful.

Discussion and conclusions: Although the small sample size precludes any firm conclusions, the overwhelming impression is that students prefer being actively involved in their learning process. In addition, traineeships appear to introduce students to professional working life the hard way. Investigating how teachers and supervisors can stimulate active learning and facilitate the introduction to professional practice might be subjects for fruitful further investigation.
\end{abstract}

\footnotetext{
${ }^{1}$ Wagenaar, A., Scherpbier, A.J.J.A., Boshuizen, H.P.A., \& Van der Vleuten, C.P.M. (2003). The importance of active involvement in learning: $A$ qualitative study on learning results and learning processes in different internships. Advances in Health Sciences Education, 8, 201-212.
} 


\section{Introduction}

For many students traineeships are the first contact with professional practice. Traineeships provide opportunities to learn from experience and apply theoretical knowledge and skills in practice. Not much is known about learning in traineeships in academic programmes. Published studies mainly concern clerkships in medical education. Specific components that influence clerkship learning were the clinical teacher, learning goals and the learning environment (Price, Miflin, Mudge, \& Jackson, 1994; Irby, Ramsey, Gillmore, \& Schaad, 1991; Irby \& Rakestaw, 1981; Erstad, Armstrong, Callahan, \& Keller, 1997; Niemi \& Vainiomaki, 1999; Rotem, Bloomfield, \& Southon, 1996). Only two studies sought students' views: a study by Lawrence, Lindemann, and Gottlieb (1999) of learning outcomes in an ambulatory primary care clerkship and a study by Epstein, Cole, Gawinsky, Piotrowski-Lee, and Ruddy (1998) on learning processes in community-based family physicians' offices. All of the studies mentioned deal with specific clerkships or clerkship components in medical education. This means that the outcomes may not be generalizable to other settings. Insight into learning in traineeships is important for optimisation of the structure and content of traineeships. Bordage, Burack, Irby, and Stritter (1998) presented a list of research questions concerning education in ambulatory settings with the key issues to be studied being the learning outcomes as well as the learning processes that occur in these settings. These questions may not be important for ambulatory settings only, but also for inpatient clinical settings or traineeships outside medicine.

The aim of the present study was to gain more insight into students' views regarding learning processes and learning outcomes in traineeships. Qualitative data about important learning experiences were obtained from interviews with medical students and students of health sciences.

\section{Method}

\section{Participants}

Undergraduate medical students and students of the Faculty of Health Sciences of Maastricht University were interviewed about their learning experiences during traineeships. The students were randomly selected from all undergraduate medical students and students in the programme of mental health studies who were doing traineeships. Students were contacted by telephone and asked to participate in an interview about their traineeship experiences. They were offered a small fee for participation.

Most students agreed to participate. 24 students were interviewed: eight medical students in the first year of clerkship, eight students who were doing a research traineeship in mental health studies (MHS-res. students) and eight students in the mental health studies programme who were doing traineeships in in-patient or ambulatory clinical settings (MHS-prac. students). The interviews were conducted at 
the university. The mean age of the participants was 23.2 years (range $22-27$ years) and five men and nineteen women participated.

\section{Traineeships}

Maastricht University offers a problem-based curriculum (Van der Vleuten, Scherpbier, Wijnen, \& Snellen, 1996). Medical students enter the two-year clerkship programme after four years during which they gain theoretical knowledge and receive intensive skills training. The mental health studies programme lasts four or five years and includes a sixmonth research traineeship and an optional traineeship in an ambulatory or inpatient clinical setting, lasting three months. We interviewed fifth year medical students and fourth or fifth year students in the mental health course.

\section{Interview}

We used the critical incidents method developed by Flanagan (1954). This technique has been used in a variety of educational and clinical care settings to gain insight into issues that have not been well described earlier (Epstein et al., 1998; Bradley, 1992; Metcalfe \& Matharu, 1995; Rosenal, 1995). A critical incident is a brief description of a significant event or experience, containing factual information and an evaluation (Brookfield, 1990).

In a one-hour interview students were asked to describe their main tasks as trainees and two instructive learning experiences, two less instructive learning experiences, one experience they found difficult due to a lack of knowledge and skills and one experience they found difficult due to personal factors. Neutral questions were asked to prompt students to describe why an experience was instructive, less instructive or difficult, how they had handled the situation, and what they had learned. For the difficult experiences additional questions were asked about students' thoughts, feelings and actions in the situation described. Students were asked to fill out a learning report for these experiences. The learning report was introduced by De Groot (1974) as a tool to report on what students learn. This concerns content and skills, learning about themselves and exceptions to what they have learned. Various forms of the learning report have been used for various goals (Van Kesteren, 1993). The learning report used in the present study presented students with four statements regarding a difficult experience.

"I have learned that/how ...";

"I have learned that/ how ... not (applicable/relevant/right)";

"I have learned that/how I...";

"I have learned that/how I . . not (applicable/relevant/right)".

Students were asked to finish these sentences and they were free to describe as many difficult experiences as they liked. In the interview students could describe any experience they considered important. The interviewer only asked further questions when an answer required clarification or further explanation. 


\section{Analysis}

The interviews were recorded on audiotape and transcribed literally. The transcripts were analysed by the first author and an assistant. The transcripts were read several times. The first few times the data were not analysed or labelled (Banister, Burman, Parker, Taylor, \& Tindall, 1994). During the final reading the researchers answered the following questions for every experience described: What was the situation, what did the student learn from the experience and how was this learned. Some students reported various learning outcomes and learning processes for a single experience. From the data a number of themes were derived which were grouped into categories.

Subsequently, two independent raters (the second and third author) assigned the learning experiences to the categories. Disagreement about the categorisation of an experience was discussed until consensus was reached.

The less instructive experiences were analysed separately in order to answer the questions: "What kinds of experience were less instructive according to the students" and "what was the situation in which the experience occurred"? The experiences were categorised according to the type of experience students found less instructive.

\section{Results}

\section{Main tasks}

The main task of the MHS-res. students was to design and perform a research project. They worked independently on their projects. Six students had to plan and carry out the study, do the data processing and report the results under supervision of their teacher. One student did all the tasks except for the data processing.

The main tasks of the MHS-prac. students were psychological testing (administering tests, writing reports and reporting to patients and GPs), observing therapy sessions or intakes, performing intakes under supervision, performing intakes or therapy sessions independently, and attending meetings where patient cases were discussed as well as team meetings.

The main tasks of the medical students were observing physicians on ward rounds, history-taking and physical examination in patients, chores (taking blood samples, collecting $X$-rays), attending meetings where patient cases were discussed and ward rounds, patient-related lectures, observing operations. They also had to write notes about the history and physical examination of two patients per day and they saw outpatients.

\section{Learning processes}

Five learning processes emerged from the data. Table 1 gives an overview of the frequency with which they were described by the three student groups. 
Table 1. Numbers of times the student groups described different learning processes for the three types of learning experiences (instructive, difficult due to lack of knowledge and skills (A) and difficult due to personal factors (B)

\begin{tabular}{|c|c|c|c|c|c|c|c|c|}
\hline \multirow[t]{4}{*}{ Learning process } & \multirow{2}{*}{\multicolumn{3}{|c|}{$\begin{array}{l}\text { MHS -students re- } \\
\text { search } \\
\text { Experiences } \\
\end{array}$}} & \multirow{2}{*}{\multicolumn{2}{|c|}{$\begin{array}{l}\text { MHS-students prac- } \\
\text { tice } \\
\text { Experiences }\end{array}$}} & \multicolumn{3}{|c|}{ Medical students } \\
\hline & & & & & & \multicolumn{3}{|c|}{ Experiences } \\
\hline & \multirow[t]{2}{*}{ Instruct. } & \multicolumn{2}{|c|}{ Difficult } & \multirow[t]{2}{*}{ Instruct. } & Difficult & Instruct. & Diffi & icull \\
\hline & & $\overline{\mathrm{A}}$ & $\bar{B}$ & & $\overline{A B}$ & & $\overline{\mathrm{A}}$ & $\mathrm{B}$ \\
\hline \multicolumn{9}{|l|}{ Information processing } \\
\hline $\begin{array}{l}\text { Learning by seeing things in } \\
\text { practice }\end{array}$ & & & & 4 & & 4 & & 1 \\
\hline Teaching & & & & & & 1 & & \\
\hline $\begin{array}{l}\text { Actively overcoming gaps in } \\
\text { knowledge and skills }\end{array}$ & & 2 & & 2 & & 2 & 3 & \\
\hline \multicolumn{9}{|l|}{ Performing tasks } \\
\hline Learning by doing & 9 & 5 & 4 & 9 & 9 & 10 & 6 & 4 \\
\hline $\begin{array}{l}\text { Learning by preparation and } \\
\text { evaluation }\end{array}$ & & & & 1 & 2 & & & 1 \\
\hline Total & 9 & 7 & $\overline{4}$ & 16 & 115 & 17 & $\overline{9}$ & $\overline{6}$ \\
\hline
\end{tabular}

The learning processes described by the students were divided into the categories information processing and performing tasks. Learning by doing was most frequently mentioned by the students.

The project did not go very well right from the start. I was supervised by the mental health service and the university. No contact had been established with the organisations that were supposed to supply subjects for the study. I had to build that up from scratch. I think you learn an awful lot from that (MHS-res.student).

Writing a report is really very difficult. There's nothing for it but to get on with it, that's why you're there. At those moments you learn a lot. You really have to synthesise everything and find the right words to express things clearly. You need to have a really good grasp of your subject before you can put it into writing. You are really forced to think hard at such a moment (MHS-prac.student).

You have learned the theory of putting up an iv and drawing blood all right, you are just unable to do it yet. Of course, things go wrong. The good part is that you find yourself picking things up really quickly as you go along, just by doing it a lot. Well it's the same for everyone (medical student).

Especially the students who worked in clinical practice also reported that they learned a lot from observing how things went in practice.

In general, I just wanted to see what sort of symptoms you see in people with brain injury. From what you read about that in books, such symptoms are often very strange and it is 
very hard to imagine what they're really like. And then you actually see it, and I think I learned a lot from that (MHS-prac. student).

Less frequently mentioned learning experiences were: actively overcoming gaps in knowledge and skills and learning by preparation and evaluation. Learning experiences where students tried to actively overcome gaps in knowledge and skills included instances when students asked for help or tried to fill in gaps by studying.

I was present at a conversation with the parents of a child at the office of the Regional Ambulatory Care Service. And yes they talked about what was wrong and why they felt that their child's behaviour was wrong. And, well I sort of don't know enough about that to be able to say, recognize, oh that fits, to make a diagnosis. In a situation like that my first reaction always is, I'll look it up. Afterwards I always ask the person who conducted the conversation what she thinks (medical student).

I find statistics really hard. I try to read as many books on statistics as possible, but usually I get only more frustrated, because I still don't get it. Yes, talking about it with other students who are working on their project and asking my supervisor for help (MHS-res. student).

Preparation refers to planning tasks in advance, knowing in advance what a task entails and evaluation may consist of asking for feedback on one's performance.

There's one client who can be aggressive occasionally. He leaves it all to me and always says immediately oh yes, I see. It's really hard to make real contact with him. I have the feeling that he does not care much. I have to do relaxation exercises with him and I get a little frustrated. Like, hey, why isn't this working out. Uh, I'm always thinking, how do I do this, how shall I put this now. How can I get him to do what I want him to do. Uh, yes, it's like that. And I try to anticipate all this by preparing and thinking about it in advance (MHS-prac. student).

Vaginal examination. Because you have observed the situation before, you sort of know what a woman does or does not feel. And, well, at first, now I always ask patients what they thought of me when I examined them, whether I caused them any discomfort or not. So I try to get a response from the patient, in how far the patient thinks I am doing o.k., I find that important. So what I mean, you know, is you get to know what's right and what's not right and uh, that's also different for every patient (medical student).

\section{Learning outcomes}

The answers to the question what students learned yielded five types of learning outcomes (Table 2). 
Table 2. Number of times the student groups described different learning outcomes for the four types of learning experiences (instructive, difficult due to lack of knowledge and skills (A), difficult due to personal factors (B) and less instructive)

\begin{tabular}{|c|c|c|c|c|c|c|c|c|c|c|c|c|}
\hline \multirow{4}{*}{ Learning outcomes } & \multirow{2}{*}{\multicolumn{4}{|c|}{$\frac{\text { MHS-students research }}{\text { Experiences }}$}} & \multicolumn{4}{|c|}{ MHS-students practice } & \multicolumn{4}{|c|}{ Medical students } \\
\hline & & & & & & Exp & rieno & & \multicolumn{4}{|c|}{ Experiences } \\
\hline & \multicolumn{3}{|c|}{$\overline{\text { instructdifficult }}$} & \multirow{2}{*}{$\begin{array}{l}\text { less } i \\
\text { nstruct }\end{array}$} & \multicolumn{3}{|c|}{ instruct difficult } & \multirow{2}{*}{$\begin{array}{l}\text { less in- } \\
\text { struct }\end{array}$} & instru & tdiff & icul & less \\
\hline & & A & B & & & $\mathrm{A}$ & B & & & $\bar{A}$ & B & \\
\hline $\begin{array}{l}\text { Learning about working } \\
\text { Learning about professional } \\
\text { compentences }\end{array}$ & $l$ & 8 & 19 & 2 & 1 & $\overline{4}$ & 5 & & & $\overline{4}$ & 7 & \\
\hline $\begin{array}{l}\text { Professional knowl- } \\
\text { edge and skills }\end{array}$ & 10 & 20 & 3 & 1 & 17 & 29 & 13 & 2 & 20 & 19 & 11 & 3 \\
\hline $\begin{array}{l}\text { Applying knowledge } \\
\text { and skills in practice }\end{array}$ & 2 & 3 & & & 7 & 3 & & & 4 & 3 & & \\
\hline Expertise & & 1 & & & 5 & 3 & 4 & & & 2 & & \\
\hline $\begin{array}{l}\text { Learning about personal } \\
\text { growth }\end{array}$ & 5 & 37 & 25 & 2 & 2 & 27 & 37 & & 3 & 26 & 24 & \\
\hline Total & 20 & 69 & 47 & 5 & 32 & 66 & 59 & 2 & 27 & $\overline{54}$ & 42 & 3 \\
\hline
\end{tabular}

The learning results could be divided into the categories learning about working, learning about professional competences, and learning about personal growth. The majority of instructive experiences and difficult experiences due to lack of knowledge and skills were related to professional knowledge and skills, such as physical examination, procedures, practical knowledge (declarative and procedural), research skills, therapeutic skills, diagnostic skills and interpersonal skills.

You learn how to make contact with organisations that supply participants for research. At first, I left the initiative too much to those organisations, and as a result the project took much longer than necessary. Now I will for instance never ask them to call me back. I always say that I will get back to them. Things like that (MHS-res. student).

You learn how to work with children, administer measuring instruments, intelligence tests, development tests, in children (MHS-res. student).

With the first patient I admitted I did not recognize that he was psychotic. Later another emergency patient was admitted, and then I did recognize it, so I thought that was quite instructive (medical student).

For both types of difficult experiences the prevailing learning outcome was related to personal growth. Personal growth concerns clarification of one's plans for the future and opportunities, career choice or choice of specialty training. Furthermore, it involves insight into one's possibilities, self-knowledge, self-confidence, independence, sense of responsibility, dealing with work pressure, assertive behaviour, personal preferences and learning styles. 
I have learned to find things out for myself and stand up for myself (MHS-res. student).

I have learned to define my boundaries in relation to others. I am better able to indicate when it's getting too much for me (MHS-prac. student).

During my first therapy sessions with clients I discovered that I find it really hard not to go into the content. I am rather inclined to focus on content, whereas I should stay at the relational level much more. That's really hard for me to do (MHS-prac. student).

I find that when physicians criticise you in a very humiliating manner my motivation to look things up gets very low. But I have learned not to take this too personally. Because at first, well you get really upset, like hey, what's happening to me here, but it doesn't bother me so much now (medical student).

Learning about working is another frequently reported learning outcome. It was most often mentioned by MHS-res. students. Learning how to work includes time management, working hours and work pace, interacting with colleagues and supervisors, position as a trainee, resolving work-related problems (for example dealing with responsibility), et cetera.

I had to do the research project all by myself and then you learn how to talk to people, how to approach people, make contact, things like that (MHS-res. student).

Interacting with and testing the boys, knowing that you are actually giving advice about someone. And that it is really very important to that person. In that way you learn to take responsibility (MHS-prac. student).

What I really hated was that I needed a grade for my paper before a set date and that both my supervisors were away on holiday. Then you discover how dependent on others you are. That really made me angry. But there isn't much you can do, I couldn't very well yell at them and call them names, because I still needed my grade. So you just have to accept there's nothing you can do. And after the holiday my supervisor said he'd lost my paper. Well, I had no idea how that could have happened, and you think how careless can you get, how can you do such a thing, hey, just go and find it! But if he hasn't got the paper, he cannot grade it, so what do you do, you go and print the whole lot once again and you hand it in and it's taking forever. So, well, but it's no use getting angry. You need good grades. You learn that as a student you can be quite powerless in relation to your supervisors (MHS-res. student).

Well, I learned something else that's very important, that, well that GPs often don't know about all the possibilities of mental health care in terms of therapy and all the types of complaints there are. A really large number of patients are referred incorrectly or it takes far too long before they finally get to the proper place, just because the GP did not recognise it or mislabelled it (medical student). 
What I find difficult is my role as a clerk. In internal medicine there was no teaching at all, and people just aren't interested in you apart from your being there as a clerk... The problem is to know how much you can say and what you cannot say, how much you can, oh, well, it also has to do zwith your role as a clerk. In medicine there's a strong hierarchy and that's really, well, it's not always easy. It's also difficult because you are dependent, you're being judged, so your options are limited (medical student).

The development of expertise as a learning outcome was reported most frequently by MHS-prac. students. It was mentioned less often than the other types of learning results. Development of expertise concerns the fact that tasks become easier with practice. Expertise building may also concern gaining a deeper understanding, like generalisation to other situations of what was learned in specific concrete situations.

The first time I administered the WAIS (an intelligence test) things were rather chaotic. But you reach a point when everything goes automatically. The first time you have to keep looking things up in the manual. Like how much time you needed, and then you had to observe the boy at the same time. Yes, there was a lot less observation at first. Because you're so busy just administering the test properly (MHS-prac. student).

I tend to accept and understand what the boys tell me and I think well, yes I can imagine that, while that is precisely what I shouldn't do. I should not try to understand what they're telling me but stimulate them to explain what's behind it. Yes, and I must try not to believe everything they say... It remains very difficult. It's different with every boy. ... But it is getting easier, because you are getting better at judging them (MHS-prac. student).

\section{Less instructive experiences}

When students were asked to describe less instructive experiences, they mainly reported experiences like "passive observation", "chores", "routine tasks", and "irrelevant experiences". Passive observation was most often mentioned by medical students, while chores were most often mentioned by MHS-res. students and routine tasks were most often mentioned by MHS-prac. students.

\section{Stress}

Besides learning processes and learning outcomes, an unexpected important issue turned out to be the remarkable difference in reported stress between medical students and students from the mental health programme. Medical students indicated that the atmosphere in the hospital could be very stressful. For instance, they mentioned having difficulty with physicians reacting bluntly when they failed to give the correct answer to a question. One medical student quoted the response she got. The physician said: "you have beautiful blue eyes but nothing useful comes out". Another medical student said with reference to problems in the way professionals and clerks interacted: "I'll make it through these weeks". These quotes would seem 
to be indicative of the stress experienced by medical students during clinical clerkship.

\section{Discussion}

In interpreting the results of this study one should be well aware of the limited size of the study population and of the fact that the findings are derived from students' perceptions of their traineeships. Nevertheless the outcomes shed some light on characteristics of this important educational experience.

The learning process mentioned most often by all groups of students was learning by doing. This type of learning was reported by the students as occurring with instructive experiences as well as difficult experiences. Students' preference for active involvement in learning can also be inferred from their view of passive observation as being less instructive. Routine tasks were also mentioned as less instructive experiences, suggesting that students prefer more challenging tasks. Actively overcoming gaps in knowledge and skills was mentioned as a learning process that occurred with instructive as well as difficult experiences. Other studies have also indicated that active involvement of the student is important for learning. Although passive observation was not always considered instructive, both medical students and MHS-prac. students also said that they learned from seeing things in practice. MHS-res. students almost exclusively referred to learning by doing as the traineeship learning process.

The data about learning outcomes show that students find experiences instructive when they perceive gains in professional knowledge and skills. Difficult experiences are also instructive in this respect. In fact in the perception of the students difficult experiences account for the bulk of learning outcomes, particularly in relation to personal growth. Outcomes in terms of learning to work are also mostly perceived to occur with difficult experiences. These findings suggest that traineeships offer students valuable, albeit it not always very comfortable experiences which enhance their personal development. It is interesting that the MHS-res. students mention learning about working more often than their colleagues, especially if we couple this outcome with the findings that these students almost exclusively see learning by doing as instructive and that their main task consists of independently conducting a research project. Clearly, the MHS-res. traineeship is characterised by a high degree of independence. The finding that these students mention fewer instructive experiences than the other trainees may reflect a lack of supervision and educational structure in this traineeship.

An interesting finding is that medical students appear to experience stress due to how they are treated by their supervisors. Helmers, Danoff, Steinert, Leyton, \& Young (1997) also found that medical students experienced stress due to the attitude of the clinical teachers. Other studies have addressed stress as a barrier to learning (Erstad et al., 1997; Banister et al., 1994). Another relevant perspective on teachers' attitudes towards trainees is the increased educational emphasis on professional conduct with the teacher as role model. The lack of supervision in the 
MHS-res. traineeship and signs that clinical teachers occasionally display a negative attitude towards students suggest that it may be worthwhile for further studies to look into the role of the supervisor in traineeships.

\section{Conclusion}

Although no firm conclusions can be drawn from this exploratory study, some issues seem to emerge that merit serious consideration. The results of this study show that students perceive learning processes to occur when they play an active role. This may lend support to efforts of those who want to design traineeships that give students a more active role and greater responsibility. Traineeships also appear to serve as an introduction to professional life. Students' perceptions concerning learning about working and personal growth in particular suggest that their initiation into the world of real work is a difficult rather than an instructive experience. An issue that appears to be well worth studying. Another important avenue for study may be the role of the teachers as supervisors and role models for their prospective colleagues.

\section{References}

Banister, P., Burman, E., Parker, I., Taylor, M., \& Tindall, C. (1994). Qualitative Methods in Psychology. A Research Guide. Philadelphia: Open University Press.

Bordage, G., Burack, J. H., Irby, D. M., \& Stritter, F. T. (1998). Education in ambulatory settings: Developing valid measures of educational outcomes, and other research priorities. Academic Medicine, 73, 7, 743-750.

Bradley, C. P. (1992). Turning anecdotes into data: The critical incident technique. Family Practice 9 , $1,98-103$.

Brookfield, S. (1990). Using critical incidents to explore learners' assumptions. In J. Mezirow (ed.), Fostering Critical Reflection in Adulthood, pp. 177-193. San Fransisco: Jossey-Bass.

De Groot, A. D. (1974). The problem of evaluating national educational systems. In H.F. Crombag \& D.N. de Gruyter (eds.), Contemporary Issues in Educational Testing, pp. 9-27. The Hague: Mouton.

Erstad, B. L., Armstrong, E. P., Callahan, P., \& Keller, J. (1997). Evaluation of practice site learning experience for entry-level doctor of pharmacy students. American Journal of Pharmaceutical Education, 61, 87-90.

Epstein, R. M., Cole, D. R., Gawinsky, B. A., Piotrowski-Lee, S., \& Ruddy, N. B. (1998). How students learn from community-based preceptors. Archives of Family Medicine, 7, 149-1.54.

Flanagan, J. C. (1954). The critical incident technique. Psychological Bulletin, 51, 327-358.

Helmers, K. F., Danoff, D., Steinert, Y., Leyton, M., \& Young, S. (1997). Stress and depressed mood in medical students, law students, and graduate students at McGill University. Academic Medicine, 72, 708-714.

Irby, D., \& Rakestraw, P. (1981). Evaluating clinical teaching in medicine. Journal of Medical Education, 56, 181-186.

Irby, D. M., Ramsey, P. G., Gillmore, G. M., \& Schaad, D. (1991). Characteristics of effective clinical teachers of ambulatory care medicine. Acadenic Medicine, 66, 1, 54-55.

Lawrence, S. L., Lindemann, J. C., \& Gottlieb, M. (1999). What students value: Learning outcomes in a required third-year ambulatory primary care clerkship. Academic Medicine, 74, 6, 715-717.

Metcalfe, D. H., \& Matharu, M. (1995). Students' perceptions of good and bad teaching: Report of a critical incident study. Medical Education, 29, 193-197.

Niemi, P. M., \& Vainiomaki, P. T. (1999).Medical students' academic distress, coping and achievement strategies during the preclinical years. Tenching and Learning in Medicine, 11, 3, 125134. 
Active involvement in learning

Price, D. A., Miflin, B. M., Mudge, P. R., \& Jackson, C. L. (1994). The quality of teaching and learning in rural settings: The learner's perspective. Medical Education, 28, 239-251.

Rosenal, L. (1995). Exploring the learner's world: Critical incident methodology. The Journal of Continuing Education in Nursing, 26, 3, 115-118.

Rotem, A., Bloomfield, L., \& Southon, G. (1996). The clinical learning environment. Israel Journal of Medicnl Sciences, 32, 705-710.

Van der Vleuten, C. P. M., Scherpbier, A. J. J. A., Wijnen, W. H. F. W., \& Snellen, H. A. M. (1996). Flexibility in learning: A case report on problem-based learning curriculum. Medical Teacher, $18,2,103-109$

Van Kesteren, B. J. (1993). Applications of de Groot's 'Learner Report': A tool to identify educational objectives and learning experiences. Studies in Educational Evaluation, 19, 65-86. 


\title{
Are students self-directed learners during internships? A qualitative exploration ${ }^{2}$
}

\begin{abstract}
Introduction: Theories of self-directed and experiential learning emphasise the importance of self-directed learning for learning environments in real practice, such as internships. However, there is a lack of robust evidence to back up this assumption. We explored self-directed learning during internships by interviewing students about their perceived use of self-directed learning skills and the way they organised their learning.

Method: We conducted critical incident interviews with students in internships in medicine and health sciences. Neutral questions were asked to elicit spontaneous observations that could shed light on learning in an authentic learning environment.

Results: Deliberate reflection was mentioned by $21 \%$ (5) of the students; $25 \%$ (6) of the students indicated that they used reflection to solve problems. Supervisors appeared to play a crucial role, but the majority of the students did not actively seek coaching and support. Most students did not formulate learning goals before entering internship.

Discussion: The results suggest that internship may not induce the type of learning described in theoretical models of self-directed or experiential learning. The lack of students' self-directed engagement in learning that emerged from the interviews suggests that students make little use of self-directed learning skills, which may explain their strong dependence on supervisors for effective learning and reflection.
\end{abstract}

Key words: clinical clerkship, internship, learning in practice, reflection, supervision, traineeship

2 Wagenaar, A., Boshuizen, H.P.A., Van der Vleuten, C.P.M., \& Scherpbier, A.J.J.A. (subm.) Are students self-directed learners during internships? A qualitative exploration. 
Self-directed learning in internships

\section{Introduction}

Most undergraduate curricula in health care education include internships where students learn by participating in professional practice supervised by professionals in an environment that is not specifically tailored to educational purposes. This requires students' active involvement in creating their own learning opportunities, i.e. they need to be self-directed learners.

Theoretical models of self-directed and experiential learning see the learner's role as one of active and constructive participation in the learning process (Candy, 1991; Simons, 2000a; Simons, Van der Linden, \& Duffy, 2000b; Zimmerman, 2002; Zimmerman \& Schunk, 2001; Kolb, 1984; Kolb \& Fry, 1975; Schön, 1983; Schön, 1990). Self-directed learners are expected to set learning goals for themselves, devise strategies for attaining these goals, monitor their performance, adapt the learning environment to their goals, manage time effectively, evaluate the methods they use, attribute results to causation, and modify their approach accordingly (Zimmerman, 2002). According to experiential learning theory, experience is the starting point of the learning cycle and learning is triggered by reflection on experiences. It involves experimenting with new strategies, reflecting on the resulting experiences and changing behaviour accordingly (Kolb, 1984; Kolb \& Fry, 1975; Schön, 1983; Schön, 1990; Boud, Cohen, \& Walker, 1993; Boud, Keogh, \& Walker, 1988; Ertmer \& Newby, 1996; Korthagen, 2001; Mezirow, 1990; Mezirow, 1991). However, doubts have been raised as to the actual occurrence of this type of learning in educational practice (Van Eekelen, Boshuizen, \& Vermunt, 2005). Self-directed learning is one of the characteristic features of problem-based learning and students following problem-based programmes are expected to be practised in this type of learning behaviour. A typical problem-based learning format is one where students collaborate in small groups to analyse problems, identify gaps in their knowledge, formulate learning goals to fill the gaps, pursue these goals in self-directed learning activities and as a group seek to solve the problem or case by critically analysing and synthesising their collective findings. It seems reasonable to expect that students who have been nurtured in this type of learning environment should be fairly accomplished self-directed learners who can transfer these learning skills to the internship setting.

In order to investigate whether we are right in presuming this, we explored PBL students' perceptions of their learning during internships. We assumed that these students would exhibit aspects of self-directed learning, such as reflection, soliciting supervision, and goal setting. Because self direction implies awareness of one's learning processes, we interviewed interns about important events related to their learning. We specifically sought answers to the following questions:

1. Do students use reflection in their learning and, if so, in what way?

2. In what way do students learn from coaching and support and does this involve self-directed learning?

3. Do students formulate learning goals for internship in advance? 


\section{Method}

\section{Participants}

We used a qualitative study design with interviews. Because the interview method necessitated a small sample we aimed for richness of data by including students who had experienced different internships. The students were recruited from the Faculties of Medicine and Health Sciences of Maastricht University, which offer 6 and 5 year PBL curricula, respectively, with internships starting in year 4 and year 5 , respectively. Students follow a PBL curriculum from year 1 onwards. We interviewed 8 medical students who were participating in clerkship rotations in year 5 , and 8 health sciences students on an elective internship in mental health care, and 8 health sciences students on an obligatory research internship. The students were randomly selected and invited by telephone to participate in the study. All invited students agreed to participate. The face-to-face interviews lasted one hour and students were paid a small fee. The mean age of the participants was 23.2 years (range 22-27 years) and there were 5 men and 19 women. This reflected the age and gender distribution of their cohorts.

\section{The internships}

The medical students were in the first of two years of clerkship rotations in secondary and primary health care (Van der Vleuten, Scherpbier, Wijnen, \& Snellen, 1996). Supervision is provided by junior doctors and senior staff, and varies considerably due to the absence of a formal structure (Van der Hem-Stokroos, scherpbier, Van der Vleuten, De Vries, \& Haarman, 2001). Health sciences students have a required research internship and additionally can choose an elective internship in an ambulatory or in-patient setting. Supervision of the research interns is provided by experienced researchers and is relatively unstructured. Supervision during the elective internships is structured. Students are expected to formulate learning goals for the internship and attend biweekly sessions in which they reflect on their experiences and a weekly scheduled supervision hour at the internship setting.

\section{Interviews}

We conducted the interviews using the critical incidents method (Van der HemStokroos et al., 2001; Flanagan, 1954; Bradley, 1992; Epstein, Cole, Gawinsky, Piotrowski-Lee, \& Ruddy, 1998; Metcalfe \& Matharu, 1995). This means that interviewees were asked to give a factual description and an evaluation of a significant event or experience (Rosenal, 1995). We used this method because it yields both facts and perceptions and triggers spontaneous observations. Our assumption was that students who are self-directed learners would spontaneously report salient learning experiences that illustrate this type of learning behaviour.

We asked the students to describe 4 learning experiences: 2 valuable ones, 1 that was problematic due to lack of knowledge and/or skills and 1 that was difficult for 
personal reasons. The students were asked to first give a factual description of the events. Then neutral questions were asked to prompt students to describe why they thought these experiences were valuable, how they had handled the situation, what they had learned, how they had managed their learning in that particular situation and what they had thought, felt and done when the difficult events occurred. The students were also asked whether they had formulated learning goals for the internship in advance.

\section{Analysis}

The interviews were audio recorded and transcribed literally. The researchers read the protocols several times without attempting to analyse or label the data (Brookfield, 1990). During the next reading, they tried to answer the questions: What was the situation? What did the student learn from this experience and how? Based on these answers, two researchers categorised the learning experiences independently. The categorisations were compared and discrepancies discussed until a consensus was reached. This procedure enabled the two researchers to supplement and challenge each other's findings (Banister, Burman, Parker, Taylor, \& Tindall, 1994) thereby strengthening the validity of the categories. Students' use of reflection was inferred from their answers to the questions about how they learned during or from experiences.

To examine how students learned from supervisors' coaching and support and whether this involved self-directed learning, we identified the experiences in which supervisors played a central role and examined the answers to the question: how did you learn during or from the experience.

\section{Results}

Nineteen students reported 2 valuable learning experiences each, 4 students reported 1 and 1 student reported 3 such experiences, bringing the total to 45 . Twenty-three students each reported 1 difficult learning experience related to lack of knowledge and skills and 1 experience that was difficult for personal reasons. One student reported 2 experiences of either type, bringing the total number of learning experiences to 95 .

The results of the analysis of the interviews are presented for each of the research questions and illustrated by citations from the interviews. The numbers refer to the internships: $1=$ research internship in mental health sciences, $2=$ internship in mental health care, and $3=$ clinical clerkships.

\section{Did the students use reflection in their learning?}

Thirteen students were categorised as 'no reflection', five as 'no deliberate reflection', and five as 'deliberate reflection'. 


\section{No reflection}

The 13 students (54\%; 4 mental health research, 4 mental health practice, 5 clerkship) who were categorised as 'no reflection' gave no indications of using reflection as a learning strategy. They gave rather brief answers to questions about learning experiences, for instance "I learned from that" or "I learned a lot about psychopathology by seeing it in practice" or they elaborated on experiences and told the interviewer what they had learned.

One of the students regretted not having reflected during her internship:

"It's a shame really [...] I only thought, I have to do this, I have to do it now and I have to do it fast. I didn't enjoy the internship. I only got involved when there were problems, but I didn't realise the impact of the internship until much later. How it had affected me" (1)

\section{No deliberate reflection}

Six students (25\%; 2 from each group) mentioned having thought about and/or analysed experiences but only as part of the process of solving a problem. They did not indicate that they deliberately reflected on experiences in order to learn.

"Working with patients [during research] is much more difficult than with healthy subjects. Patients may say they are willing to participate in the study, but then they just don't show up. So I learned I had to deal with them differently [ . . . " (1)

"I'm generally not very much awvare that I am learning. [...] I had a difficult patient whom I had to teach new coping strategies. This was very hard because he was very passive. It was a good learning experience because now I prepare better for sessions. I think about how to deal with this patient. With this patient I think I'm really learning things" (2)

"I learn afterwards when I feel that things didn't go as well as they should have. Then I think about what I could have done differently and I try that next time" (3)

\section{Deliberate reflection}

Five students (21\%; 2 mental health research, 2 mental health practice, 1 clerkship) described how they had looked back on an experience, analysed it and placed it in a broader perspective. They reflected on the learning process, the learning environment and on concrete experiences. We categorised this as deliberate reflection for the purpose of learning.

"During the internship I realised I could learn from it. [...] I asked myself: how did I handle this and what could I have done better. [...] I'm the sort of person who learns from himself, always evaluating things and actively learning."(1)

"After an experience, I think: was this a new experience and did I learn from it. Sometimes I tell other people about it and they give their views [...] Then you can find out what you're most comfortable with." (3) 
Self-directed learning in internships

\section{How do students learn from coaching and support and does this involve self- directed learning?}

Seventeen $(18 \%)$ of the 95 reported experiences referred to supervisors' involvement, such as insufficient supervision, talks with supervisors, supervisors who actively discussed and explained things.

The main component of supervision was supervisors' attitudes towards teaching and students. Experiences with supervision were described by 15 students (63\%, 5 from each group): 8 students described positive experiences, 4 students negative experiences and 3 students described both negative and positive experiences. Positive experiences were: being able to discuss certain issues with supervisors; doing things together; supervisors who stimulated the learning process and were tolerant of students' mistakes.

"But I could talk about it (having too much work) with my supervisor. [...] She said I could take the occasional day off to work on my thesis. She said I should learn from this and watch out for it in future" (2)

"When he (the supervisor) is writing psychological reports, he pulls up a chair and we do it together. I learn a lot from that. [...] We assessed a patient to see if he had ADHD. We didn't think so. We rather thought of psychotic symptoms. Then we looked it up in the literature and talked to other psychologists to try and solve it. I learned a lot from that" (2).

"You learn more from senior staff than from junior staff. (...). Senior doctors ask more questions and let you find things out for yourself. They stimulate you to think so that you discover that you knowv more than you thought you did" (3)

Negative learning experiences relating to supervision centred on supervisors' attitudes or inadequate or non-existent supervision.

". . supervision zoas not structured. It was all up to me." (1)

"We didn't get any supervision. We discussed it with our supervisor, but that didn't help much." (1)

"I had to see patients with a doctor I didn't get along with. I hated his bluntness towards patients. . . he did nothing to put me at ease. Everything I said was wrong. I felt very stupid and didn't know what to say." (3).

Seven students (29\%; 2 mental health research, 3 mental health practice and 2 clerkship) described positive experiences related to observing supervisors in complicated situations. This type of experience was always reported as positive.

[The supervisor announced he would take a firm line with a patient] "I was amazed that he really did [...]. And it really worked. We later heard she'd got a job. It was brilliant to see 
how you can start a conversation with a patient and have a strategic plan, and that it works out the zoay you planned." (2)

"I've learned how to think about research data. I think I've learned that in conversations with my supervisor. He was very good at seeing connections between things and listing all the points, so I learned how to think." (1)

Finally, 19 students (79\%; 6 mental health research, 6 mental health practice, 7 clerkship) described experiences concerning help, explanation and advice they received from supervisors. Only 2 of these students described a negative experience, i.e. insufficient help and feedback. The experiences of the other students were all positive.

"I had no idea how to write a research proposal. [...] it turned out alright, because my supervisor explained it to $m e^{\prime \prime}(1)$

"On the very first day of clerkship, I had to see a patient on my own. I didn't know what I was supposed to do and I didn't know what questions to ask, but I did it." (3)

"It was a very interesting case. My supervisor also thought it was interesting and he explained a lot about the illness, about complications, et cetera" (3)

Did students formulate learning goals before the internships?

Eight students (33\%; 1 mental health research, 5 mental health practice, and 2 clerkship) said they had formulated learning goals before internship. These goals concerned knowledge and skills and 3 students reported personal learning goals as well. The other students reported no learning goals or only rather vague ones (" $\mathrm{I}$ wanted to see certain syndromes in practice" or "I wanted to find out whether I liked it $\left.^{\prime \prime}\right)$.

\section{Discussion}

We explored students' views about experiential learning during internships and examined whether students' behaviour was in line with what is expected in light of theories of self-directed and experiential learning, such as reflecting in order to learn, actively seeking coaching and support, and formulating learning goals. We created diversity in our small study sample by including students from three different internships. Nevertheless, the sample is too small to draw any firm conclusions from the findings, although the results raise some points that would be interesting to follow up in future research.

Contrary to expectations, only a few students reported deliberate reflection in order to learn. This may be explained by effects of the shock of practice, i.e. students are overwhelmed by their first contact with professional practice (Boud et al., 1993; Boud et al., 1988; Malterud, 2001). This has been shown to be detrimental to their learning and the same may apply to reflection. Interestingly, van Eekelen, et. al. (2005) found a lack of self-regulated learning among teachers in higher education as 
well. They reported few learning experiences that involved deliberate reflection, and planned and structured learning, even though they were expected to encourage their students to reflect. Most of their reflections arose within the context of an acute problem. Other studies have also demonstrated that reflection does not come easy to most students. Even when reflection is formally required in a course, many students are reluctant to reflect or report on their reflections (Prince, Van de Wiel, Scherpbier, Van der Vleuten, \& Boshuizen, 2000; Henderson, Berlin, Freemand, \& Fuller, 2002; Henderson, Hogan, Grant, \& Berlin, 2003; Sobral, 2000). According to Boud and colleagues $(1993 ; 1988)$ and Kilminster and Jolly $(2000)$ reflection may be inhibited by negative feelings towards supervisors or experiences. This seems to underscore the importance of a safe learning environment where mistakes are accepted as part of the learning process. On the whole our findings seem to suggest that self reflection may be more complicated than some theories on learning from experience suggest.

As for supervision, it appeared to be related to both positive and negative experiences. We found no evidence for the expected active role of students in seeking supervision. Some students referred to their own contribution in situations where they tried to resolve problems or actively sought support. The majority of the comments were confined to what supervisors did or failed to do. The impact of supervisors on student learning is in line with findings from other studies (Kilminster \& Jolly, 2000; Kilminster, Jolly, \& Van der Vleuten, 2002). The importance of coaching and support is not disputed by self-directed learning models (Simons, 2000a). It seems only reasonable that students cannot be expected to do all their learning by themselves. Simons (2000a) advocated a gradual transition from teacher-centred learning, via shared regulation, to self direction of the learning process by students. A vital task for supervisors seems to be to foster skills for reflection and selfdirected learning in students. Successful performance of this task is probably conditional on supervisors actually possessing these skills themselves. Although the study among teachers in higher education by Van Eekelen and colleagues (2005) failed to produce very promising outcomes in this respect, it may be an important subject for further research.

Most students did not formulate learning goals, although this is part of the structure of the practical internships of the mental health sciences students'. Setting learning goals has been argued to be important for guiding learning and for reflection on learning experiences (Korthagen, 2001). It can also be seen as a first step towards self-directed learning. Therefore, the conclusion appears justified that students should receive more guidance with respect to formulating and evaluating personal learning goals.

Although this study can only offer very tentative results, the findings suggest that on entering internships even our PBL students may not possess the array of self-directed learning skills that theories of self-directed and experiential learning may lead us to expect. This supports results of other studies (Wagenaar, Scherpbier, Boshuizen, \& Van der Vleuten, 2003). Students' limited use of reflection, limited 
active role in seeking supervision and failure to set learning goals for themselves, which constitute the main impressions from our exploration, should be pursued in further studies, because of their potential implications for the design of experiential learning environments. If our findings are confirmed by studies in larger samples, they would imply a mismatch between students' competence and the demands made on them by the curriculum. This would mean that students are unable to reap the full benefits of the opportunities offered by learning in practice (Dornan, 2006). Perhaps we should reappraise the self-directed and experiential learning models which postulate that students complete cycles of experience, reflection, behavioural adaptation, experience etc of their own accord. Perhaps our goals are unrealistic when we assume that undergraduate students can become fully accomplished selfdirected learners. In summary, the tentative findings of our study - if proved accurate - would justify a re-evaluation of our thinking about students' learning in authentic learning environments.

\section{References}

Banister, P., Burman, E., Parker, I., Taylor, M., \& Tindall, C. (1994). Qualitative methods in psychology: a research guide. Philadelphia: Open University Press.

Boud, D., Cohen, R., \& Walker, D. (1993). Using experience for learning. Buckingham: the Society for Research into Higher Education \& Open University Press.

Boud, D., Keogh, R., \& Walker, D. (1988). Reffection: Turning experience into learning. London: Kogan Page.

Bradley, C. P. (1992). Turning anecdotes into data: The critical incident technique. Family Practice, 9 , 98-103.

Brookfield, S. (1990). Using critical incidents to explore learners' assumptions. In J. Mezirow (Ed.), Fostering critical reflection in adulthood (pp. 177-193). San Francisco: Jossey Bass.

Candy, P. C. (1991). Self-direction for lifelong learning. A comprehensive guide to theory and practice. San Francisco: Jossey-Bass.

Dornan, T. (2006). Experience based learning. Learning clinical medicine in workplaces. [dissertation] Maastricht: Universiteit Maastricht.

Epstein, R. M., Cole, D. R., Gawinsky, B. A., Piotrowski-Lee, S., \& Ruddy, N. B. (1998). How students learn from community-based preceptors. Archives of Family Medicine, 7, 149-154.

Ertmer, P. A., \& Newby, T. J. (1996). The expert learner: Strategic, self-regulated, and reflective. Instructional Science, 24, 1-24.

Flanagan, J. C. (1954). The critical incident technique. Psychological Bulletin, 51, 327-358.

Henderson, E., Berlin, A., Freemand, G., \& Fuller, J. (2002). Twelve tips for promoting significant event analysis to enhance reflection in undergraduate medical students. Medical Teacher, 24, $121-124$.

Henderson, E., Hogan, H., Grant, A., \& Berlin, A. (2003). Conflict and coping strategies: A qualitative study of student attitudes to a significant event analysis. Medical Education, 37, 438-446.

Kilminster, S., \& Jolly, B. (2000) Effective supervision in clinical practice settings: A literature review. Medical Education, 34, 827-840.

Kilminster, S., Jolly, B., \& Van der Vleuten, C. P. M. (2002). A framework for effective training for supervisors. Medical Teacher, 24, 385-389.

Kolb, D. A. (1984). Experiential learning. Experience as the source of learning and development. Englewood Cliffs: Prentice-Hall.

Kolb, D. A., \& Fry, R. (1975). Towards an applied theory of experiential learning. In C.L. Cooper (Ed.), Theories of group processes (pp. 33-58). London: John-Wiley.

Korthagen, F. A. J. (2001). Linking practice to theory: The pedagogy of realistic tencher education. London: Lawrence Erlbaum Associates. 
Self-directed learning in internships

Malterud, K. (2001). Qualitative research: Standards, challenges, and guidelines. The Lancet, 358, 483-488.

Metcalfe, D. H., \& Matharu, M. (1995). Students' perceptions of good and bad teaching: Report of a critical incident study. Medical Education, 29, 193-197.

Mezirow, J. (1990). Fostering critical reflection in adulthood. San Francisco: Jossey-Bass.

Mezirow, J. (1991). Transformative dimensions of adult learning. San Francisco: Jossey-Bass.

Prince, K. J. A. H., Van de Wiel, M. W. J., Scherpbier, A. J. J. A., Van der Vleuten, C. P. M., \& Boshuizen, H. P. A. (2000). A qulaitative analysis of the transition from theory to practice in undergraduate medical training in a PBL medical school. Advances in Health Sciences Education, 5, 105-116.

Rosenal, L. (1995). Exploring the learner's world: Critical incident methodology. The Journal of Continuing Education in Nursing, 26, 15-18.

Schön, D. A. (1983). The reflective practitioner: How professionals think in action. London: Temple Smith.

Schön, D. A. (1990). Educating the reflective practitioner. San Francisco: Jossey Bass.

Simons, P. R. J. (2000). Towards a constructivistic theory of self-directed learning. In G. Straka (Ed.), Self-learning (pp. 1-12). Munster/New York: Waxman.

Simons, P. R. J., Van der Linden, J., \& Duffy, T. (2000). New learning: Three ways to learn in a new balance. In P.R.J. Simons, J. van der Linden \& T. Duffy (Eds.), New learning (pp. 1-20). Dordrecht: Kluwer Academic.

Sobral, D. T. (2000). An appraisal of medical students' reflection-in-learning. Medical Education, 34, $182-187$.

Van der Hem-Stokroos, H. H., Scherpbier, A. J. J. A., Van der Vleuten, C. P. M., De Vries, H., \& Haarman, H. J. (2001). How effective is a clerkship as a learning environment? Medical Teacher, 23, 6, 599-604.

Van der Vleuten, C. P. M., Scherpbier, A. J. J. A., Wijnen, W. H. F. W., \& Snellen, H. A. M. (1996). Flexibility in learning: A case report on problem-based learning curriculum. Medical Tencher, $18,103-109$.

Van Eekelen, I. M., Boshuizen, H. P. A., \& Vermunt, J. D. (2005). Self regulation in higher education teacher learning. Higher Education, 50, 3, 447-471.

Wagenaar, A., Scherpbier, A. J. J. A., Boshuizen, H. P. A., \& Van der Vleuten, C. P. M. (2003). The importance of active involvement in learning: A qualitative study on learning results and learning processes in different internships. Advances in Health Sciences Education, 8, 201-212.

Zimmerman, B. J. (2002). Becoming a self-regulated learner: An overview. Theory into Practice, 21, 64-70.

Zimmerman, B. J., \& Schunk, D. H. (2001). Self-regulated learning and academic achievement: Theoretical perspectives. Mahwah/NJ: Erlbaum. 


\title{
How do medical and mental health sciences students cope with stressful situations in their internships and how does stress influence learning? An in-depth interview study ${ }^{3}$
}

\begin{abstract}
Objectives: To gain insight into how students cope with stressful experiences during internships and the effects of stress on their learning.

Method: Interviews with medical students and mental health sciences students with very high and very low self-reported stress levels about stressful experiences and how they impacted their learning.

Results: Situations that students frequently described as stressful were those in which they were anxious to make a good impression, afraid of making mistakes or being judged, or insecure about their skills. Students with high stress levels used mainly emotion-oriented and/or avoidant coping strategies. They tried to reassure themselves and carried on working instead of confronting their stress. Students with low reported stress fell into a group using mostly avoidant coping and a group using mostly task-oriented and emotion-oriented coping. The latter group was successful in reducing stress levels. Most students said that stress stimulated learning, but five students with high stress levels reported negative effects.

Discussion: Students did not experience internship as a safe learning environment where mistakes were acceptable. This may be a barrier to learning. Most students were not very successful at coping with negative situations that they could not change. Some students were so successful at avoiding stressful situations or denying feelings of stress that they actually did not experience stress. The results suggest that students would benefit from being taught about effective strategies for coping with stressful situations and from a more propitious learning climate.
\end{abstract}

${ }^{3}$ Wagenaar, A., Scherpbier, A.J.J.A., Boshuizen, H.P.A., \& Van der Vleuten, C.P.M. (subm.) How do medical and mental health sciences students cope with stressful situations in their internships and how does stress influence learning? An in-depth interview study. 
The influence of stress and coping on learning

\section{Introduction}

This study is a sequel to an earlier study, in which we examined the learning processes and outcomes of undergraduate internships (Wagenaar, 2003). The results of that study indicated that medical students valued active involvement in experiential learning situations, a finding that was also reported in a later study by Dornan, Hadfield, Brown, Boshuizen, and Scherpbier (2005). Students also spontaneously talked about the stress of internship. That stress plays an important role in medical education has been reported in many studies. Shapiro, Shapiro, and Schwartz (2000) found over 600 articles discussing the importance of addressing the stress of medical education, because stress presumably has substantial consequences for students' professional functioning. Stress reduces attention and concentration, affects decision making and interferes with the ability to build good working relationships with patients (Levey, 2001; Shapiro et al. 2000). Stress also appears to be detrimental to learning (Shors, 2007). Negative emotions, including stress, may block mental operations and inhibit learning (Bolhuis, 1995; Christianson, 1992; Lazarus, 1993; Yuille \& Tollestrup, 1992). Other researchers have found that psychological stress leads to distractibility (Cohen, Evans, Krantz, \& Stokols, 1980) and a narrow perspective on time and information (Wyer \& Srull, 1986).

The relationship between stress and learning can be explained at various levels of reductionism, such as that of neurophysiological hormonal factors (Shors, 2007). However, neurophysiological theories provide few clues for training and treatment. A theory that may be able to do so is that of 'ego depletion' (Baumeister, Bratslavsky, Muraven, \& Tice, 1998), which assumes that individuals draw on and exhaust limited resources for acts involving active volition. Similar assumptions underlie Sweller's theory of Cognitive Load (Sweller, 1999), which goes back to cognitivistic models of the human mind such as Newell's and Simon's (1972). Baumeister et al. take a different perspective and assume that a) the limited resource that is tapped by acts of volition can be depleted by b) different, seemingly unrelated, volitional acts that share this resource, such as self-control, making choices, taking initiative, controlling the environment. At the same time, the resource is constantly being replenished at a rate depending on the types of activities in which people engage. Ego depletion refers to the diminished power of this resource after an act of volition, whereby the self's capacity to engage in new volitional actions is temporarily impaired. Baumeister et al. (1998) demonstrated this phenomenon in persons who, after resisting the temptation to eat chocolate cookies in one experiment and after voluntarily and deliberately consenting to give a speech in another experiment, showed less persistence in trying to solve anagrams than persons who had not exercised active volition. According to the theory of ego depletion, tapping resources for self-control and coping with stressful situations drains the resources available for active and self-regulated learning. Thus the effects of unsuccessful coping with stress may be highly detrimental. 
So, if stress impairs students' (active) learning, it seems important to tackle the causes of high stress levels or teach students how to cope with stress. Many studies have examined possible causes of stress in medical education (Coles, 1994; Hayes, Feather, Hall, Sedgwick, Wannan, Wessier-Smith, et al. 2004; Prince, Van der Wiel, Scherpbier, \& Van der Vleuten, 2000; Radcliffe \& Lester, 2003; Spiegel, Smolen, \& Hopfensperger, 1986; Wolf, 1994) but most of them did not address coping with stress (see also: Deary, 1994), except for a study by Paice, Rutter, Wetherell, Winder, \& McManus (2002), who examined the stress and coping strategies of newly qualified doctors. However, this was a questionnaire study with several limitations. First, it was not clear whether or when respondents actually used the coping strategies they claimed to use and, second, a questionnaire is not suitable for in-depth examination of the micro-processes of coping, the sequence of coping strategies, and which strategy is successful under which circumstances.

To examine how students deal with the stress of internship and how it affects their learning we interviewed students with very high and very low self-reported levels of stress. Our aim was to answer the following research questions: a) How do students cope with stressful experiences during internships? And 2) What are the effects of feelings of stress on the learning of students during internships?

We expected students with low stress levels to use successful coping strategies and experience no problems in relation to learning. Students with high stress levels were expected to use ineffectual coping strategies and experience problems with learning.

\section{Method}

\section{Procedure}

The study was conducted at the Faculties of Medicine and Health Sciences of Maastricht University, the Netherlands. We asked medical students in the first of two clerkship years and mental health sciences students engaged in clinical or research internships $(n=189)$ to rate their stress levels on a 100 millimetre Visual Analogue Scale (VAS; $0=$ no stress at all; $100=$ maximum stress). By including students from different disciplines, we hoped to capture a variety of stressful situations. The medical students were invited to participate when they were attending a one-day educational programme at the medical school. The mental health sciences students undertaking research internships were sent the VAS, a letter explaining the purpose of the study, and a reply paid envelope, followed by a reminder to non-responders one week later. The mental health care students undertaking clinical internship were approached at an intervision session at the university.

The VAS was completed and returned by 153 students (81\%): 108 (70.6\%) medical students and $45(29 \%)$ mental health sciences students. The different numbers of students per faculty reflect the difference in the total numbers of students in the two faculties. Of the mental health sciences students $14(32 \%)$ were undertaking research 
internship, $15(33 \%)$ clinical internship, and $16(35 \%)$ combined these two types of internship. The male-female ratio of the medical and mental health sciences students was 46:61 and 5:40, respectively, reflecting the ratios in the corresponding populations.

When we asked students to complete the VAS, we also asked if they would be willing to be interviewed about how they handled stress during internship. From the students who agreed to being interviewed we selected those with the highest and the lowest stress levels. We first invited for an interview the students with the most extreme scores on either end of the VAS and proceeded in descending order to invite students with less extreme scores. Eighteen students were interviewed: six from each group (medical, mental health research, mental health practice), three with extremely high and three with extremely low stress levels.

\section{Participants}

The mean age of the students completing the VAS was 23.7 years $(\mathrm{SD}=3.16$, range 21-46), with no significant difference between the medical students (23.5 years $(\mathrm{SD}=1.31$, range 21-27) and the mental health sciences students (24 years $(\mathrm{SD}=5.49$, range 21-46). The mean age of the students who were interviewed was 22.94 years ( $S D=1.21$; range 21-25 years). The mean age of the students with high and low stress levels was 23.22 ( $\mathrm{SD}=1.2$, range $21-25$ years) and 22.67 ( $\mathrm{SD}=1.23$, range 21-25 years), respectively. Students with high and low stress levels had mean VAS scores of 70.33 $(\mathrm{SD}=6.2$; range 60-77) and $8.67(\mathrm{SD}=5.05$; range $1-15)$, respectively.

\section{The interview}

For in-depth analysis of the students' experiences and coping strategies we used an incident method and a detailed interview schema known from cognitive behavioural therapy, in which a situation is examined in detail (objective description of the situation, cognitions, emotions, behaviour, and consequences of behaviour). This method yields a systematic and lively picture of the experience and, very importantly, of participants' interpretations of them. It also enables pinpointing of stressful elements.

The interviewers selected the most stressful situation or experience from five brief descriptions of such situations by a student, who was then asked to describe this situation or experience as concretely as possible (what was the situation; who were present; where was it; how long did it last; what was the most stressful element). The aim was to obtain as vivid a description as possible. Students were also asked to describe their emotions, indicating intensity on a VAS ( $0=$ not intense at all; $100=$ most intense), and their thoughts about the situation, the other people in it, themselves, and their ability to handle the situation. In this way the interviewers ascertained whether all cognitions were reported by making sure that the reported thoughts could reasonably be expected to give rise to the reported emotions. Next, students were asked how they had reacted to the situation and how they had dealt with it over time. This question was intended to explore the function and effects of 
coping strategies. Students were asked to describe the consequences of their reactions (did the situation change? was your stress level reduced?). Finally, students were asked how stress affected their learning (what did you learn? what were you planning to learn? did the feelings of stress affect your learning? do you learn more or less during periods of stress?).

Two interviewers conducted all the interviews, with one interviewing while the other one observed and at the end of the interview asked questions about points requiring clarification. The interviewers alternated the roles of interviewer and observer in different interviews. Both interviewers had a background in psychology and were experienced in this interview method. Three pilot interviews were conducted to practice the method and test the strategy. Few adjustments were made. The interview was limited to one instead of two stressful experiences due to time constraints.

\section{Analysis}

After the interviews were transcribed literally and read without attempts to analyse or label the data (Banister, Burman, Parker, Taylor, \& Tindall, 1994), parts relating to coping were identified and coping strategies were labelled, according to their function, as task oriented (aimed at changing the situation), emotion oriented (aimed at changing the student's emotions), or avoidant (aimed at avoiding the situation and/or denying or ignoring emotions). Finally, coping profiles were prepared for individual students, showing which coping strategies they used and in which order.

The first author and another researcher analysed and discussed the first four interviews. There was full agreement about the occurrence of coping processes. Process type was easy to identify for task-oriented coping but emotion-oriented coping and avoidant coping were sometimes hard to distinguish, either because the function of a strategy was not clear or one strategy fulfilled both functions. To tackle this problem, the coping processes were summarised by one researcher, after which two researchers categorised the processes using a consensus procedure.

\section{Results}

Most of the students used several coping strategies, with one or two main strategies being discernable. We report only the main strategies. A clear order in which different strategies were employed was observable for some students while others used a mixture of strategies. Because the results differed for students with high and low stress levels, they are presented separately. A summary is given in Table 1. Small group sizes prohibited analysis of between group differences but these differences are part of the case descriptions. The numbers in the headings of the case descriptions refer to individual students. 


\section{High stress levels}

For seven of the nine students with high stress levels, the main stress factors were anxiety about the impression they made on their supervisors, fear of being judged and of making mistakes, and/or insecurity about their abilities. They mainly used a combination of emotion-oriented and avoidant coping, or either of these strategies separately. Task-oriented coping strategies, if used at all, were used ineffectually or only very late in the coping process, when stress levels had soared.

\section{Ineffective coping with high stress (medical student 186)}

Situation: Answering difficult questions about anatomy asked by doctors in theatre, afraid of being judged and worried what impression she was making.

Coping: She persuaded herself that the situation was not stressful. During the interview she repeatedly indicated that she did not consider the situation very stressful ("well it's not all that stressful really", "It sounds more serious than it really is"), although between the lines it was obvious that she was experiencing a lot of stress. She tried to avoid doctors whom she thought were likely to ask questions and she avoided talking to other students about her problems. She pre-empted expected questions by asking questions herself first. When a doctor was answering her question, he or she could not ask her one. At other times she imagined which questions might be asked and what her answer might be. She did not prepare for observing in theatre even though this would make it much easier for her to answer questions. She only prepared when she knew that a particular doctor always asked questions about a particular subject. Her behaviour was dictated by efforts to stay clear from stressful situations, denial of feelings of stress, and attempts to suppress feelings of stress and anxiety.

\section{Ineffective coping with high stress (mental health sciences student 089)}

Situation: Counselling parents while being observed. She thought she was unable to give advice to the parents ("I felt the pressure of being expected to help them, while all I could do was ask questions. I didn't know what was expected of me. I thought I had to give them advice"). During the counselling session she was nervous and had negative thoughts about herself. She also worried what her supervisor might think of her.

Coping: She tried to continue the session for as long as possible and then left it to her supervisor to finish it. While talking with the parents, she tried to stay calm, concentrate on the session, and be relaxed by reassuring herself that it would be alright (emotion-oriented coping). She told herself that she could do this and that she was not yet expected to function at the level of a professional therapist. However, this emotion-oriented coping strategy did not work. She remained nervous and kept thinking she had to be the perfect therapist (II will disappoint the parents, they would have preferred an experienced therapist. And my supervisor will think I'm not a good therapist'). After the session she sought comfort and support from her supervisor. When she did not receive this, she concluded that her supervision was 
inadequate, attributing the problem to her supervisor instead of to herself (emotionoriented coping). She generally tried to give a very professional impression, suppressing increasingly strong feelings of insecurity and dejection (avoidant coping). In the fourth month of internship she talked to her supervisor about her insecurity and her wish for more positive feedback. However, things did not change (ineffective task-oriented coping). She then asked other counsellors for advice, but her feelings of incompetence and dejection persisted (ineffective task-oriented coping). These feelings made her consider giving up her studies but in the end she did not do so.

Interviews with students with high stress levels who had completed their internships afforded insight into the full sequence of coping strategies employed by students. In the end, these students managed to reduce their stress levels through taskoriented coping strategies.

Unsuccessful and successful coping with high stress (medical student 038)

Situation: A feeling of being constantly judged by hospital staff ("I have to be there, I have to perform well, I have to ask all the right questions, I cannot take a day off because my mark depends on it, I must work 60 hours a week and be perfect, they have to like me")

Coping: She mainly used avoidant coping strategies and did not deal well with the situation. She just got on with her work and ignored her stress. She even convinced herself that she was feeling great, that everything was going very well (denial). However, at one point she felt unable to continue and dropped out of the clerkship (avoidant coping strategy). At first she just slept and did not think about her experiences. However, once she started to view the situation differently (task-oriented coping) she was able to reduce her stress level and try new behaviour in the next clerkship (worrying less about making a bad impression, studying and learning for herself instead of for high marks, more breaks, shorter working hours, taking a day off every now and then).

Unsuccessful and successful coping with high stress (mental health sciences student 063)

Situation: Her research project went wrong. The patients did not understand her questionnaire and the therapists did not cooperate with her training programme.

Coping: She tried to get the therapists involved (task-oriented coping) but the situation did not change. Next, she tried to convince herself that she would be alright and talked about the situation with her parents and friends (emotion-oriented coping) but stress remained high. She then stopped internship for a while (avoidant coping) and learned to deal with her feelings regarding the failure of her research project (emotion-oriented coping), thereby alleviating her stress. Finally, she resumed her research project and tried to make the best of it (task-oriented coping). 
The influence of stress and coping on learning

\section{Low levels of stress}

The students reporting low stress levels fell into two groups. The first group consisted of four students (Low 1 in Table 1) who used mainly avoidant or emotionoriented coping strategies, which helped them ignore feelings of stress. Their tendency to reassure themselves was noticeable during the interviews, in which they made contradictory statements. For example: a student who rated stress as 60 on the VAS insisted that stress levels were not all that high. The students were generally reluctant to express anxiety-provoking thoughts and mostly recounted thoughts that helped them reassure themselves.

\section{Unsuccessful coping with low stress (mental health sciences student 062)}

Situation: Discussing a client in a team meeting. She was afraid to discuss a client because others might consider her client not important or her story not coherent.

Coping: She tried to discuss as few clients as possible (avoidant coping). She convinced herself that she did not need to discuss a client, because she discussed any problems with her supervisor. When she did discuss a client, she avoided criticism by repeatedly telling the team that this was just practice for her to help her meet learning goals. She suppressed feelings of stress by reassuring herself (' 1 am an intern and have a lot to learn, so criticism is not really stressful', 'I am still learning'). Furthermore, she sought reassurance from her supervisor, who told her she was doing alright (emotion-oriented coping). In supervision she asked for concrete advice on handling stressful experiences, but this did not help (ineffective task-oriented coping). Finally, she prepared very thoroughly for a planned presentation of a client, but this did not make things any easier for her either (ineffective task-oriented coping).

\section{Unsuccessful coping with low stress (mental health sciences student 080)}

Situation: An intake session with a client. Being watched by her supervisor through a one-way mirror was stressful. She was worried what her supervisor might think of her and her skills and afraid to make mistakes, because this would make her feel a failure.

Coping: She used mostly emotion-oriented and avoidant coping. She tried to reassure herself saying: "It will be alright, and when it is not, well never mind, I just have to go on"..."When I make mistakes my supervisor will come in and help me" (although she also said it made her very nervous that her supervisor was observing her), "It's no disaster when I forget to ask a question, I can always ask it later and other people forget things too'. She also used avoidant coping by planning other chores on the morning before the intake session and talking with colleagues about other matters. Her tendency to attribute failure to external factors also helped her avoid feeling a failure.

The second group (five students) with low stress used mainly a combination of effective emotion-oriented and task-oriented coping strategies. One student used task-oriented coping only. This group actually managed to reduce stress levels. 


\section{Effective coping with low stress (medical student 124)}

Situation: Clerking a patient with a stomach carcinoma. The patient had to undergo an operation whose success was uncertain because of possible metastases. This uncertain outcome for the patient upset the student greatly.

Coping: She mainly used emotion-oriented coping, which was effective because the situation could not be changed. She tried to control her emotions by suppressing them and by focusing on the patient (emotion-oriented coping). She remained aware of her feelings. When she had finished clerking, she talked to the other students and a resident about the situation (emotion-oriented coping). She discussed with the resident questions she still had about the patient and the patient's questions she had not been able to answer so that he could evaluate her (task-oriented coping). The operation went well. She visited the patient several times (emotion-oriented coping) and was happy to see the patient doing well. By immersing herself in the situation and trying to deal with it, she hoped to learn how to keep her distance in the future (task-oriented coping). Furthermore, she read up on the patient's questions so as to be able to answer them in the future (task-oriented coping).

\section{The influence of stress on learning}

Of the nine students with high stress levels, five said that high stress levels interfered with their learning because they made them focus more on themselves and their emotions than on tasks. Three said their learning was either better or unaffected when they were under stress, although two of them said that if stress levels became too high their learning would suffer. One student expressed no opinion on this topic.

\section{Negative effect of high stress on learning (medical student 186)}

'(I learn) less, yes. And I focus on why I'm nervous and things like that. Then I learn less, yes."

\section{Negative effect of high stress on learning (medical health sciences student 013)}

"But whatever I am doing, yes I want to do it really well. So the idea of suppose I don't do well, suppose things go wrong, that does interfere, yes. Because you are somewhat less confident. You think like er I'm not going to succeed and then you're bound not to. If you keep saying that to yourself then ..... does that really interfere? Yes, it does actually. Then I'm focusing on myself and not on what I'm learning. But rather on how I'm behaving."

Seven of the nine students with low reported stress levels said that stressful experiences had a positive or no impact on their learning. The other two expressed no clear thoughts on the subject.

All low-stress students who coped successfully with feelings of stress said they learned more, because stress made them more alert and motivated them to study up on topics about which they did not know enough. 
The influence of stress and coping on learning

Positive effect of stress on learning (mental health sciences student 083)

It is just like getting into a situation. When you are nervous when you have to make a phone call. Well fine, everyone is perfectly capable of making a phone call normally, so, it is really more a matter of making yourself do it. Just persist and it will be alright.

\section{Positive effect of stress on learning (mental health sciences student 294)}

"At least I don't learn less, it's not that. When there is pressure it means I have to take action, and then I always seem to manage, even if I don't set about it in the best possible way."

From the interviews with the four stress-avoiding students, a different picture emerged. Even for the students claiming to learn more under stress, the interviews clearly showed that they were not concerned with learning at all. They only talked about how to avoid stressful situations and they denied feelings of stress. The interviews contained no evidence that they attended to their learning. For example, one of the mental health sciences students (062) said that she would learn more from stressful experiences because they confronted her with her limitations and made her think about situations and her behaviour, but the interview revealed a picture of a student who was avoiding learning experiences to escape from feelings of stress and anxiety. The findings are summarised in Table 1.

Table 1. Reported stress levels, coping strategies, and learning

\begin{tabular}{|c|c|c|c|}
\hline & \multicolumn{3}{|l|}{ Reported stress levels } \\
\hline & $\operatorname{High}(9)^{*}$ & Low $1(4)$ & Low $2(5)$ \\
\hline Strategies: & $\begin{array}{l}\text { Emotion-oriented and } \\
\text { avoidant coping; task- } \\
\text { oriented coping late in the } \\
\text { process }\end{array}$ & $\begin{array}{l}\text { Mainly avoidant } \\
\text { coping strategies or } \\
\text { emotion-oriented } \\
\text { coping strategies that } \\
\text { help students ignore } \\
\text { feelings of stress }\end{array}$ & $\begin{array}{l}\text { A combination of } \\
\text { effective emotion- } \\
\text { oriented and task- } \\
\text { oriented coping stra- } \\
\text { tegies, or only task- } \\
\text { oriented coping }\end{array}$ \\
\hline Stress reduction: & $\begin{array}{l}\text { No or insufficient stress } \\
\text { reduction; stress reduction } \\
\text { after a break (2) }\end{array}$ & $\begin{array}{l}\text { No or insufficient } \\
\text { stress reduction }\end{array}$ & $\begin{array}{l}\text { Successful stress } \\
\text { reduction }\end{array}$ \\
\hline Learning: & $\begin{array}{l}\text { Better reported learning } \\
(3) ; \\
\text { No effect or diminished } \\
\text { learning (5) }\end{array}$ & $\begin{array}{l}\text { Students report no } \\
\text { effect or better learn- } \\
\text { ing; } \\
\text { Interviews reveal } \\
\text { negative effects on } \\
\text { learning. }\end{array}$ & $\begin{array}{l}\text { Better reported learn- } \\
\text { ing }\end{array}$ \\
\hline
\end{tabular}

* Number of students involved 


\section{Discussion}

This study addressed the research questions: a) How do students cope with stressful experiences during internships? And b) What are the effects of feelings of stress on the learning of students during internships?

As for the first question, we found that most students used more than one coping strategy. Five of eighteen students who managed to reduce stress used taskoriented or emotion-oriented coping strategies or both. The students who combated stress unsuccessfully used avoidant and/or emotion-oriented coping.

There was no clear relationship between stress ratings (VAS) and the use of successful coping strategies. Surprisingly, many of the students reporting low stress levels were actually under a lot of stress but managed to avoid stressful situations or denied feeling stressed, like the student who told herself she was doing fine until she could no longer cope and dropped out of internship. Can someone be so adept at denying or avoiding stress that it is not felt at all? Studies of the effects of social exclusion or rejection (Twenge et al. 2002 and 2003) may have an answer. Exclusion and rejection resemble the stressful experiences reported in this study, such as negative evaluation by supervisors. Twenge et al. found no change in reported mood after social exclusion or rejection, although the persons involved were evidently affected by being excluded. They hypothesised that social exclusion might generate inner numbness, which may ward off the emotional distress that might otherwise arise by defensively isolating affect and keeping negative feelings out of awareness. This state was characterised as cognitive deconstruction, marked not only by a lack of emotion but also by an altered sense of time, an immersion in the present rather than past or future (as was also reported by Wyer et al. (1986) in relation to stress), a relative absence of meaningful thought, and lethargy, all of which may be driven by attempts to escape from aversive self-awareness. A similar mechanism may have been at work in the students who successfully denied their feelings of stress.

Concerning the second research question, the results are somewhat paradoxical. Although most students reported a favourable or neutral relationship between stress and learning, the impact of stress on behaviour and learning was strong and for many negative. Stress may keep students with relatively low stress levels or good coping strategies on their toes and stimulate them to learn. However, this does not apply for students with higher stress levels (Baumeister et al. 1998, 2002, 2005; Bolhuis 1995; Christianson 1992; Lazarus 1993; Yuille et al. 1992), even when they convince themselves that they learn much and enjoy internship in an attempt to repress their feelings of stress.

The students with high stress and those denying stress were more preoccupied with avoiding stress than with learning. Always being on the alert to circumvent negative experiences uses up resources which are unlikely to be replaced quickly, since replenishment depends on rewarding experiences such as attaining learning goals or a feeling of mastery. This is in line with the evidence for ego depletion as described by Baumeister et al. (1998) and with Mandler's $(1984,1993)$ theory that 
anxiety interferes with thinking and problem solving. When anxiety levels are too high, attention tends to shift to internal arousal. Because conscious attentional capacity is limited, there will not be enough resource left for the task in hand. However, Mandlers' theory cannot explain long-term effects.

Apart from the view of stress as an obstacle to learning, the results offer a more positive perspective as well. The interviews with the students who had completed internship showed that stressful experiences may be valuable, because they teach students important general skills for coping with stress and give them insight into their own attitudes and performance. However, there is no denying that a similar outcome might also have been achieved in a more positive learning climate.

Stress during internship appears to be linked to two problem areas. First, students did not experience internship as a safe learning environment where they were allowed to learn from their mistakes. Unfortunately, this situation was aggravated by the perfectionism of some of the students. Safety is an essential ingredient of internships if they are to offer a truly powerful learning environment. Second, most students did not use effective coping strategies but relied on avoidant coping, which is mostly unsuccessful, drains mental resources, and raises stress levels. These problem areas might be addressed by efforts to create a safe learning climate for students and by teaching students effective coping strategies. A powerful approach might be techniques from Rational Emotive Therapy (Ellis et al.1977), although this would require further research. Better supervision may improve the learning climate. In an unpublished study by Wagenaar et al., students indicated that supervisors played a crucial role in internship learning, even though most students did not actively seek coaching and support. Students valued being able to discuss certain issues with supervisors, working alongside them, and being stimulated to learn by supervisors who offer a supportive learning climate. Similar findings were reported by Dornan et al. (2007).

Our findings suggest that stress is detrimental to learning during internships and this effect is intensified when students resort to avoidant coping strategies. In the end students' mental resources will be exhausted by their efforts to deny stress and reassure themselves and some students may even be forced to withdraw from a placement that has become a source of problems rather than of learning. Low stress appeared to be associated with task-oriented coping, sometimes combined with effective emotion-oriented strategies. These strategies do not take up an excessive amount of students' cognitive resources and as a result students will have ample resources left for active involvement in learning situations even stressful ones.

Although this study gives us insight into some of the micro-dynamics of coping with stress and learning, some aspects were not investigated sufficiently to allow conclusions. The study sample was too small to examine the relationship between stress and type of internship and gender. Another limitation is the measurement of stress levels. Students who do not differentiate between absence of stress and numbness, will not recognise their need to learn other coping strategies than avoidance and denial. This is both a theoretical and a practical problem. If our 
measurement instruments are not sensitive to this difference, we will have to develop a scale that is appropriate for screening purposes.

\section{References}

Banister, P., Burman, E., Parker, I., Taylor, M., \& Tindall, C. (1994). Qualitative Methods in Psychology. A Research Guide. Open University Press, Philadelphia.

Baumeister, R. F., Bratslavsky, E., Muraven, M., \& Tice, D. M. (1998). Ego depletion: is the active self a limited resource? Journal of Personality and Social Psy/hology, 74, 1252-1265.

Baumeister, R. F., DeWall, C. N., Ciarocco, N. J., \& Twenge, J. M. (2005). Social exclusion impairs self-regulation. Journal of Personality and Social Psychology, 88, 589-604.

Baumeister, R. F., Twenge, J. M., \& Nuss, C. K. (2002). Effects of social exclusion on cognitive processes: Anticipated aloneness reduces intelligent thought. Journal of Personality and Socinl Psychology, 83, 817-827.

Bolhuis, S. (1995). Leren en veranderen bij volwassenen. Een nieuzwe benadering [Learning and changing in adults. A new approach]. Coutinho, Bussum.

Coles, C. (1994). Learning to cope: Stress and medical career development in the United Kingdom. Medical Education, 28, 18-25.

Christianson, S. A. (1992). Emotional stress and eyewitness memory: A critical review. Psychological Bulletin, 112, 284-309.

Cohen, C., Evans, G. W., Krantz, D. S., \& Stokols, D. (1980). Psychological, motivational, and cognitive effects of aircraft noise on children: Moving from the labaratory to the field. American Psychologist, 35, 231-243.

Dahlin, M., Joneborg, N., \& Runeson, B. (2005). Stress and depression among medical students: A cross-sectional study. Medical Education, 39, 594-604.

Deary, I. J. (1994). Need medical education be stressful? Medical Education, 28, 55-57.

Doman, T. L., Hadfield, J., Brown, M., Boshuizen, H., \& Scherpbier, A. (2005). How can medical students learn in a self-directed way in the clinical environment? Design-based research. Medical Education, 39, 356-364.

Dornan, T., Boshuizen, H., King, N., \& Scherpbier, A. (2007) Experience-based learning: a model linking the processes and outcomes of medical students' workplace learning. Medical Education, 41, 84-91.

Ellis, A., \& Grieger, R. (1977). Handbook of Rational-Emotive Therapy, Springer, Berlin.

Hayes, K., Feather, A., Hall, A., Sedgwick, P., Wannan, G., Wessier-Smith, A., et al. (2004). Anxiety in medical students: Is preparation for full-time clinical attachments more dependent upon differences in maturity or on educational programmes for undergraduate and graduate entry students. Medical Education, 38, 1154-1163.

Kaslow, N. J., \& Rice, D. G. (1985). Developmental stresses of psychology internship training: What training staff can do to help. Professional Psychology: Research and Practice, 16, 253-261.

Lazarus, R. S. (1993). From psychological stress to the emotions: A history of changing outlooks. Annual Review of Psychology, 44, 1-21.

Levey, R. E. (2001). Sources of stress for residents and recommendations for programs to assist them. Academic Medicine, 76, 142-150.

Mandler, G. (1984). Mind and body: Psychology of Emotion and Stress. Norton, New York.

Mandler, G. (1993). Thought, memory, and learning: Effects of emotional stress. In: Handbook of Stress. Theoretical and Clinical Aspects (eds L. Goldberger \& S. Breznitz), pp. 40-55. The Free Press, New York.

Newel, A., \& Simon, H. A. (1972). Human Problem Solving. Prentice Hall, Englewood Cliffs, NJ.

Paice, E., Rutter, H., Wetherell, M., Winder, B., \& McManus, I. C. (2002). Stressful incidents, stress, and coping strategies in the pre-registration house officer year. Medical Education, 36, 56-65.

Prince, K. J. A. H., van de Wiel, M. W. J., Scherpbier, A. J. J. A., van der Vleuten, C. P. M., \& Boshuizen, H. P. A. (2000). A qualitative analysis of the transition from theory to practice in undergraduate medical training in a PBL-medical school. Advances in Health Sciences Education, 5, 105-116.

Radcliffe, C., \& Lester, H. (2003). Perceived stress during undergraduate medical training: A qualitative study. Medical Education, 37, 32-38. 
The influence of stress and coping on learning

Rodolfa, E. R., Kraft, W. A., \& Reilley, R. R. (1988). Stressors of professionals and trainees at APAapproved counseling and VA medical center internships sites. Professional Psychology: Research and Practice, 19, 43-49.

Shapiro, S. L., Shapiro, D. E., \& Schwartz, G. E. R. (2000). Stress management in medical education: A review of the literature. Academic Medicint, 75, 748-759.

Spiegel, D. A., Smolen, R. C., \& Hopfensperger, K. A. (1986). Medical student stress and clerkship performance. Journtal of Medical Education, 61, 929-931.

Sweller, J. (1999). Instructional Design in Teclmical Areas. ACER Press, Camberwell, Australia.

Twenge, J. M., Catanese, K. R., \& Baumeister, R. F. (2002). Social exclusion causes self-defeating behavior. Journal of Personality and Social Psychology, 83, 606-615.

Twenge, J. M., Catanese, K. R., \& Baumeister, R. F. (2003). Social exclusion and the deconstructed state: Time perception, meaninglessness, lethargy, lack of emotion, and self-awareness. Journal of Personality and Socinl Psychology, 85, 409-423.

Wagenaar, A., Scherpbier, A. J. J. A., Boshuizen, H. P. A., \& van der Vleuten, C. P. M. (2003). The importance of active involvement in learning: A qualitative study on learning results and learning processes in different internships. Advances in Health Sciences Education, 8, 201-212.

Wolf, T. M. (1994). Stress, coping and health: Enhancing well-being during medical school. Medical Education, 28, 8-17.

Wyer, R. S., \& Srull, T. K. (1986). Human cognition in its social context. Psychological Review, 93, 322359.

Yuille, J. C., \& Tollestrup, P. A. (1992). A model of the diverse effects of emotion on eyezitness memory. In: Handbook of Memory and Emotion: Theory, Research and Practice (ed. S.A. Christianson), pp. 201-215. Erlbaum, Hillsdale. 


\title{
5
}

\section{Differences in cognitive processes between beginning and experienced counsellors during a diagnostic interview ${ }^{4}$}

\begin{abstract}
Objectives: To examine differences in cognitive diagnostic interviewing skills between beginning, intermediate and experienced counsellors.

Design: Counsellors of three levels of experience interviewed the same simulated client. Their cognitive processes were examined using stimulated recall.

Methods: The stimulated recall protocols were analysed and inter group differences examined using log linear analysis.

Results: The experts diagnosed most accurately. They simultaneously considered diagnostic reasoning, regulation of the interview, working relationship with the client, and treatment plan. Novices and intermediates focused on one thing at a time and were uncertain. Intermediates reported fewer thoughts and/or doubts than novices and more thoughts about structuring and regulating the interview.

Conclusions: The three groups differed in process and quality of cognitive diagnostic interviewing skills. Novices and intermediates experienced difficulties. Although skills will improve with work experience, enhancing them also appears to be a major task for educational programmes and supervisors. Stimulated recall may be a powerful educational tool in this.
\end{abstract}

Key-words: diagnostic reasoning, diagnostic expertise, diagnostic interviewing, insession cognitions, stimulated recall, cognitive interviewing skills.

${ }^{4}$ Wagenaar, A., Boshuizen, H.P.A., Muijtjens, A.M.M., Bögels, S.M., Dik, K., Scherpbier, A.J.J.A., \& Van der Vleuten, C.P.M. (subm.) Differences in cognitive processes between beginning and experienced counsellors during a diagnostic interview. 
Differences in cognitive processes

\section{Introduction}

Conducting a good diagnostic interview requires substantial skill (Othmer \& Othmer, 1994; Shea, 1988). Bögels (1999) distinguished three categories of diagnostic interviewing skills that are essential for a counsellor: content skills, process skills and cognitive skills. Content skills are used to collect appropriate diagnostic, aetiological, and contextual information (asking the right questions). Process skills comprise interpersonal and communication skills (asking the right questions the right way) and cognitive skills include application of knowledge; they govern the thought processes of mental health professionals in diagnosing a client. Cognitive skills involve attending to and seeking information about oneself, the client, and the therapeutic relationship, organising and integrating information into viable hypotheses and client conceptualisations, and planning, guiding, and evaluating the ongoing interview process. Their integrated use is assumedly the key to successful diagnostic interviewing and to diagnostic accuracy.

Bögels (1994) showed that experienced counsellors outperformed beginning counsellors in both content and process interviewing skills. However, her study revealed very little about cognitive diagnostic interviewing skills. Yet, cognitive skills are a prerequisite for the purposeful performance of the other interviewing skills. For instance, counsellors should be able to interpret and organise client information in order to formulate diagnostic hypotheses and select appropriate questions to test them.

To our knowledge, only a few studies have focused on differences between beginning and experienced counsellors in isolated cognitive diagnostic interviewing skills. A first group of studies looked at differences between beginning and experienced counsellors in diagnostic accuracy. Diagnostic accuracy can be seen as an important indicator of cognitive diagnostic reasoning skills. The reports on differences between beginning and experienced counsellors' diagnostic accuracy were mixed. Some studies showed greater diagnostic accuracy in experts (Bögels, 1994; Nurcombe \& Fitzhenry-Coor, 1987); other studies found no differences between experts and non-experts (Fitzhenry-Coor \& Nurcombe, 1983; Garb, 1989; Hillerbrand \& Claiborn, 1990); and Witteman and Van de Bercken (2007) found a nonlinear relationship with a decrease after graduation which was only evened out after several years of experience. A few explanations for these mixed results can be suggested. One is that relatively simple tasks or parts of authentic tasks were used, such as written client cases, psychological test data or transcripts of diagnostic interviews. These tasks were less complex than a full diagnostic interview with a real patient, which may have made it much easier for beginning counsellors to arrive at an accurate diagnosis. Bögels' study (1994) was the only one in which the participants conducted a real diagnostic interview and she ascertained differences between the various groups of participants. Another explanation for the mixed results on diagnostic accuracy may be that in many studies the novice and expert groups did not span the entire novice expert continuum. Often the terms 'expert' and 'novice' are 
used comparatively; hence the experts in a study can be graduate students or counsellors whose practical experience differs only little from that of novices.

A second set of studies focused on diagnostic hypothesis formulation and testing (Fitzhenry-Coor \& Nurcombe, 1983; Nurcombe \& Fitzhenry-Coor, 1982, 1987). Again this cognitive diagnostic interviewing skill was studied in isolation. Compared with beginners, expert counsellors were found to formulate more diagnostic hypotheses early in the interview and to reconsider hypotheses more often over the course of the interview.

Finally, Borders, Fong-Beyette, and Cron (1988) explored naturally occurring insession cognitions of one student-counsellor during a full non-simulated counselling session. Although this study did not focus on differences between beginning and experienced counsellors in cognitive diagnostic interviewing skills, it is important because it is the only study to focus on the full range of in-session cognitions instead of on one isolated aspect. Borders et al. found that the novice counsellor had difficulty performing cognitive interviewing skills. The student had few intentional thoughts, raised many questions but generated few answers, had many doubts about her skills and actions, and had hardly any thoughts that showed an understanding of interactive counsellor-client effects. However, since this study was limited to one single student, it does not elucidate differences between students or between beginning and experienced counsellors.

From the above-mentioned studies we can conclude that there is insufficient information about differences between beginning and experienced counsellors in their use of cognitive diagnostic interviewing skills. We know that experienced counsellors outperform beginning counsellors in content and process skills and that differences exist between these groups in diagnostic hypothesis formulation and testing. Furthermore, beginning counsellors seem to have difficulty using cognitive interviewing skills. However, a lot of questions remain unanswered. The results of studies of differences between beginning and experienced counsellors in diagnostic accuracy are inconclusive and there is a lack of information about the full range and integrated use of cognitive diagnostic interviewing skills. Given the importance of diagnostic interviewing and of cognitive interviewing skills, this lack of insight seems highly surprising, the more so since insight into this issue is likely to have implications for training programmes in diagnostic interviewing skills.

The goal of the present study was to gain more insight into cognitive diagnostic interviewing skills used by counsellors during diagnostic interviewing and into any differences between beginning and experienced counsellors in the use of these skills. The following research questions were formulated: What do counsellors of various levels of experience think during a diagnostic interview? What are the differences between beginning and experienced counsellors' cognitive processes? In addition we wanted to know: do beginning and experienced counsellors differ in diagnostic accuracy?

Since, as discussed earlier, reported discrepancies in diagnostic accuracy between beginning and experienced counsellors may be an effect of the study 
design, an authentic task was used in the present study. Furthermore, we selected the novices and experts in such a way that they differed considerably in amount of experience. Following Borders et al. (1988), stimulated recall was used to enable reliable assessment of the participating counsellors' in-session cognitions. Stimulated recall has been used in research of cognitive processes or thought-inaction of counsellors, physicians, teachers, and students, among others (Benedek \& Bieniek, 1977; De Grave, Boshuizen, \& Schmidt, 1996; Elstein, Shulman, \& Sprafka, 1978; Kagan, 1984; Kagan \& Kagan, 1991; Kagan, Krathwohl, \& Miller, 1963; Yinger, 1986). Ericsson and Simon $(1980,1993)$ argued that useful and reliable verbal reports can be obtained when clear probes are used and retrospective reports are elicited directly after the task in hand. Van Gog, Paas, \& Van Merriënboer (2005) have shown that stimulated retrospective reports can be a good replacement of think aloud protocols although they found higher reported frequencies of metacognitive statements. Unsupported retrospective protocols, on the other hand, included fewer action, why and how statements than did think aloud protocols, and had equal numbers of metacognitive statements. Kagan (1984) also used stimulated recall as a method for skills training and to teach students an intentional use of therapeutic techniques.

\section{Method}

\section{Participants}

The thirty-nine participants were evenly distributed over three groups of thirteen counsellors with varying degrees of diagnostic expertise: a trained but inexperienced novice group, a trained intermediate group with some experience, and an expert group who were highly trained and experienced. The novices and intermediates were master students in mental health sciences at Maastricht University. The novices had completed the initial skills training programme but not yet started internships, while the intermediate group consisted of students pursuing internships in ambulatory or clinical settings. The intermediates had diagnostic experience with adults, except for one student whose internship was in paediatric care. The experts were mental health professionals (psychologists, psychotherapists and psychiatrists) with an average of 14 years of diagnostic experience in mental health care (SD = 7.3; range 5-27 years) and good knowledge of the Diagnostic and Statistical Manual of Mental Disorders (DSM-IV-TR, American Psychological Association, 2000). The mean ages of the novice, intermediate and expert group were 21.2 years $(\mathrm{SD}=$ 0.8 ; range $20-23$ years), 22.9 years $(\mathrm{SD}=2.6$; range $21-26$ years) and 40.4 years $(\mathrm{SD}=$ 8.4; range 29-52 years), respectively. The male female ratio was 1:12 in the novice group, 2:11 in the intermediate group and 7:6 in the expert group. For all groups this ratio was similar to that in the corresponding population. 


\section{The diagnostic interview}

All participants interviewed the same simulated client for a maximum duration of thirty minutes. Several studies have reported that doctors were unable to distinguish simulated patients from real ones (Norman, Tugwell, \& Feightner, 1982; Rethans, Sturmans, Drop, \& Van der Vleuten, 1991; Sanson-Fisher \& Poole, 1980). Hence we assumed that it would be acceptable to regard an interview with a welltrained simulated client as an authentic setting. The interviewers were instructed to give an initial diagnosis in accordance with the DSM-IV-TR classification (APA, 2000). Authenticity was enhanced by allowing the participants to take notes during the interview.

One actor portraying the same role was interviewed by all participants. The role was written especially for this study. To maximize authenticity, the role was based on a real client and adapted to the simulated client's personal situation. The role was sufficiently complex to make it an interesting case for beginners and experts (Skovholt, Ronnestad, \& Jennings, 1997). It contained two diagnoses, namely depression and hypochondriasis.

To ensure equivalence of performance across interviews, the actor received intensive training before the experiment, was retrained regularly during the study and was given feedback after each interview.

\section{Stimulated Recall}

The rationale for the use of this method was that the recording of the original event contained many cues or stimuli that might help participants relive the situation with the immediacy of the original event (Bloom, 1953, 1954). Because we wanted to maximise the number of cues during stimulated recall, the camera recording the interview was positioned in such a way that both the simulated client and the counsellor were on the videotape. The participants were allowed to use any notes they had taken during the interview.

\section{Procedure}

To familiarise the participants with the stimulated recall method, we performed a mock stimulated recall procedure before the actual experiment. In the mock stimulated recall the participants were videotaped while trying to solve a verbal riddle. The participants received feedback afterwards in order to make sure that they knew exactly what was expected of them during the actual experiment.

The participants received information about the client's name, date of birth, marital status, number of children, occupation and reason for referral by the family doctor immediately before the interview with the simulated client. The interview was directly followed by the stimulated recall session. In this session, one of the researchers invited the participants to watch the videotape of the interview and report anything they could remember of their thinking processes during the actual interview. Whenever participants remembered a thought, feeling, or emotion, they stopped the videotape and verbally reported their thoughts. All stimulated recall 
procedures were guided by the same experimenter. It was the experimenter's task to stimulate the participants to verbalise their thinking processes. The experimenter could stop the videotape when objective cues for thoughts were observed (when the participant wrote things down or showed a change in facial expression while watching the videotape) or when the participant had not reported a thought for more than three minutes. The experimenter was cautious about stopping the video, however, to prevent interference with the stimulated recall process. The stimulated recall was recorded on videotape and a time code was added.

Immediately after the stimulated recall session, the participants were asked to write down their final diagnosis. The participants were allowed to consult the DSMIV-TR (APA, 2000). They had 20 minutes to fill in the questionnaire to prevent them from studying the DSM-IV-TR.

\section{Analysis \\ Cognitive processes}

A protocol analysis was performed of the types of thought generated during stimulated recall (Ericsson \& Simon, 1980, 1993) and a log linear analysis was used to examine the differences between the three groups in the frequencies of these thought categories. For the protocol analysis, the interviews and the thoughts elicited during the stimulated recall were transcribed literally. We merged interview and stimulated recall by entering the reported thoughts into the interview protocol at the place in the interview - as identified by the time code - where the participant reported their occurrence. The protocols were analysed in a way derived from Boshuizen and Schmidt (1992). First they were read several times to identify the structure (i.e. the course and progress of formulating, testing and evaluating diagnostic hypotheses, the themes about which questions were asked, returning to various subjects). The structure of the interview and think-aloud protocol was schematised in three columns representing client information, counsellor's thoughts, and counsellor's questions, respectively. Next, different diagnostic hypotheses and themes were colour coded to identify different interview processes and to locate thoughts within the context of the interview. After re-reading the thoughts, we categorised and labelled the essence of the thoughts. When several different thoughts were reported in relation to one event, they were categorised separately.

The first and the fifth author jointly categorised the thoughts and established the final categorisation using a consensus procedure. They schematised the protocols independently and discussed the labelling of the thoughts. The second author read the protocols and examined the categorisation of the thoughts to preclude bias in the analysis. In determining the number of categories identified we gave priority to observed differences in the content of thought processes and did not collapse small categories for the sake of statistical power. The resulting 38 thought categories are detailed in Appendix 1.

Next, we examined the commonalities and differences between the groups by aggregating thought frequencies across categories and participants for the three 
groups. This resulted in a $38 \times 3$ cross table, which we analysed using log linear analysis from the statistical package BMDP. Log linear analysis was preferred over separate analyses of variance, because it is appropriate for analysing frequencies that are not distributed normally and it reports the relative frequencies of the different categories in one analysis. A Bonferroni procedure was used to maintain an overall significance level of 0.05 . Finally, the three groups were characterised in terms of the most frequent categories and distinctions from other groups.

In order to make the results easier to interpret, we grouped these categories into larger content clusters based on consensus: A) Metacognition (2 categories), B) Regulation of the diagnostic interview (8 categories), C) Diagnostic reasoning (8 categories), D) Content of the diagnostic interview (7 categories), E) Client counsellor relation and communication (4 categories), F) The client ( 2 categories), and G) Miscellaneous (7 categories) (see Appendix 1).

\section{Diagnostic accuracy}

We developed a scoring key for diagnostic accuracy in accordance with Bögels et al.'s (1995) method. Three experts who were not involved in the study read the role script and reported what they thought were the most likely diagnostic hypotheses and differential diagnosis. Their responses were used to compile a list of accurate, semi-accurate and inaccurate answers. The diagnoses of the panel were labelled as accurate, their differential diagnoses as semi-accurate, and any other diagnoses were considered inaccurate. Two, one and zero points were awarded for accurate, semi-accurate and inaccurate answers, respectively. A sum score was calculated for every participant. Each participant could thus receive a maximum of four points (for depression and hypochondriasis). Analysis of variance was used to test the differences between the groups in diagnostic accuracy.

\section{Results}

\section{Cognitive Processes}

The 38 thought categories that were established by the protocol analysis are presented in the Appendix. The analysis of think-aloud protocols resulted in a total frequency of 3407 thoughts. The contribution per group was 794 (23\%), 1044 (31\%), and $1569(46 \%)$ for novices, intermediates and experts, respectively. 
Figure 1. Commonalities and differences between novices, intermediates, and experts in number of thoughts in the 38 categories of thoughts.

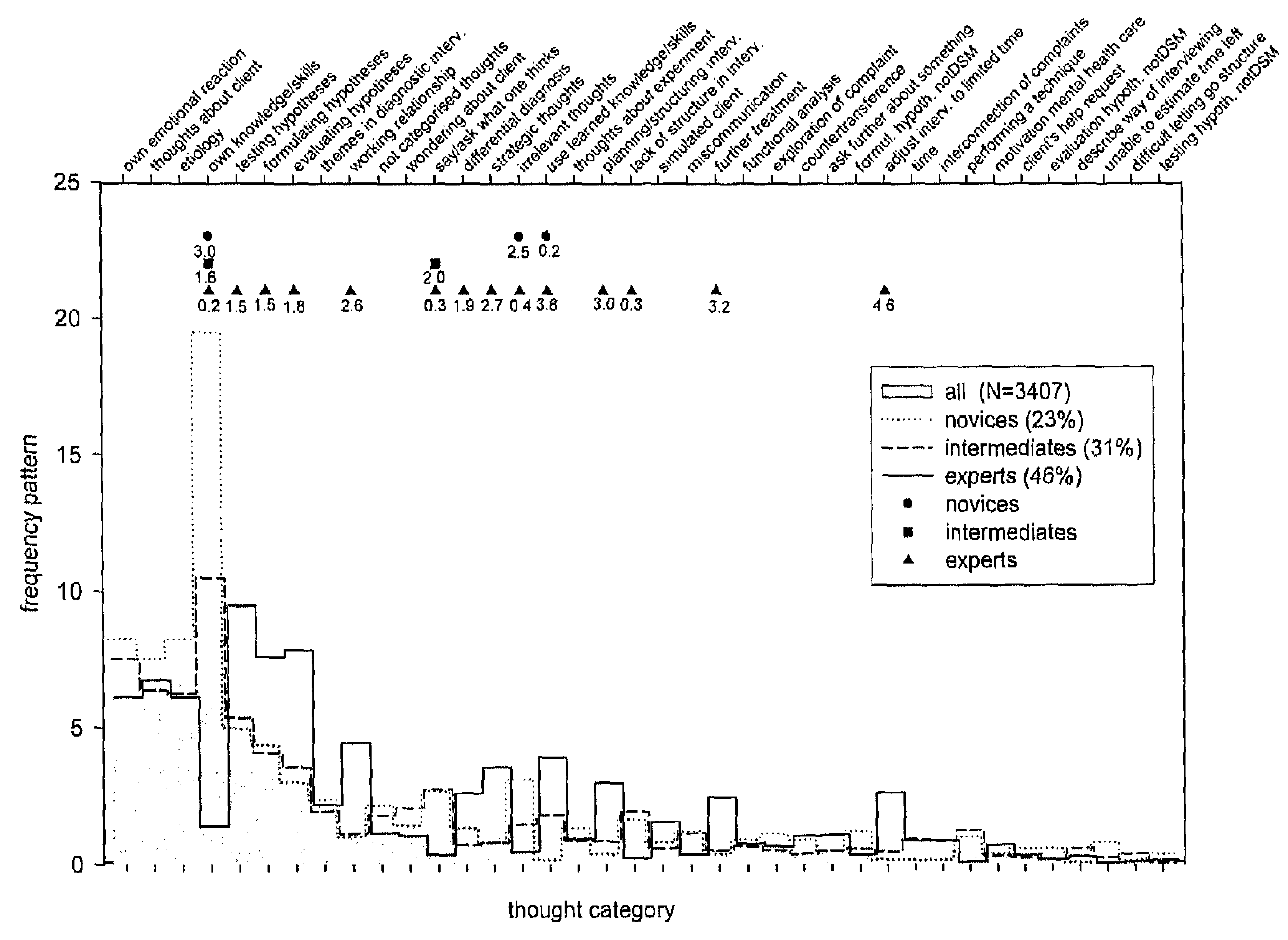

Figure 1. Differences between novices, intermediates, and experts in frequencies of thoughts in the 38 thought categories. The $x$-axis represents the 38 categories and the $y$-axis represents the standardised frequency of the thoughts. Frequencies were standardised for the general level of frequencies (in all there were 3407 thoughts) and for the different total frequencies per group (23\%, $31 \%$, and $46 \%$, for novices, intermediates, and experts, respectively). The resulting frequency patterns are shown for novices (dotted line), intermediates (broken line), and experts (solid line), and in grey the average pattern is shown. Categories were sorted along the $\mathrm{x}$-axis in descending order of the altitude in the average pattern (grey). The symbols above the frequencies show per category whether groups deviated significantly from the average pattern: a triangle indicates a significant deviation for the experts, a square for the intermediates, and a circle for the novices. The numbers below the symbols indicate the magnitude of the effects: e.g. 3.0 below a triangle means that the frequency of the experts was three times as high as the corresponding frequency of the average pattern.

Figure 1 shows the differences between novices, intermediates, and experts in frequencies of thoughts in the 38 categories. The $x$-axis represents the 38 categories and the $y$-axis represents the standardised thought frequency. Frequencies were standardised because we wanted to focus on between-group differences of fre- 
quency patterns across categories. Hence, we were not interested in general frequency levels (in all there were 3407 thoughts) nor in the differences in frequencies between groups (which amounted to $23 \%, 31 \%$, and $46 \%$ ). Using the results of loglinear analysis, the required standardisation can be obtained in two steps. In step 1 the observed frequency is standardised for the general frequency level by dividing by 13.9, which represents the (geometric ${ }^{5}$ ) average frequency per cell in the $38 \times 3$ table. In step 2 the frequency is standardised for the general between-group differences, i.e. the observed frequency is divided by a parameter representing these differences. For the current data these parameters are $0.685,1.066$, and 1.37, for the novices, intermediates, and experts, respectively. Let us illustrate this by an example: for novices the $4^{\text {th }}$ thought category had an observed frequency of 185 . Standardising this value for the general level of frequency and for general betweengroup differences in frequency is obtained by dividing 185 by 13.9 and by 0.685 . This results in 19.4, which is represented in the graph by the dotted line at the $4^{\text {th }}$ category. Repeating this procedure for all categories results in the dotted pattern of standardised frequencies for novices. The patterns for the other two groups were obtained in the same way (a solid line for experts, a broken line for intermediates). The grey pattern represents the (geometric) average of the patterns for the three groups. The categories in figure 1 were presented along the $x$-axis in descending order of altitude of the average pattern (grey).

The symbols above the frequencies show per category whether groups deviated significantly from the average pattern: a triangle indicates a significant deviation for the experts, a square for the intermediates, and a circle for the novices. The numbers under the symbols indicate the magnitude of the effects: e.g. 3.0 under a triangle means that the frequency of the experts was three times as high as the corresponding frequency of the average pattern.

The analysis shows that most thoughts expressed in the stimulated recall protocols relate to the following categories: Counsellors' emotional reactions to the client's story or complaints, thoughts about the client, aetiology, thoughts and/or doubts about (lack of) knowledge and skills, and testing, formulating and evaluating hypotheses. The first three do not show differences between the three groups. The latter three are more prominent in the experts' protocols but are also a strong feature of the novices' and intermediates' thoughts. Thoughts and/or doubts about (lack of) knowledge and skills are very prominent in the novices' and intermediates' protocols and are quite rare for the experts. This suggests a common core in the cognitive processes of beginning and experienced counsellors, though beginning counsellors also pay much attention to their knowledge and skills.

\footnotetext{
${ }^{5}$ With loglinear models the geometric average is used instead of the more commonly used arithmetic average (which most commonly is indicated as the avernge). The geometric average of a set of $n$ values is obtained by taking the $n$-th root of the product of the $n$ values. The loglinear model is a multiplicative model and, as a consequence, a multiplicative average (the geometric average) is used instead of the arithmetic average, which is additive.
} 
Figure 1 also shows that the three groups demonstrate marked differences with respect to 14 categories. These differences are also depicted as the percentage of categories per cluster yielding significant differences between expertise levels (Figure 2).

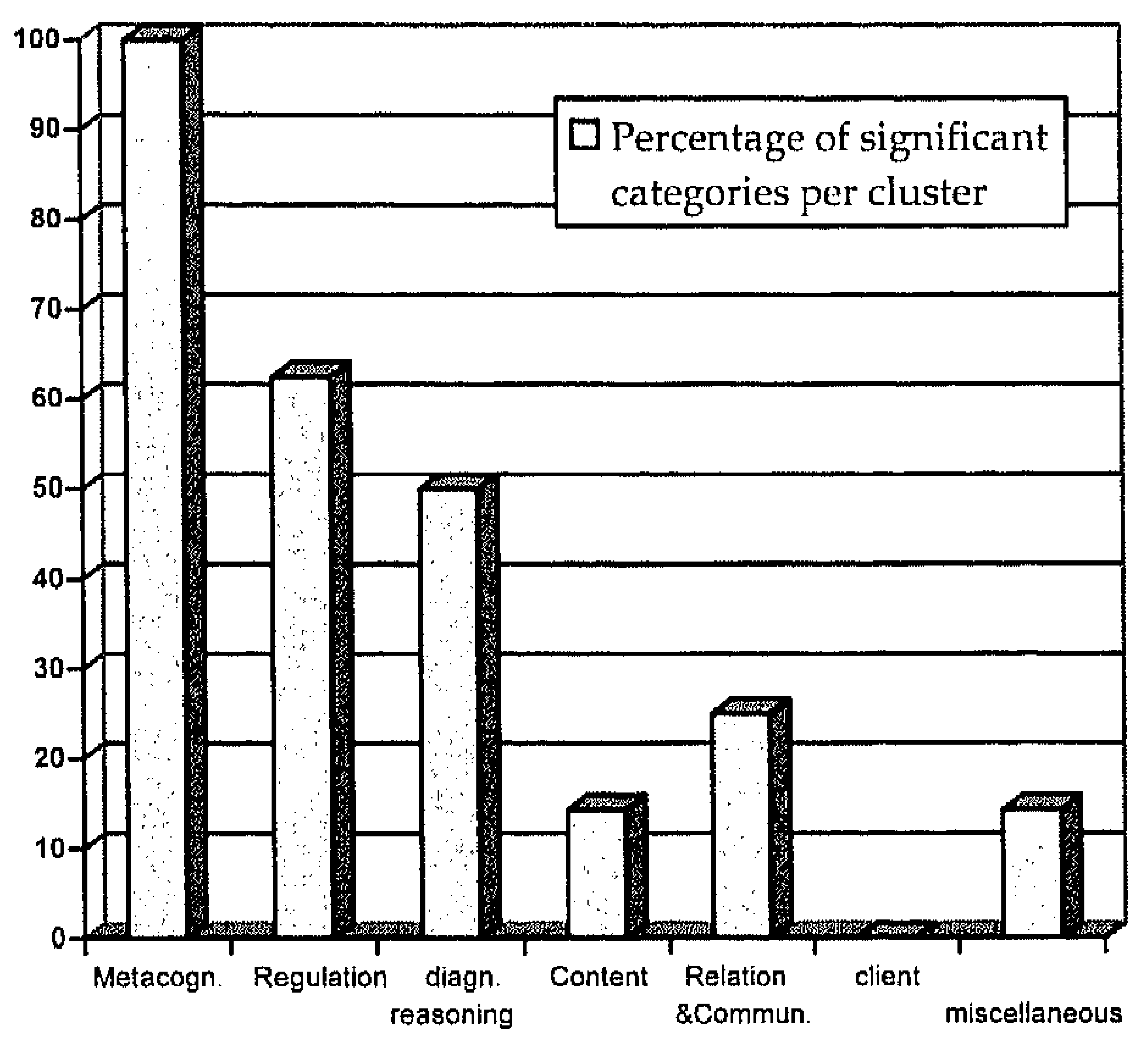

Figure 2. Percentage of categories per cluster for which significant differences were found

\section{Clusters}

Significant differences were found for the two categories in the 'Metacognition' cluster (100\%). Most of the novices' metacognitive thoughts are related to thoughts and/or doubts about (lack of) knowledge and skills and only few thoughts are concerned with the application of prior knowledge and/or skills. The intermediates were also found to have many metacognitive thoughts in the first category, although much fewer than the novices. Experts have the fewest thoughts in this category and more thoughts than the other two groups on using prior knowledge and/or skills.

In the cluster 'Regulation of the diagnostic interview', significant differences were found for $62.5 \%$ of the categories. Experts report few thoughts in the categories saying/asking what one is thinking and lack of structure and have many thoughts about planning and structuring, adjusting the interview to the limited available time, and strategic thoughts. Intermediates, on the other hand, have many thoughts in the category saying/asking what one is thinking. This category contains thoughts that merely reflect what the counsellor is doing or asking at that moment in the interview. 
Significant differences were found for $50 \%$ of the categories in the cluster ' $\mathrm{Di}$ agnostic reasoning'. Experts have most thoughts in the categories testing diagnostic hypotheses, formulating diagnostic hypotheses, evaluating diagnostic hypotheses, and differential diagnosis.

For the 'Content of the diagnostic interview', the three groups show the same number of thoughts for all categories except for further treatment. Experts report significantly more thoughts in this category.

As for the thoughts in the cluster on 'Client-counsellor relationship and communication', experts have many thoughts regarding the working relationship (25\% of the categories in this cluster). For the other categories in this cluster no differences were found between the groups.

The cluster 'The client' yielded no differences between the three groups and the cluster 'Miscellaneous' yielded significantly more thoughts in the category irrelevant thoughts for novices compared to the other two groups.

\section{Groups}

The novices' protocols are most strongly characterised by thoughts or doubts about (lack of) knowledge and skills. The novices also pay much attention to the aetiology of the client's complaint, to the client himself and how he presents his complaints, and to their own emotional reactions to the client's story and complaints. Hypothesis generation, testing and evaluation play an important role, but novices also have a considerable number of irrelevant thoughts. They have fewer thoughts than expected on the application of learned techniques.

The intermediates' protocols are similar to those of the novices regarding thoughts on the aetiology of the client's complaint, on the client himself, on their own emotional reactions to the client's story and complaints, and on hypothesis generation, testing and evaluation. Though intermediates' protocols are also most strongly characterised by thoughts or doubts about (lack of) knowledge and skills, these thoughts play a significantly smaller part than in the novices protocols. Finally, the intermediates' protocols are unique in verbalisations of what the participant was going to do or ask without giving reasons.

The majority of the statements in the experts' protocols regard hypothesis formulation, testing and evaluation. In contrast to the other groups, the experts consider differential diagnoses during the interview. Like the others, they have many thoughts on the aetiology of the client's complaint, on the client himself, and on their own emotional reactions to the client's story and complaints. Unlike the other groups, the experts pay attention to the working relationship with the client and to further treatment. They comment on their use of learned interviewing techniques and more specifically on the strategic way they use their knowledge and skills. Finally, experts think about planning and structuring the interview, adjusting it to the limited time available; they comment less on lack of structure. 
Differences in cognitive processes

\section{Diagnostic accuracy}

A significant difference in the accuracy of the diagnoses was found between the experts and the other two groups $(F(2,36)=10.40, p<0.001)$, with the experts making more accurate diagnoses than the novices and intermediates. The difference between novices and intermediates is not significant. The mean scores on diagnostic accuracy are $1.23(\mathrm{SD}=0.83)$ for the novices, $2.08(\mathrm{SD}=1.26)$ for the intermediates, and $3.00(\mathrm{SD}=0.82)$ for the experts.

\section{Discussion and conclusions}

The aim of the present study was to gain insight into the cognitive processes of counsellors during a diagnostic interview and in any differences in these processes between groups with different levels of counselling expertise, i.e. novice, intermediate and expert. In addition, differences between the three groups in diagnostic accuracy were studied.

The results of the analysis of cognitive processes in diagnostic interviewing show that the groups have a common understanding of the content to be covered in the diagnostic interview and of the way to do that. This common core of cognitive processes, shared by all groups, involves: understanding the client, his complaints and the way these complaints are expressed, the aetiology, hypothesis generation, testing and evaluation, and their own emotional reactions. However, the novices' cognitive processes are accompanied by many thoughts concerning doubts about their knowledge and skills in the present situation. The same applies to the intermediate group although their doubts are less extensive. The intermediates also show some structuring of the interview process. Both groups do not really formulate a differential diagnosis during the interview. They only make a diagnosis after completing the interview and the stimulated recall and evaluating their findings using the DSM-IV manual. This result is in line with the study by Borders et al. (1988) and shows the difficulties of beginning counsellors in purposefully applying their skills.

Experts' protocols also include this core of cognitive processes but they formulate differential diagnoses during the interview. The experts show multitiered thought processes and manage to deal with many issues simultaneously, such as diagnostic reasoning (formulating, testing and evaluating DSM-IV-TR hypotheses, and differential diagnosis), regulation of the diagnostic interview (planning and structuring the interview and adjusting the interview to the limited available time), building a therapeutic relationship with the client, and planning ahead in thinking about a treatment plan. The finding that experts have more attention for establishing and maintaining a working relationship with the client confirms results of earlier studies and is in accordance with counsellor development models (O'Brien \& DeLongis, 1996; Sakai \& Nasserbakht, 1997; Skovholt \& Ronnestad, 1992; Stoltenberg, 1981; Stoltenberg, McNeill, \& Crethar, 1994). Furthermore, the experts' interviews are guided by clearer goals and more explicit strategies for obtaining important information than the interviews of the other 
groups. This enables experts to monitor their information gathering and adjust their strategies to the available time and emerging issues. This multi-tasking by experts is in no way paralleled by the task performance of the novices and intermediates in the present study.

This difference between experts on the one hand and novices and intermediates on the other hand is also reflected in their diagnostic accuracy and is in line with our hypothesis that diagnostic accuracy is seen to improve with experience when authentic tasks are used.

Unlike previous studies, our study investigated the use of cognitive diagnostic skills and quality of performance and outcome in an integrated, holistic way, yielding insights into commonalities and differences in cognitive task execution at different levels of expertise. However, the method we used has its drawbacks as well. This study is a cross-sectional study with unequal intervals between expertise levels. What processes can bridge the gaps between the different levels? We used stimulated recall as a method. Can there be an interaction between the outcomes of stimulated recall and expertise levels? There are many confounding factors related to expertise levels. How do they affect the outcomes? We used a bottom-up procedure to determine the categories. Can this have affected the outcomes? In the remaining part of this discussion we will consider these questions and we will conclude with implications for further research and education.

The cross-sectional nature of this study, with unequal intervals between expertise levels has several implications. Cross-sectional studies are generally used when the developmental period under investigation is long. The advantage is that information becomes immediately available, which is a major asset for processes that can take several decades. Disadvantages are many, however. The most important one is group inequality: there is no guarantee that the group of novices will ever reach the level of expertise of the experts in this study. In this specific study the two student groups (beginners and intermediates) are comparable since the internship that was just completed by the intermediates is obligatory for all students of mental health science. Hence, the difference between the intermediates and the novices in this study may be largely attributable to experiences during placements and how students dealt with them. Sitting in with experts, doing interviews on their own, attending client discussions, engaging in self-directed study, receiving feedback and reflecting on this may all have contributed to this specific outcome. Careers after graduation, however, are more divergent and selection and self-selection processes may partly explain the differences between intermediates and experts. The long period after graduation, filled with required training and experience in several settings, is likely to have contributed most.

Expertise level contains many confounding variables reflecting how careers develop. The most obvious confounder is age. Especially in domains that require long training and where professional practice is highly regulated, higher expertise levels are related to higher age. In the domain of chess, where it is easier to find young and older age groups showing similar variation in expertise, it was found that age 
did not affect performance on chess related tasks, while expertise level did (Schneider, Gruber, Gold, \& Opwis, 1993). Another confounding factor might be gender. The gender distribution in the present study reflects gender specific careers related to different decades. It is hard to say whether the generation of new graduates will develop different ways of diagnostic interviewing and whether gender differences will play a role. However, present experts are role models for the new generation, which may imply at least some continuity.

The stimulated recall method has been used frequently in different domains but so far little research has focused on its strengths and weaknesses. Van Gog et al.'s (2005) study is an exception, investigating the differences between three methods, but not taking into account expertise effects. There are reasons to assume that expertise level may have some effect on methods that require recall. Since the seminal studies of De Groot $(1946,1968)$, we know that experts have superior recall in relation to domain relevant tasks. This phenomenon was explained by experts' superior knowledge in terms of amount, content and structure (Claessen \& Boshuizen, 1992; Boshuizen \& Schmidt; De Groot, 1946, 1965). This advantage may also play a role in stimulated recall. Probably the level and structure of the participants' knowledge affects their task execution and the later stimulated recall of that. However, by using a video recording with both the client and the counsellor on film, we tried to maximise the amount of cues or stimuli to help participants relive the situation with the immediacy of the original event (Bloom, 1953, 1954), which is assumed to have positively affected the number of recalled thoughts and the reliability of recall in all three groups.

In defining the categories in this study a bottom-up procedure was used, giving priority to discriminating between different contents and steps of the cognitive activities that were part of cognitive processes during the diagnostic interview. We did not make distinctions in terms of the quality of those contents and steps, e.g., the quality of the hypotheses under investigation. As a consequence we cannot draw conclusions about the quality of the processes within a category. At a higher level, overarching the separate categories, different pictures, expressing different levels of mastery and quality of the process emerge. The granularity of the analysis was a direct consequence of the departure point that in defining categories credit should be given to differences between protocol fragments. This can be at odds with the requirements for statistical analysis. That is, the finer the differentiations and the smaller the categories, the bigger the chance that the resulting tables cannot be analysed statistically due to empty cells or too low frequencies. Deleting or collapsing categories can increase the power of the analysis but is only indicated when these adjustments do not undermine the approach taken and when the resulting categories make sense. As we did not perform such procedures it is rather pointless to dwell on 'What-if' reasoning to find out whether a different approach could have resulted in different outcomes.

The results of this study leave many questions open and generate several new ones. Educationally speaking, the phenomenon that novices express so much doubt 
about their knowledge and skills and have fewer explicit thoughts about diagnostic reasoning and other issues is intriguing. Within educational contexts, doubts are often perceived as unproductive or counterproductive thoughts that drain cognitive energy that cannot be spent on the problem solving process itself (Sweller, 1988). A first possible explanation for the fact that novices and intermediates are so doubtful may be that the quality and structure of novices' knowledge and cognitive skills require conscious activation, requiring their full attention and leaving little cognitive space for things like diagnostic hypothesis formation, testing, and evaluating or building a good working relationship with the client (Dunphy \& Williamson, 2004; Glaser \& Chi, 1988; Sweller, 1994). Another potential explanation may be that the novices lack the cognitive skills needed to interpret and organise client information. As a result they may have difficulty formulating diagnostic hypotheses on the basis of client information and keep asking questions and doubting their skills instead. A third possibility may be that insecurity is a direct effect of lack of experience. More research using on-line cognitive load measures and more direct investigation of knowledge quality and application will have to clarify this issue and will have both theoretical and educational implications.

Another issue is the unequal distances between the levels of expertise in the present study, with two groups only differing in practical experience and a third group consisting of highly trained and experienced professionals. These levels offer a good insight into what graduates still have to learn, but no insight at all into how higher levels of expertise are reached. Research in other fields (e.g., Arts, Gijselaers, \& Boshuizen, 2006) shows that performance may develop at a nonmonotonic rate, possibly associated with different phases in a counsellor's career. Further research along this line should include several levels of experience, good performance measures to corroborate other expertise measures and stimulated recall.

\section{References}

American Psychological Association (2000). Diagnostic and statistical mantal of mental disorders (4th edition TR ed.). Washington DC: American Psychiatric Association.

Arts, J. A. R., Gijselaers, W. H., \& Boshuizen, H. P. A. (2006). Understanding managerial problemsolving, knowledge use and information processing: Investigating stages from school to the workplace. Contemporary Educational Psychology, 31, 4, 387-410

Benedek, E. P., \& Bieniek, C. M. (1977). Interpersonal process recall: An innovative technique. Journal of Medical Education, 42, 939-941.

Bloom, B. S. (1953). Thought processes in lectures and discussions. Jommal of General Education, 7, 160-169.

Bloom, B. S. (1954). The thought processes of students in discussions. In S. J. French (Ed.), Accent on tenching: Experiments in general education. New York: Harper.

Bögels, S., Van der Vleuten, C. P. M., Blok, G., Kreutzkamp, R., Melles, R., \& Schmidt, H. G. (1995). Assessment and validation of diagnostic interviewing skills. Joumal of Psychopathology and Behnvioral Assessment, 17, 3, 217-230.

Bögels, S. M. (1994). Teaching and assessing diagnostic interviewing skills. Maastricht: Universitaire Pers Maastricht.

Bögels, S. M. (1999). Diagnostic interviewing in mental health care: Methods, training, and assessment. In A. Memon \& R. Bull (Eds.), Handbook of the psychology of interviewing (pp. 3-19). New York: John Wiley \& Sons. 
Differences in cognitive processes

Borders, L. D., Fong-Beyette, M. L., \& Cron, E. A. (1988). In-session cognitions of a counseling student: A case study. Counselor Education and Supervision, 28, 59-70.

De Grave, W. S., Boshuizen, H. P. A., \& Schmidt, H. G. (1996). Problem based learning: Cognitive and metacognitive processes during problem analysis. Instructional Science, 24, 5, $321-341$.

Boshuizen, H. P. A., \& Schmidt, H. G. (1992). On the role of biomedical knowledge in clinical reasoning by experts, intermediates and novices. Cognitive Science, 16, 153-184.

Claessen, H. F. A., \& Boshuizen, H. P. A. (1985). Recall of medical information by students and doctors. Medical Education, 19, 61-67.

De Groot, A. D. (1946). Het denken van den schaker: een experimenteel-psychologische studie (The chess player's thinking: an experimental psychological study). PhD Thesis University of Amsterdam; Amsterdam: Noord-Hollandsche Uitg. Mij

De Groot, A. D. (1965). Thought and choice in chess. The Hague, Mouton.

Dunphy, B. C., \& Williamson, S. L. (2004). In pursuit of expertise. Toward an educational model for expertise development. Advances in Health Sciences Education, 9, 107-127.

Elstein, S., Shulman, L.S., \& Sprafka, S.A. (1978). Medical Problem Solving: An Analysis of Clinical Reasoning. Cambridge, MA: Harvard University Press.

Ericsson, K. A., \& Simon, H. A. (1980). Verbal reports as data. Psychological Review, 87, 3, 215-251.

Ericsson, K. A., \& Simon, H. A. (1993). Protocol analysis: Verbal reports as data. Revised edition. Massachusetts: Massachusetts Institute of Technology.

Fitzhenry-Coor, I., \& Nurcombe, B. (1983). Assessing clinical reasoning: The development of a new test in psychiatric education. The Journal of Psychiatric Education, 7, 183-196.

Garb, H. N. (1989). Clinical judgment, clinical training, and professional experience. Psychological Bulletin, 105, 3, 387-396.

Glaser, R., \& Chi, M. T. H. (1988). Overview. In M. T. H. Chi, R. Glaser \& M. J. Farr (Eds.), The nature of expertise (pp. 15-28). Hillsdale: Erlbaum.

Hillerbrand, E., \& Claiborn, C. D. (1990). Examining reasoning skill differences between expert and novice counselors. Journal of Counseling \& Development, 68, 684-691.

Kagan, N. (1984). Interpersonal process recall: Basic methods and recent research. In D. Larson (Ed.), Teaching psychological skills: Models for giving psychology awny. Monterey: Brooks/Cole.

Kagan, N. I., \& Kagan, H. (1991). Interpersonal process recall. In P. W. Dowrick (Ed.), Practicnl guide to using video in the behnvioral sciences (pp. 221-230). New York: Wiley.

Kagan, N., Krathwohl, D. R., \& Miller, R. (1963). Stimulated recall in therapy using video tape: A case study. Journal of Counseling Psychology, 10, 3, 237-243.

Norman, G. R., Tugwell, P., \& Feightner, J. W. (1982). A comparison of resident performance on real and simulated patients. Journal of Medical Education, 57, 708-715.

Nurcombe, B., \& Fitzhenry-Coor, I. (1982). How doe psychiatrists think? Clinical reasoning in the psychiatric interview: A research and education project. Australian and New Zealand Journal of Psychiatry, 16, 13-24.

Nurcombe, B., \& Fitzhenry-Coor, I. (1987). Diagnostic reasoning and treatment planning: I. Diagnosis. Australian and New Zealand Journal of Psychiatry, 21, 477-483.

O'Brien, T. B., \& DeLongis, A. (1996). The interactional context of problem-, emotion-, and relationship-focused coping: The role of the Big Five Personality factors. Journal of Personality, 64, 4, 775-813.

Othmer, E., \& Othmer, S. C. (1994). The clinical interview using DSM-IV Volume 1: Fundamentals (Vol. 1). Washington: American Psychiatric Press.

Rethans, J., Sturmans, F., Drop, R., \& Van der Vleuten, C. P. M. (1991). A method for introducing standardized (simulated) patients into general practice consultations. Britisch Journal of General Practice, 41, 94-96.

Sakai, P. S., \& Nasserbakht, A. (1997). Counselor development and cognitive science models of expertise: Possible convergences and divergences. Educational Psychology Review, 9, 4, 353359.

Sanson-Fisher, R., \& Poole, A. D. (1980). Simulated patient and the assessment of medical students' interpersonal skills. Medical Education, 14, 249-253.

Schneider, W., Gruber, H., Gold, A., \& Opwis, K. (1993). Chess expertise and memory for chess positions in children and adults. Journal of Experimental Child Psychology, 56, 328-349. 
Shea, S. C. (1988). Psychiatric interviewing: The art of understanding. Philadelphia: W.B. Saunders Company.

Skovholt, T. M., \& Ronnestad, M. H. (1992). The evolving professional self: Stages and themes in therapist and counselor development. West Sussex: Wiley.

Skovholt, T. M., Ronnestad, M. H., \& Jennings, L. (1997). Searching for expertise in counseling, psychotherapy, and professional psychology. Educational Psychology Review, 9, 4, 361-369.

Stoltenberg, C. (1981). Approaching supervision from a developmental perspective: The counselor complexity model. Journal of Counseling Psychology, 28, 1, 59-65.

Stoltenberg, C. D., McNeill, B. W., \& Crethar, H. C. (1994). Changes in supervision as counselors and therapists gain experience: A review. Professional Psychology: Research and Practice, 25, 4, 416-449.

Sweller, J. (1988). Cognitive load during problem solving: Effects on learning. Cognitive Science, 12, 257-285.

Sweller, J. (1994). Cognitive load theory, learning difficulty, and instructional design. Learning and Instruction, 4, 295-312.

Van Gog, T., Paas, F., Van Merriënboer, J. J. G., \& Witte, P. (2005). Uncovering the problem solving process: Cued retrospective reporting versus concurrent and retrospective reporting. Journal of Experimental Psychology: Applied, 11, 237- 244.

Witteman, C. L. M., \& Van den Bercken, J. H. L. (2007). Intermediate effects in psychodiagnostic classification. European Journal of Psychological Assessment, 23, 1, 56-61

Yinger, R. (1986). Examining thought in action: A theoretical and methodological critique of research on interactive teaching. Teaching and Teacher Education, 2, 3, 263-282 


\title{
6
}

\section{The first contact with a client in mental health care: Differences in diagnostic reasoning and knowledge structure between beginning and experienced counsellors $^{6}$}

\begin{abstract}
This study examines differences between beginning and experienced counsellors in the quality of cognitive processes during diagnostic interviewing and the relationship between knowledge structure and cognitive processes. Counsellors of three levels of expertise: students (novices, $n=13$ ), interns (intermediates, $n=13$ ), and experienced counsellors (experts, $n=13$ ) interviewed and diagnosed the same simulated client and reported their thoughts during the interview in a stimulated recall procedure.

We found qualitative differences between the groups in cognitive processes on three levels: overall structure of the interview protocols (advance planning and adjustments during the interview), how and how much control was exercised, and the steps of the diagnostic reasoning process (information detection, interpretation, conclusions or actions based on interpretations, and evaluation). Indications of knowledge restructuring were found. Knowledge and skills in diagnostic interviewing appear to become automated with experience. Knowledge about the DSM-IV-tr categories of psychological disorders appears to expand with experience, can be activated by multiple cues and its application becomes automated. Knowledge clusters become interrelated. Illness script-like structures may be formed, including DSM-IV-tr knowledge supplemented by knowledge about client behaviour, counsellor-client relationship, mental pictures of prototypical patients and variations. Even a minimum of practical experience appears to lead to restructuring of knowledge.
\end{abstract}

\footnotetext{
${ }^{6}$ Wagenaar, A., Boshuizen, H.P.A., Van der Vleuten, C.P.M., \& Scherpbier, A.J.J.A. (subm.). The first contact with a client in mental health care: Differences in diagnostic reasoning and knowledge structure between beginning and experienced counsellors.
} 
The first contact with a client in mental health care

\section{Introduction}

Learning to conduct a diagnostic interview in mental health care settings is a very complex process involving the acquisition of several constituent skills. The successful and coordinated application of these skills requires varying kinds and levels of knowledge. For instance, asking the right kind of questions to rule in or out a diagnosis is a knowledge-rich skill. Asking open-ended questions on the other hand is a knowledge-lean skill. Training programmes use these differences by incorporating knowledge-lean skills at earlier stages. Training components are often sequenced on an intuitive basis because to date little is known about how integration of knowledge and skills develops in this domain. The aim of the present study is to gain more insight into the kind of knowledge students and experts use during a diagnostic interview and how that knowledge is applied. For this purpose we examined differences between beginning and experienced counsellors in the quality of cognitive processes during a diagnostic interview. We also wanted to unravel some of the knowledge development and cognitive restructuring processes underlying these differences.

Unfortunately, there appears to be a paucity of research in this domain and no integrated model for knowledge development and application is available. This contrasts markedly with some other domains such as accountancy, chess and medical diagnostic skills. Especially the outcomes of expertise development research in medicine are relevant here, for, despite numerous differences, the two professions have much in common, such as the importance of diagnostic interviewing.

Most expertise theories in the medical domain start from changes in the organisation of knowledge and how this relates to reasoning (Norman, Eva, Brooks, \& Hamstra, 2006). They distinguish three broad kinds of knowledge: causal knowledge (understanding basic mechanisms), analytical knowledge (the formal relation between diagnoses and features - signs and symptoms - of various conditions), and experiential knowledge (the accumulation of a storehouse of prior cases that comes with experience) (Schmidt, Norman, \& Boshuizen, 1990; Gruppen \& Frohna, 2002). Greater experience seems to result in greater reliance on exemplarbased knowledge and less on formal knowledge. The relationship between these knowledge bases and their use in clinical reasoning is the object of Boshuizen and Schmidt's (2000) theory of the development of expertise. This theory is embedded in cognitive psychological information processing theories. It postulates four stages of knowledge restructuring, associated with increasing levels of expertise in clinical reasoning. The first stage of expertise development is thought to be characterised by the acquisition of biomedical, causal knowledge and the use of detailed steps in the diagnostic reasoning process. In the second stage, constantly expanding knowledge structures are formed while the lines of reasoning are shorter. Stage three is that of knowledge encapsulation, involving the following process. Repeated use of detailed causal knowledge forges and strengthens direct links between patient findings and clinical concepts. As a result the steps in the reasoning process become less detailed, because diseases are recognised without activation of every single detail of the 
relevant biomedical knowledge. In other words, biomedical knowledge is becoming encapsulated within the knowledge about specific diseases. It is still accessible when needed, but there is no need to activate it when patients present with straightforward symptoms and complaints. The fourth stage is the formation of illness scripts. An illness script is activated as an undivided whole when a doctor sees a patient with certain complaints or symptoms. Illness scripts are composed of three parts that are activated simultaneously: 1) 'enabling conditions', i.e. the conditions or constraints under which a disease occurs and which involve personal, social, medical, hereditary and environmental factors; 2) the 'fault', i.e. the pathophysiological or anatomical processes that are involved in a specific disease and which are represented in encapsulated form; and 3) the 'consequences of the fault', i.e. the signs and symptoms of a specific disease.

We conjecture that similar restructuring processes resulting from repeated application of domain knowledge and experience with clients may characterise expertise development in mental health professions (Strasser, 2006). Nevertheless, the medical model cannot be directly transferred to this domain. Diagnostic interviewing in mental health care differs from that in medicine in many ways. Firstly, the diagnostic tasks of counsellors are very different from those of doctors in the sense that symptoms or symptom complexes are not linked to distinct underlying pathophysiological mechanisms. There is no clear dichotomy between clinical and pathophysiological reasoning in mental health care. Consequently, a process like knowledge encapsulation, if it occurs at all, will be different from what is seen in medicine. Secondly, counsellors' tasks are less clearly structured and less well defined than the problems to be resolved by doctors or chess players (Locke \& Covell, 1997). Mental disorders are mainly descriptive and thus less straightforward than problems in chess and medicine. The development of expertise in mental health care is further complicated by the co-existence of a variety of theoretical orientations (Lichtenberg, 1997). Different theoretical orientations are characterised by specific ways of describing and analysing psychological problems as well as by the use of specific interventions. Finally, it is not always obvious which intervention will and which intervention will not be effective for a particular client (Lichtenberg, 1997), whereas in medicine the relationship between problem and treatment is generally less complicated. These same characteristics also complicate research into expertise development in clinical reasoning in the domain of mental health care. This may explain why expertise research in this field hardly ever looks at the whole task of diagnostic reasoning or diagnostic interviewing. Instead performance differences on isolated aspects or subtasks are investigated yielding a hotchpotch of partly contradictory results, which do not allow conclusions about the relation between expertise development, professional performance and underlying knowledge use and structure (see Wagenaar et al., submitted).

Despite these difficulties, Wagenaar et al. (submitted) decided that the paucity of research into expertise development in mental health care and the important implications of results from such research for teaching and training justified a study of 
a whole, authentic task. The focus of this study was the cognitive reasoning process of counsellors during a diagnostic interview. The diagnostic interview was chosen because of its crucial role in mental health care services. The blurring effect due to different theoretical schools was resolved by requiring the participants to use the Diagnostic and Statistical Manual of Mental Disorders (DSM-IV-tr, American Psychological Association (APA), 2000) as a common frame of reference for diagnostic decision making. This study showed that higher expertise levels were associated with better diagnostic performance; it also gave insight into commonalities and differences in cognitive task execution and performance at different levels of expertise. The cognitive reasoning processes of the three groups of participants (experts, interns, and students) appeared to have a common core, shared by all groups. This involved understanding the client, his complaints and the way these complaints are expressed, the aetiology of the complaints, hypothesis formulation, testing and evaluation, and the counsellor's own emotional reactions. Differences between the groups were also found. The novices' cognitive processes were accompanied by many thoughts expressing doubts about their knowledge and skills in the present situation. A similar situation applied to the intermediates, albeit to a lesser extent. Experts' protocols, on the other hand, showed multi-tiered thought processes; they managed to deal with many issues simultaneously, such as diagnostic reasoning, regulation of the diagnostic interview, building a working relationship with the client, and planning ahead in thinking about a treatment plan.

Although the outcomes of this study are very interesting, they are limited to commonalities and differences in how participants of different levels of expertise approach an authentic diagnostic interviewing task. This is a good first step but the results may give rise to misleading interpretations, because quantitative differences and commonalities may or may not coincide with qualitative differences. Therefore, the present study focused on the quality of the cognitive processes during a diagnostic interview and on differences between three levels of expertise. Furthermore, because expertise development is expected to involve knowledge restructuring, we looked for possible indications of knowledge restructuring in the domain of mental health care.

\section{Method}

\section{Participants}

Thirty-nine participants took part in this study. They were evenly distributed over three groups of thirteen counsellors with different diagnostic expertise: a trained but inexperienced novice group, a trained intermediate group with some experience, and an expert group who were highly trained and experienced. The novices and intermediates were master level students in mental health sciences at Maastricht University, the Netherlands. The novices had completed the initial skills training programme but had not yet started internships, while the intermediate group consisted of students pursuing internships in ambulatory or clinical settings. 
The intermediates had diagnostic experience with adults, except for one student whose internship was in paediatric care. The experts were mental health professionals (psychologists, psychotherapists and psychiatrists) with an average of fourteen years of diagnostic experience in mental health care $(\mathrm{SD}=7.3$; range 5-27 years) and a good knowledge of the DSM-IV-tr (APA, 2000). The mean ages of the novice, intermediate and expert group were 21.2 years ( $S D=0.8$; range 20-23 years), 22.9 years $(\mathrm{SD}=2.6$; range $21-26$ years) and 40.4 years $(\mathrm{SD}=8.4$; range $29-52$ years), respectively. The male female ratio was 1:12 in the novice group, 2:11 in the intermediate group and 7:6 in the expert group. For all groups this ratio was similar to that in the corresponding population.

\section{The diagnostic interview}

All participants interviewed the same simulated client for a maximum duration of thirty minutes. Several studies have reported that doctors were unable to distinguish simulated patients from real ones (Norman, Tugwell, \& Feightner, 1982; Rethans, Sturmans, Drop, \& Van der Vleuten, 1991; Sanson-Fisher \& Poole, 1980). That is why we assumed that it would be acceptable to regard an interview with a welltrained simulated client as an authentic setting. The interviewers were instructed to make an initial diagnosis in accordance with the DSM-IV-tr classification (APA, 2000). Authenticity was enhanced by allowing the participants to take notes during the interview.

The same actor portraying the same role was interviewed by all participants. The role was written especially for this study. To maximise authenticity, the role was based on a real client and adapted to the simulated client's personal situation. The role was sufficiently complex to make it an interesting case for beginners and experts (Skovholt, Ronnestad, \& Jennings, 1997). It contained two diagnoses, namely depression and hypochondria.

To ensure equivalence of performance across interviews, the actor received intensive training before the experiment, was retrained regularly during the study and was given feedback after each interview.

\section{Stimulated Recall}

The rationale for the use of this method was that the recording of the original event contained many cues or stimuli that might help participants relive the situation with the immediacy of the original event (Bloom, 1953, 1954). Because we wanted to maximise the number of cues during stimulated recall, the camera recording the interview was positioned in such a way that both the simulated client and the counsellor were on the tape. During the stimulated recall, the participants could use any notes they had taken during the interview.

\section{Procedure}

To familiarise the participants with the stimulated recall method, we performed a mock stimulated recall procedure in which the participants were videotaped while 
trying to solve a verbal riddle. The participants received feedback afterwards in order to make sure that they knew exactly what was expected of them during the actual experiment.

The participants received information about the client's name, date of birth, marital status, number of children, occupation and reason for referral by the family doctor immediately before the interview with the simulated client. The interview was directly followed by the stimulated recall session in which the participants watched the videotape of the interview after one of the researchers had asked them to watch the tape and report anything they could remember of their thinking processes during the actual interview. Whenever participants remembered a thought, feeling, or emotion, they stopped the videotape and verbally reported their thoughts. All stimulated recall procedures were guided by the same experimenter It was the experimenter's task to stimulate the participants to verbalise their thinking processes. The experimenter could stop the videotape when objective cues for thoughts were observed (when the participant wrote something down or showed a change in facial expression while watching the videotape) or when the participant had not reported a thought for more than three minutes. The experimenter was cautious about stopping the video, however, to prevent interference with the stimulated recall process. The stimulated recall was recorded on videotape and a time code was added.

Immediately after the stimulated recall session, the participants were asked to write down their final diagnosis. The participants were allowed to consult the DSMIV-tr (APA, 2000). They had 20 minutes to fill in the questionnaire to prevent them from studying the DSM-IV-tr.

\section{Analysis}

An in-depth protocol analysis (Ericsson \& Simon, 1980, 1993) was done. The interviews and the thoughts elicited during the stimulated recall were transcribed literally. We merged interview and stimulated recall by entering the reported thoughts into the interview protocol at the place in the interview - as identified by the time code - where the participant reported their occurrence. The method used to analyse the protocols was derived from Boshuizen and Schmidt (1992). Firstly, the protocols were read several times to identify the structure (i.e. the course and progress of the diagnostic reasoning process, the subjects about which questions were asked, returning to various subjects later in the interview). The structure of the interview and think-aloud protocol was schematised by three columns representing client information, the counsellor's thoughts, and the counsellor's questions, respectively. Next, different diagnostic hypotheses and themes were colour coded to identify different interview processes and to locate thoughts within the context of the interview.

To investigate differences in quality between the three expertise groups the protocols were analysed at three different levels: overall structure of the interview protocols (planning of the interview and adjustments during the interview); the 
relation between the local and the global structure (exercising control over the interview), and the local structure (steps in the diagnostic reasoning process). The schematised interview structures provided the basis for the analyses on the first and second levels. The first level concerned the way the participants planned the diagnostic interview and their approach to the client and how they adapted their plan in the course of the interview. Differences between the groups in the relationship between the global and local structure of the diagnostic interview and stimulated recall protocols were investigated by mapping the course and progress of the diagnostic reasoning process, the themes about which questions were asked, and how participants returned to various subjects raised earlier in the interview. The analysis at the third level concerned the consecutive steps in the diagnostic reasoning process during the interview. The following four steps in reasoning were distinguished: detecting information, interpretation of this information, drawing conclusions on the basis of the interpretation or acting upon these interpretations and evaluation of the interpretations. We studied the quality of the interpretations, the information on the basis of which interpretations were made, the quality of the questions and actions based on these interpretations and the evaluations.

The following indications were used to investigate knowledge organisation: experiences and references to cases, and automation. We also looked at indirect evidence such as what kind of information triggers activation of what kind of knowledge.

The first author and a student-assistant jointly analysed the interview protocols and categorised the thoughts using a consensus procedure. They schematised the protocols independently and discussed their labelling of the thoughts. The thoughts were read several times. Then indications of the quality of the cognitive processes were labelled, using the computer software ATLAS.ti (Version 4.1). Codes were assigned to indications of qualitative differences in structuring and planning of the interview, in knowledge use, in information on the basis of which interpretations were made, and in the quality of the interpretations or actions.

To enhance the reliability of the analysis, the second and third author read the protocols and examined the categorisation of the thoughts to preclude bias in the analysis. No biases were detected.

\section{Results}

The results will be described for each of the three levels of analysis. For every level the three groups are contrasted. Finally, indications of knowledge restructuring are described. The results are illustrated by thoughts reported during the stimulated recall. The number codes at the end of the thoughts refer to the participants. The first digit indicates the level of expertise $(0=$ student, $1=$ intern, and $3=$ expert $)$. 


\section{Level 1: The overall structure of the interview protocols; planning and adjustments}

The experts and the two student groups clearly differed in how they planned to approach the interview before the start of the interview (see Table 1). Experts' planning consisted of thoughts about what information they were going to seek and what they were going to leave out ("I thought, er I only have half an hour, so that means I'll concentrate on the complaint. I won't go into the past, but I'm going to ask about all that in connection with the complaint." 342). Students and interns did not plan the interview in advance ("That was the first time I think that I er did not know what to ask, until then I had just asked whichever question occurred to me, by that time I was wondering if I shouldn't er use a more structured approach" 031) or thought only about how to perform a diagnostic interview in general ("At that moment I thought er I actually had in mind to start with an extensive history of the complaint" 117; "At this point I was really thinking too much about the interview process. Oh, how was this supposed to go. So then I was really thinking like how should I start and I, my main learning objective is always not to forget the introduction, so I really was like, well just get on with the introduction and I will see how it goes." 023) Furthermore, the experts adjusted their planning during the interview. ("I am thinking that I will have to accept that I will not get the really good details, and after all that is not really what it is about (...) the diagnosis can be made anyway, even without the details" 327) Thoughts about adjusting the planning of the interview are absent in the interview protocols of the students and the interns.

The three groups differed markedly in their response to the warning signal that they had only five more minutes left to finish the interview. The experts marked time and reflected on what to ask in the final minutes of the interview ("but I actually thought, oh this will be the first warning signal. Er I should really be asking about a number of things (...) I just need to give a sort of summarisation to move on, to make a sort of bridge also to a lot of concrete information that I want to have, such as this alcohol, such as, what else, life events, in any case alcohol" 301; "At that moment I thought, just before that I had realised that time was running out a little, I cannot really look at my watch, so I think I have to make sure in any case that I know what his complaints are" 304; "Oh dear there is still so much I need to ask, haha, so and that flashes through my mind. And one of the most important things is his personality, zohat is his personality structure like. And indeed there are other important events in his life, but this is very last minute, I can tell, so at the last minute because of the beep. I am trying to get the most out of it I think" 343). For the interns the signal just indicated that they had to conclude the interview ("at the beep I thought er yes I had better work towards the conclusion" 117 and "Then I thought, oh dear, that is the beep, so I should almost start to close"138). Some students had difficulty keeping the interview going for half an hour or had concluded the interview before the signal. (21:54:5 "Yes I thought (...) now I am going to close, because I really did not know what to do next (...) it doesn't matter, right now I just don't know what to do next and I don't have to wait for the beep" 019). Other students were relieved to hear the beep ("I was really pleased. I think I have enough information for now, I will er let me see what I can do with that" 030). 
Table 1. Characteristics of the overall structure of the interview protocol of experts, intermediates and students

\begin{tabular}{llll}
\hline Characteristics & Experts & Interns & Students \\
\hline Planning & $\begin{array}{l}\text { Planning the content } \\
\text { of the diagnostic in- } \\
\text { terview beforehand }\end{array}$ & $\begin{array}{l}\text { Absent or thinking } \\
\text { about how to perform } \\
\text { a diagnostic interview } \\
\text { in general }\end{array}$ & $\begin{array}{l}\text { Absent or thinking } \\
\text { about how to perform } \\
\text { a diagnostic interview } \\
\text { in general }\end{array}$ \\
\hline $\begin{array}{l}\text { Adaptation of plan- } \\
\text { ning during the inter- } \\
\text { view }\end{array}$ & $\begin{array}{l}\text { Based on time avail- } \\
\text { able and information } \\
\text { gathered }\end{array}$ & Absent & Absent \\
\hline $\begin{array}{l}\text { Adaptation of plan- } \\
\text { ning at } 5 \text { minutes } \\
\text { warning signal }\end{array}$ & $\begin{array}{l}\text { Reflection on what to } \\
\text { ask in the time left }\end{array}$ & $\begin{array}{l}\text { Thoughts about wind- } \\
\text { ing up the interview }\end{array}$ & $\begin{array}{l}\text { Wound up before } \\
\text { signal; Thoughts } \\
\text { about winding up the } \\
\text { interview and/or } \\
\text { relief }\end{array}$ \\
\hline
\end{tabular}

Level 2: The relation between the global and local structure of the interview protocols: exercising control

Experts, interns and students differed markedly in their level of control over the interview (see Table 2). The experts took control of the interview while the students and interns mainly followed the client. This difference pertained to both the timing and the content of the questions asked. The students and the interns mainly responded directly to what the client revealed spontaneously, which resulted in incoherent interview protocols. Some students and the interns were aware of this. ("Here I first thought, well, I know that now, I will return to that later, I will first continue with the complaints, but then he did go on about it and then I thought like, oh I really should go into that a bit now" 023; "Here I thought something like, er well he went to school for four years and he is about 8 years old then [this is a miscalculation based on wrong assumptions] well what would such a boy be doing next, then he says 'then I go home' yes, what do you do when you get home? so that is what I really would like to know" 026; "Well then I suddenly think, what, then something new comes up, er that he indicates like well er something happened with my father, and I immediately start to pursue that like, well then, now I think with hindsight that I dropped that rather quickly because I was really still trying to figure out like er how suicidal he is right now, but because he indicates this I now go into what happened with that father of his" 138; "I notice again that in my thinking I react really quickly to what he is saying, so he mentions something and then I think I should do something with that. So now he says depression and then I immediately think like hey but where does that come from and how does he see that in himself." 144).

Experts, on the other hand, knew what information they needed and when and how to obtain it. They kept track of insufficiently answered questions and incomplete information and remained in control of the interview, which resulted in much more cohesive interview protocols. Experts often referred to things they had to ask later in the interview ("Then I thought, well, when he said I used to like that I was intending to ask him later about what things used to be like, but I really wanted to finish the function analysis first" 305) and actually did return to previous topics (12:28:7 "I will re- 
The first contact with a client in mental health care

turn to that because it still is not clear to me when that depression actually started"/ 15:22:3 "When he said his father had committed suicide then I thought he must be afraid that he will do that himself or he does have the same wish or something" / 17:03:2 "Drink and aggression" [the client's father was an alcoholic]/17:09:7 "It is at the back of my mind that I need to know if he drinks and I want to know if he is afraid he will commit suicide too" 304). In the twentieth minute she asked whether the client was worried he was like his father as far as suicide was concerned ("Yes I have been carrying that around in my pocket for a long time that question") and if he was drinking heavily ("Yes I thought now I will take the bull by the horns, for now he is really saying 'I may be like my father' and maybe he is also drinking a lot" 304).

Experts knew when the client had revealed enough information to draw conclusions and when to talk about other important issues ("I er am leaving the depression track more and more because apparently he is still able to enjoy the things he does and I would like to get back to the track of physical complaints" 315; "And then I notice that I already have five [criteria for depression] and that should really be enough to know that he is severely depressed" 304).

Furthermore, experts reflected during the interview and made choices about what to ask apart from what the client told them. ("I remember that at that moment I thought hey shall I first make a rough inventory of the complaints, so checking the whole range of complaints, or shall I ask him straight out, hey, what really happened during that period. Er that he like it coincides with his disability to work or in any case with stopping work and I er thought no I think I will first finish my list of his chief complaints" 303; "This was a phase in the interview when I was thinking, well I will not go into his life history any more because I do not have time for that, although it was in my mind. And then I thought, er like yes what do I still have to do now, and then I thought, I should take a family history. I also remember that I thought oh dear maybe I should also ask some questions about this man's personality structure, but then I thought yes I am not going to get around to that so I should just leave it. I do have a picture of this man but I am not going to ask about it any further" 303; "Then I think I was really thinking what do I have and what do I still want to know, so standing still for a moment for myself, at the moment when he is telling that, it suddenly occurs to me that I really want to know a bit more about whether he was a victim of that abuse but it is actually also a good moment to find out a bit more about his background" 301; "Then I thought I will do a function analysis, so I need to know a bit more about situations and thoughts and how he is feeling" 305 ("I deliberately ignored that, she was such a sweet' Of course you immediately start to wonder what was that relationship like, why was she so sweet. Er the objective of the interview is not to build a therapeutic relationship here but to gather information, while this, well of course this asks for exploration when someone says it like that but I decided not to do that." 309)

Students and interns often did not follow up on earlier thoughts. They did think they had to ask about something later, but often did not do so ("Yes, here I was thinking about something neurological. I was going to ask if he had been in an accident but in the end I didn't. I don't know why" 025). When they did come back to earlier issues, it was 
often because they were reminded of it by information revealed spontaneously by the client.

Some interns, however, showed some control over the interview but their questions were less extensive and their control less structured (Participant 124 took control by returning to questions about depression by summarising and asking about sleeping 0:07:47 "Well here I wanted to ask about those other criteria, like er sleeping pattern, things like that. And er eating habits too, if he still had er yes a good appetite or maybe not, but he did seem quite well so I thought something like, er he is probably eating quite well." After asking about eating and sleeping she resumes asking questions about the client's family: 09:16:07 "Then I wanted to get back to his family for a bit, (...) I felt that I had not really understood that part about his childhood, so I wanted er to see if there are factors in his family that contribute to him being the way he is").

Table 2. Control structure of the interview protocol of experts, intermediates and students

\begin{tabular}{llll}
\hline Control & Experts & Interns & Students \\
\hline Who is in control? & Counsellor & $\begin{array}{l}\text { Counsellor mainly } \\
\text { follows the client. } \\
\text { Some interns start } \\
\text { taking control, but } \\
\text { less extensively and } \\
\text { structured than ex- }\end{array}$ & Mainly following the \\
& & $\begin{array}{l}\text { client } \\
\text { perts }\end{array}$ & \\
& & $\begin{array}{l}\text { Sometimes, but often } \\
\text { in reaction to client }\end{array}$ & Sometimes, but often \\
& in reaction to client \\
& & information & information \\
\hline $\begin{array}{l}\text { Coming back to earlier } \\
\text { issues }\end{array}$ & Frequently & Never & Never \\
\hline $\begin{array}{l}\text { Making deliberate choices } \\
\text { about what to ask }\end{array}$ & Frequently & & \\
\hline
\end{tabular}

Level 3: Subsequent steps in diagnostic reasoning: detecting, interpretation, drawing conclusions or acting, and evaluation

Students, interns and experts dealt differently with information that was implicitly available, given or collected during the interview; different kinds of information meant different things, if anything, to the three groups of participants (see Table 3).

Experts detected and used more and a wider variety of information. The following types of information were very telling to experts but not or to a lesser extent to the students and intermediates. Non-verbal and paraverbal information: an important cue that gave rise to experts' interpretations was the way the client presented his complaints ("A typical pain patient, giving very brief answers and making me ask about everything, probably pain disorder" 327; "He does not answer my question, and er yes I see that a lot in pain patients, that they're very bad and very bad at being able to turn inside. So when you ask them a question they sometimes just don't listen or that people are very much stuck in their own track, so that was something I recognised" 327; "I still remember that I thought, oh man, I just want to know a bit more precisely what it is like, (...) That is also the moment in the conversation that I thought hey what about this man's cognitive functioning, so diagnostically I also think like I should ask about er dementia later. Er 
The first contact with a client in mental health care

problems with orientation (...). This is the moment in the conversation (...) when I think hey stop maybe this man is deteriorating cognitively. And at that moment I also think I remember I must remember to try and estimate his intellectual ability" 303).

Also a moment of silence during the interview could lead to diagnostically relevant reflection ("For a moment I started to think because he remained silent for so long, hey he is really very absent, er he is worrying or there is something else. For a moment it entered my mind that er is he hearing voices, seeing things, is he dissociating. Those thoughts went through my mind but I stuck with the er word 'not recognising mood" 305; "Here I allowed the silence to continue to see if more would come but then nothing at all happens. So as a therapist you have to as it were actively work to keep him going for it is not as if he is going to talk of himself. So that again is er a sign of er for instance of being depressed but in any case not something for psychotherapy" 328). Experts also used information about the progress of the interview and how the working relationship with the client was developing. ("I am quite pleased with that. I felt that the message was clear and that I had won him over a little. So we could start walking along the same path for a bit (...) here I don't see any indication of for instance a very serious personality pathology from cluster $A$ or B or something like that" 309). Furthermore, experts used more and other information that was explicitly given. Three experts reported having formulated diagnostic hypotheses based on the referral letter from the family doctor before seeing the client ("mood disorder, somatisation disorder, anxiety disorder, no schizophrenia" 309). The information the client revealed was very telling for the experts ("That was another hypothesis somewhere in the story, after he had said his father drank I thought I must not forget to ask about that later. I thought, of course that may explain his headache and perhaps also part of his sadness, so that is why I include that here" 328). When the client said he had been admitted to a psychiatric hospital: "This is cause for alarm, when someone has been admitted. It may indicate psychotic depression or a risk of suicide or a suicide attempt" 301; "Then I immediately thought it must be serious. So then I am still thinking it can also be bipolar or some such disorder or after all really a psychotic or depression with psychotic characteristics" 304).

The students and the interns used hardly any non-verbal and paraverbal information and had difficulty interpreting the client's information ("That he isn't smart, that has probably something to do with his complaint I thought. Should that ring a bell. Then I thought I had no idea which bell, but then I thought, when after that he said then I don't know how to get to the specialists, then I thought again hypochondria?, but I wouldn't know many other disorders so nothing much came to mind" 108; "Here I was thinking like I just have to ask that, because that is what you are supposed to do, that is what I was taught, but I thought like whatever he is going to say next I wouldn't know er yes for instance if they are antidepressants or something or er I just don't know anything about that." 019; "Then I believe I thought, yes I think he is probably a bit depressed or something, but then, I had to think for a bit ... what you should ask about that, let's say" 020; "I knew there was something about a month with er mood disorders, but I could not remember exactly which mood er which specific disorder that was again", 025). Their reasoning was mainly the result of information spontaneously revealed by the client ("I thought like 
sad in the moming, that is some sort of characteristic of depression that it's very bad in the morning, something with vital characteristics, that you are already very sad in the morning and then things gradually get a little bit better as the day goes on, I thought something like that and I should just ask about that" 108). Students and interns sometimes made interpretations on the basis of other kinds of information but their interpretations were less thorough than those of the experts. One example is their reaction to the client saying he had been hospitalised. Where experts formulated diagnostic hypotheses (see earlier citations 301 and 304), an intern recognised the importance of the information, but did not formulate diagnostic hypotheses ("Then ten alarm bells went off", 124), and a student thought it was useful information but had no idea why ("Yes that is good. Er I thought that a very useful indication that he said I have been admitted before, that is something with which you should do something" 031). Sometimes, students and interns seemed to sense the importance of the working relationship ("I thought it will not do the relationship much good if I quote him inaccurately" 030; "I did ask that question because I already thought like well he is very worried about his er headache and what do I know (...) I might just as well take him very seriously because I can see it is very important to him, so I will just go into that a bit more" 138).

Furthermore, the experts interpreted client information in terms of DSM-IV-tr diagnostic categories. Although many students and interns were able to interpret client information and generate some diagnostic hypotheses described in DSM-IV$\mathrm{tr}$, many of their interpretations were framed in everyday concepts and language ("I thought (...) that he that that neighbour meant something to him, er, well that that may be something he liked" 030; "Then I was thinking like it really is the fear also from the past as it were, that apparently something happened with his mother and his sister [they died of breast cancer], so maybe yes some sort of fear like I am bound to get something too" 124; "At that point I was thinking oh I should also ask him if he has had er very positive episodes, when he was very cheerful" 037; "Here I am thinking, aha, depression, (...) and if so if is it dichotomous or, er, just a normal depression" 022; "Yes I was thinking more oh yes there definitely is that fear that he will contract some scary disease" 106).

The third step in the reasoning process is acting upon or drawing conclusions from interpretations. The way the experts reasoned was rather thorough and comprehensive; they took various factors into account and acted upon information that the client revealed. One example is that experts thought about asking questions about criteria to test diagnostic hypotheses and actually did ask such questions ("(...) Er with depression er, when he said that 'then I would be rid of it and so would my wife,' at that point I thought passive suicide ideations, but then I thought I should first find out anyway before I go into that further about those suicide risks et cetera, their duration, I need to know if it is generally all the time, most of the time, or if it is also er very clearly sadness. So I have to, then I have a list in my mind that I should check, long time (...) greater part of the day, more days on which present than not present, also interests, eating, sleeping, energy (...). I did consider what was said about hypochondria, what flashed through my mind is are there things like not reassured, or er reassured for a while, but not in the end by examination by the doctor, keeps asking for examinations, must be six months 
at least, those types of thoughts are going through my head" 301). Experts also asked questions to arrive at a differential diagnosis, such as questions about various subclassifications of depression (13:16:01 "At this point I am thinking so depressive disorder or not, for a very long time, then I immediately think of dysthymic disorder"/ 13:55:4 "Er what I am thinking here is er, maybe there is a double depression because apparently he all those years he has, I'll assume that for the time being, worked normally and functioned normally, at least with his mood disorder. But not any more, because now he has a headache and he also labels his mood" / 14:30:4 "At this point I want to know if er I am still thinking that he has had multiple depressive episodes, dysthymia, er here comes too like hey I have to check if there have been ups as well. Something bipolar, for instance did he also have a brief hypomanic episode. I did not return to that, so I have not heard anything that reminded me of that but I do know I thought about that here" / 14:49:4 "Here he is about to say "that is a long time isn't it," it cannot have been that. He thinks it is almost unimaginable, feeling good for a whole year. In a way I am implicitly concluding that this man is not having a hypomanic episode, (...) If it was more than a fezv months that would argue against dysthymia in general, because that is not what you hear when look at the American books. According to the DSM a few months is o.k. so in that case you could still dysthymia er. But when he, I think it was when he said, yes a year that is a long time isn't it, that sounded so much like never having a period during which you feel really well, or what people with bipolar type 2 sometimes say, like yes I did feel really wonderful for two months that summer, amazing you know, because for a few weeks you were convinced that it was a bit hypomanic. There was something in his story that made me not ask that question eventually, like you should actually ask it, like have there been moments when you felt really good. I don't think I have asked him that. Somewhere in one of those sidetracks I thought" I 15:12:4 "Double depression, let me check" / 15:15:. "And here I reject that" 309).

The interns and the students on the other hand did not ask extensively about the diagnostic criteria. Most of them asked about mood and suicide when they tried to test their diagnostic hypothesis of depression, while some remembered to ask about eating and sleeping. Other criteria were not checked. ("Before I asked that question, I thought when someone is depressed you have to ask those questions about sleeping and eating" 021; "Well here I wanted to start asking about those other criteria, like er sleeping pattern, I wanted to know if he er if he had trouble going to sleep, well he brought that up himself, sleeping uninterruptedly things like that. And er also with eating habits, if he still had a good appetite or not, but he looked quite well so I thought well er he is probably eating well" 124). Because interns and students did not consistently test diagnostic hypotheses, their diagnostic reasoning consisted of switching between various diagnostic hypotheses on the basis of information the client revealed (01:25:8 "At that point I thought: totally disturbed, something like schizophrenia or something like that, that someone is forcing something on him (...)"105:28:3 "At that point I thought maybe it runs in the family or something, migraine I thought then"l 05:40:7 "I thought that I was thinking something like yes cancer, a bit hypochondriac like is that I thought something like that" / 05:49:5 "Yes I thought tired and all those headaches and I did not think he seemed really cheerful either, so I thought like yes tired, maybe tired is also depression, so then I 
thought of depression"/ 06:22:7 "Then I already thought hypochondriac, but then I thought it is also possible that er there has been a brain tumour in the family before and then it may be logical that he is thinking about that; then it doesn't have to be pathological, and that is why I say that" / 11:30:5 "At that point I continued to explore hypochondria, what is a hypochondriac anyway I thought, because actually I have no idea what the criteria of hypochondria are, they worry about everything, are always thinking there is something wrong with them, well there had to be more, maybe that he is always thinking something, but he only had those two things, so I thought something like, er well yes moybe it isn't that after all" / 11:49:9 "Well depression I was thinking there, er perhaps I had better pursue that again"108)

The experts acted not only on the basis of the information given by the client. They also recognised other important kinds of information and adapted their actions accordingly. One type of information consisted of feelings of countertransference ("I am a bit irritated, he, now and then he irritated me a little, because of being so passive, but also actually denying that the moment it happens. And what I did next (...) well not trying very hard to get that out of him, but mainly indicating what he did reveal, or what he did tell, and next (...) or er trying to make it simple. Something like the thought of not er, not in that, er how shall I put this, not only reacting to that feeling, not only getting angry or irritated, it is no use" 301; "Yes with these people I have always very deliberately tried to understand them, because then I can better, er, yes because then I get less annoyed or the irritation goes away again" 327; "Er, what I always have with these people is having to suppress the inclination to er to reassure them or say that it is absolutely not possible with bone cancer, or something, that er. I think, er, I have to control myself, I just thought like, o dear, of course it is not likely that someone has had bone cancer for such a long time, so that crosses your mind, but you keep it back, yes" 334). Students and interns, on the other hand reported feelings evoked by the client, but did not call it countertransference and did not comment on ways to handle these feelings or use them diagnostically. These feelings often concerned irritation or compassion ("Then for a brief moment I felt a lot of pity" 124; sounding slightly irritated "Here I am thinking, come on man tell be more, I asked you a er relatively open question, but unfortunately, nothing came" 133). Experts also acted on their assessment of the development of the working relationship ("And in this phase I was very strongly awoare, (...) aware of the fact that I had better not ask too much because he was telling about it anyway quietly at his own speed" 304; "I thought mind your words. That man, er, yes pain patients can easily feel misunderstood. So I thought, er, here I already felt something like, hey I should not start interpreting too quickly because then I will lose his goodwill and I really do need that to get good information fast." 327). Although, some students and interns seemed to sense the importance of the working relationship with the client (see earlier) they did not draw conclusions and hardly acted upon their thoughts unless they had had internship experiences with the working relationship ("Er I tried to go along with him that his physical complaints were important. Because otherwise he might think that only his mental states were important and there might be a chance that he would leave. That happened to me once" 107 and "Only recently I had a patient who was very er yes er psychotic, and because I did not 
go along with his communication, every time there was a communication battle. And now I am thinking that I should be careful not to do that again. I should just talk the way he does and adapt to that" 107).

The final step in diagnostic reasoning is evaluation of interpretations. Experts often explicitly evaluated their diagnostic hypotheses ("I am thinking that it probably is not problems related to life phase, because around 30 yenrs old" 301; 15:12:4 "Double depression, let me check that" / 15:15: "And that one I reject here." 309). Sometimes an expert's evaluation of a diagnostic hypothesis occurred implicitly ("I don't find anything alarming. I know that I didn't even ask about suicide because he's afraid to die, although that can exist side by side. Because this man never gave the impression that he was suicidal, because I know that I thought somewhere well leave it. I was confident that he would come back, that the working relationship was o.k., and that there was enough ground to put things right and to figure things out" 309). Definite evaluations of diagnostic hypotheses are absent from the students' and interns' protocols. They did not make a diagnosis until after the interview.

Table 3. Diagnostic reasoning steps of experts, intermediates and students

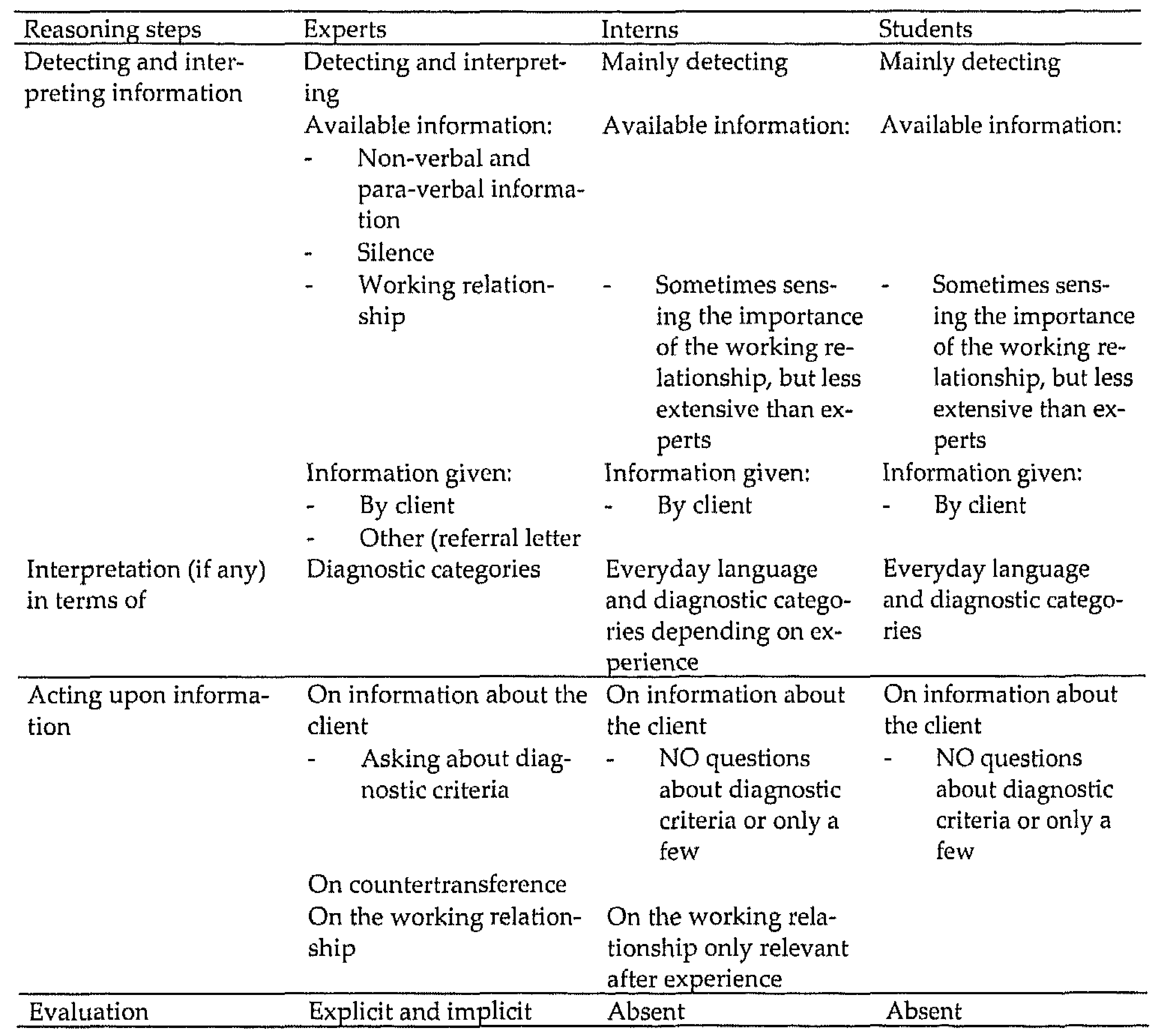




\section{Knowledge organisation}

Post-hoc think-aloud protocols reveal a lot about the application of knowledge and differences between levels of expertise. They are less suitable to directly detect differences in knowledge and knowledge structure but are an abundant source of hypotheses that can be investigated later, in a study specially designed to investigate that. Yet some direct indications of knowledge development and change could be identified. Both the direct and the indirect evidence will be presented here.

\section{Direct evidence - experience and automation}

The protocols of the students, interns and experts differed in terms of references to experiential knowledge. This knowledge concerns both patients and patient categories, how other professionals deal with that type of patient and the working relationship. Experts' protocols are concerned with these three aspects ("Because, er, on the other hand I was thinking well, oh medication is not helping, that may mean something for instance that it is not depression, but on the other hand I immediately thought that GPs often prescribe medication in too low dosages, especially with Fevarin, so that went through my mind" 301; "otherwise he would mention other physical symptoms. (...) a person who is in a panic should mention that immediately" 305; "I am being nice here because people who are hypochondriacs (...) but are often also somewhat angry saying 'that is why you are the doctor" 309; see also citation 327 above about a typical pain patient, and citation 334 about having to suppress the inclination with this type of patient to reassure them, and citation 301 later). The interns also use experiential knowledge ("well yes that is what GPs do prescribing an antidepressant very quickly" 107; "er it does occur rather often that people you have seen that parents drink a lot that they turn to drink too" 133 "because I am always surrounded by schizophrenics, at first er I was thinking sort of er is he also er", 124). However, most of their experiential interpretations are not followed up and the diagnostic hypotheses that interns came up with on the basis of client information were not always logical (Expert 309 already rejected the diagnostic hypothesis schizophrenia when reading the referral letter: "I do not think this man will be a schizophrenic for example, probably because of the prior history. You see, you use some epidemiological data and some probability, like whatever. And of course he may be psychotic when he comes in but I'll see. But that is not the first thing I would consider when I see this." Intern 124, on the other hand, thought: "(...) yes that is probably because I am surrounded by schizophrenics all the time, at first er I was thinking something like, well, would he also er, yes he immediately starts to talk about throbbing [a throbbing headache], I thought maybe he is hearing something or seeing things"). The earlier citation of intern 107 showed that she referred to and acted upon internship experiences concerning the working relationship with the client. Interns were the only ones referring to experience with individual patients. The students' protocols did not include references to such experiences.

Indications of knowledge automation were only found in the experts' protocols. Their knowledge of the DSM-IV-tr seems to be automated. Especially expert 301's protocol is very revealing: "When I ask that I think it was at that point I have been con- 
centrating on sleeping and that depression, the moment I ask that, because that is about the list I have in mind, like you can almost see it before you when you are writing up the intake, the first bit for the complaints, the second bit for the current situation and there are things like sleeping, eating (physical?), hobbies, alcohol, smoking things like that. At the moment I ask that, when I, it comes to you automatically. I (...) It is not something I think about very consciously but it flashes through my mind, eating, sleeping, energy, things like that. And it is in my mind, the moment I hear that, for it is number six or seven on the list and then I see, almost literally I see a sort of SCID form before me, one of those scoring forms for when I an administering the SCID, where when you are asking about things you first have $A 1$ and A2, to screen if someone really, I am telling you this because I really see that before me, you use that to screen if someone does or does not meet depression. And if yes, you ask further questions, and suicide is much further down the list. And then there is suicide it is the sixth or seventh B criterion, oh no A criterion, but the second part of it. And then there is a death wish, actively thinking about death, a plan, an attempt, those sort of things are checked then. And what he was just telling me then I think 'oh yes that is that, that goes there, but I should just first ask on top of that if, er, if he, if he has depression at all' / (..) but the same applies for hypochondria and panic, what I often find, what I also found then, is that when I am asking about those things and I stop to think about it, I very often see it in the form of a scoring form of the SCID." 301).

\section{Indirect evidence - reorganisation}

The results on reasoning processes described above can be regarded as indications for possible knowledge restructuring with increased experience. It appears that experts easily interpret client information in terms of a diagnostic hypothesis, in terms of building or maintaining a working relationship with this client, in terms of the kind of person the client is, and that their interview is rather cohesive in the sense that they ask questions to test their interpretations, come back to earlier subjects, draw conclusions from the client's answers to their questions and evaluate diagnostic hypotheses. This might indicate that experts have developed many different knowledge clusters that are activated and remain activated throughout the interview, such as knowledge about diagnostic interviewing, knowledge about symptoms and diagnostic categories as described in DSM-IV-tr, knowledge about which questions to ask, and knowledge about the working relationship. Furthermore, these knowledge clusters of experts seem to be interrelated. For example, diagnostic hypotheses are formulated or rejected on the basis of knowledge of DSM-IV-tr, of knowledge about the working relationship, of feelings of countertransference, or on the basis of experiences with earlier clients. The other way around, thoughts about building or maintaining the working relationship with the client are triggered by their knowledge of DSM-IV-tr, feelings of countertransference, and/or experiences with earlier clients (see citations of experts 327, 309, 305 above). 


\section{Discussion}

The present study was aimed at gaining insight into differences between beginning and experienced counsellors in the quality of their cognitive processes during a diagnostic interview. Furthermore, this study examined differences in knowledge structure that may be related to differences in cognitive processes.

The following results emerged from the study. Expert counsellors dynamically plan the interview. They are aware of time constraints and adapt the interview to available time and current information need. Experts are in control of the interview. They ask questions deliberately, with different purposes; issues raised at one moment can be readdressed later. Information, regardless of whether it is actively sought or available in the situation, holds much more information for experts than for less experienced counsellors. Experts 'see' and use non-verbal and paraverbal information, moments of silence during the interview, the working relationship, and information that is explicitly given by the client or that became otherwise available (e.g. the referral letter). They use it for various purposes; diagnostic reasoning, evaluation of and maintaining the working relationship and dealing with feelings of countertransference. This leads to better diagnostic outcomes than students' and interns' interviews (Wagenaar et al., subm.). Interns and students do not plan the interview, though some of them think in advance about how to perform a diagnostic interview in general. Their interview protocols show no adaptations and awareness of available time. Interns and students are not in charge of the interview; they seem to follow rather than direct the course of the interview and depend strongly on what the client tells them. Though interns occasionally try to structure the interview according to their information needs, they are not very successful at this. Interns and students are at a disadvantage compared to experts when it comes to detecting and interpreting available information. They are barely able to read the emerging situation. They see no diagnostically valuable information in silence, emotions and non-verbal and paraverbal behaviour and they are unable to use this type of information in other professional respects. Contrary to experts, who interpret information in DSM-IV-tr terms irrespective of whether it is available in the situation, given or actively collected, interns and especially students often use everyday language, which can be seen as indicative of a lack of ontological knowledge (Nievelstein, Van Gog, Boshuizen, \& Prins, in press). The three groups also differed markedly in how they acted on this information. Where experts asked about all relevant diagnostic criteria, students and interns only addressed the most common criteria. No students and only some interns acted on information related to the counsellor client relationship. None of the students or interns acted on feelings of countertransference.

These outcomes corroborate and refine the outcomes of a study by Wagenaar et al. (submitted). Especially the findings on hypothesis testing and evaluation and the working relationship show that the common core of the interviews of the three groups is rather empty where interns and students are concerned. The study also contributes unique findings regarding information detection, interpretation of in- 
formation, action based on information and interpretation and evaluation of the process.

Think-aloud protocols are thought to be a valid method to investigate problem solving, based on the assumption that participants verbalise information that is kept in working memory (Ericsson \& Simon, 1984). Despite errors of omission and commission, think-aloud protocols have proven to provide valid data to investigate problem solving. They are especially useful to investigate cognitive processes. Post hoc think-aloud protocols have not been used as concurrent protocols. Research by Van Gog, Paas, Van Merriënboer, and Witte (2005) have shown that they reveal more meta-cognitive statements but are comparable in other aspects. Post hoc and concurrent think-aloud protocols are not the method of choice to investigate knowledge and knowledge structure. Actually a combination of methods is required. Therefore our conclusions regarding knowledge differences between students, interns and experts are incomplete. Nevertheless, they are a first step towards formulating hypotheses about the development of knowledge structures and their relationship with diagnostic reasoning.

Our finding that experts' knowledge structures enable them to easily interpret client information in terms of a diagnostic hypothesis, in terms of building or maintaining a working relationship and in terms of the kind of person the client is and also enable their coherent diagnostic reasoning in the sense that they ask questions to test their interpretations, come back to earlier subjects, draw conclusions from the client's answers to their questions, and evaluate diagnostic hypotheses seem to indicate that many different knowledge clusters are activated and remain activated during the interview, i.e., knowledge about diagnostic interviewing, knowledge about symptoms and diagnostic categories as described in DSM-IV-tr, knowledge about which questions to ask and knowledge about the working relationship. We also found that experts' knowledge is easily activated by a variety of information and other knowledge. By contrast, the same information may have no meaning at all for students and interns, although they are sometimes aware that it should ring a bell. Furthermore, apart from well-developed, formal professional knowledge, experts used generalised experiential knowledge. Interns also used some case-based reasoning but this was not generalised. This is consistent with Strasser's (2006) finding that semi-experts used recent cases but experts and students did not, while experts used more generalised cases than did the other groups. We also found that experts use automated knowledge.

As hypothesised, the present study revealed indications that knowledge is being restructured with increasing experience although the restructuring seems to be of a different nature than knowledge encapsulation in the medical domain. Firstly, knowledge and skills in diagnostic interviewing appear to become automated with experience. Secondly, knowledge about the DSM-IV-tr categories of psychological disorders may expand and become more extensive with experience, be activated by an increasing number of cues and its application becomes automated. Simultaneously, various knowledge clusters appear to become interrelated. In terms of illness 
scripts (Boshuizen \& Schmidt, 2000; Schmidt, Norman, \& Boshuizen, 1990), it is possible that illness script-like structures are formed, including DSM-IV-tr knowledge supplemented by knowledge about client behaviour, counsellor-client relationship issues, mental pictures of prototypical patients and variations. Even a minimum of practical experiences seems to lead to restructuring of knowledge.

The present study was a first attempt to gain in-depth insight into the diagnostic reasoning processes of counsellors at various stages of experience in mental health. A couple of drawbacks should be noted. Firstly, the indications that were found that knowledge was being restructured are rather preliminary and hypothetical. The results consist of a series of hypotheses that are not generalisable. More research is needed to enable generalisation of the findings and to complete the picture. For example, it is not clear yet when knowledge clusters become interrelated. Participants with intermediate experience levels have to be included in research. Such studies are important because a better picture of the development of counselling expertise may help to improve training programmes. Furthermore, it would be interesting to study the extent of and relations between knowledge clusters in a more direct way. A possible way to study this is to ask participants of various experience levels to report everything they know about a particular issue, for example a client with hypochondria or depression, a method used by Van de Wiel, Boshuizen, and Schmidt (2000) in the medical domain. Mind mapping and card sorting methods could be used to investigate relations within and between clusters.

\section{References}

American Psychological Association (2000). Diagnostic and statistical manual of mental disorders (4th edition TR ed.). Washington DC: American Psychiatric Association.

Bloom, B. S. (1953). Thought processes in lectures and discussions. Journal of General Education, 7, 160-169.

Bloom, B. S. (1954). The thought processes of students in discussions. In S. J. French (Ed.), Accent on teaching: Experiments in general education. New York: Harper.

Boshuizen, H. P. A., \& Schmidt, H. G. (1992). On the role of biomedical knowledge in clinical reasoning by experts, intermediates and novices. Cognitive Science, 16, 153-184.

Boshuizen, H. P. A., \& Schmidt, H. G. (2000). The development of clinical reasoning expertise. In J. Higgs \& M. Jones (Eds.), Clinical reasoning in the henlth professions, Oxford: Butterworth Heinemann.

Ericsson, K. A., \& Simon, H. A. (1980). Verbal reports as data. Psychological Review, 87, 3, 215-251.

Ericsson, K. A., \& Simon, H. A. (1993). Protocol nnalysis: Verbal reports as dnta. Revised edition. Massachusetts: Massachusetts Institute of Technology.

Gruppen, L. D., \& Frohna, A. Z. (2002). Clinical reasoning. In: G. R. Norman, D. I. Newbla, \& C. P. M. van der Vleuten (Eds.). International handbook of research in medical education (pp. 205-230). Dordrecht: Kluwer.

Lichtenberg, J. W. (1997). Expertise in counselling psychology: A concept in search of support. Educational Psychology Review, 9, 3, 221-238.

Locke, T. F., \& Covell, A. J. (1997). Characterizing the expert psychologist behaviour: Implications from selected expertise literature. Educational Psychology Rcview, 9, 3, 239-249.

Nievelstein, F., Van Gog, T., Boshuizen, H. P. A., \& Prins, F. J. (in press). Expertise-Related Differences in Conceptual and Ontological Knowledge in the Legal Domain.

Norman, G., Eva, K., Brooks, L, \& Hamstra, S. (2006). Expertise in medicine and surgery. In: K. A. Ericsson, N. Charness, P. J. Feltovich, \& R. R. Hoffman (Eds.). The Cambridge handbook of expertise and expert performance (pp. 339-353). Cambridge: Cambridge University Press. 
The first contact with a client in mental health care

Norman, G. R., Tugwell, P., \& Feightner, J. W. (1982). A comparison of resident performance on real and simulated patients. Journal of Medical Education, 57, 708-715.

Rethans, J., Sturmans, F., Drop, R., \& Van der Vleuten, C. P. M. (1991). A method for introducing standardized (simulated) patients into general practice consultations. British Journal of General Practice, 41, 94-96.

Säljö, R. (2007, August 28 - September 1). Learning, technologies and social memory. Presidential address. 12th Biennual conference of the European Association on Research about Learning and Instruction. Budapest, Hongary.

Sanson-Fisher, R., \& Poole, A. D. (1980). Simulated patient and the assessment of medical students' interpersonal skills. Medical Education, 14, 249-253.

Schmidt, H. G., Norman, G. R., \& Boshuizen, H. P. A. (1990). A cognitive perspective on medical expertise: Theory and implications. Acndemic Medicine, 65, 611-621.

Skovholt, T. M., Ronnestad, M. H., \& Jennings, L. (1997). Searching for expertise in counseling, psychotherapy, and professional psychology. Educational Psychology Review, 9, 4, 361369.

Strasser, J. (2006). Erfahrung und Wissen in der Beratung - theoretische und empirische Analysen zur Entstehung und Entwicklung professionellen Wissens in der Erziehungsberatung [Knowledge and experience in counselling - theoretical and empirical analysis of the origin and development of professional knowledge in educational counselling]. Göttingen: Cuvillier.

Van de Wiel, M. W. J., Boshuizen, H. P. A., \& Schmidt, H. G. (2000). Knowledge restructuring in expertise development: Evidence from pathophysiological representations of clinical cases by students and physicians. European Journal of Cognitive Psychology, 12, 3, 323-355.

Van Gog, T., Paas, F., van Merriënboer, J. J. G., \& Witte, P. (2005). Uncovering the problem-solving process: Cued retrospective reporting versus concurrent and retrospective reporting. Journal of Experimental Psychology: Applied, 11, 237-244.

Wagenaar, A., Boshuizen, H. P. A., Muiitjens, A. M. M., Bögels, S. M., Dik, K., Scherpbier, A. J. J. A., \& Van der Vleuten, C. P. M. (subm.). Differences in cognitive processes between beginning and experienced counselors during a dingnostic interview.

Wittemann, C. L. M., \& Van de Bercken, J. H. L. (2007). Intermediate effects in psychodiagnostic classification. European Journal of Psychological Assessment, 23, 1, 56-61 


\section{7 \\ General discussion}

\section{Main conclusions}

The five studies in this thesis are aimed at gaining a better understanding of what and how students learn during internships. In this final chapter the results of these studies are summarised and discussed and general conclusions are drawn. The results will be discussed for each of the main research questions formulated in the introduction: what do students learn during their internships and how do students learn during their internships. The research question concerning factors contributing to or impeding learning will come up in the discussion of these main research questions.

\section{What do students learn during their internships?}

The results of Study 1 showed that students often enter internships with the broad but unspecified idea that they will learn as much as possible about professional knowledge and skills. Indeed, professional knowledge and skills was the learning result reported most frequently in the interviews. This is in accordance with results of earlier studies in different clinical settings in medical education (Irby, 1995; Lawrence, Lindemann, \& Gottlieb, 1999; Niemantsverdriet, Majoor, Scherpbier, \& Van der Vleuten, 2004). However, this suggests that students have a narrow view of what they can learn during their internships. Many students are not aware that they can learn other important things, such as learning about personal growth and learning about working. They do not learn these things - or are not aware that they do so - until they are faced with difficult experiences that force them to learn about personal growth or working. These learning experiences do not appear to be very positive ones, however.

Furthermore, the results of Study 3 gave insight into the influence of stress on what students learn during internships. This study revealed a remarkable discrepancy between what students reported and what the results showed. Many of the students who were interviewed said that feelings of stress had a positive influence on their learning, whereas many interviews revealed that feelings of stress hindered learning. An important factor that seemed to mediate the influence of stress on learning appeared to be the coping strategy used by students to handle stressful experiences. Students who used task-oriented coping strategies, sometimes in combination with emotion-oriented coping strategies, were the only students who were 
successful in reducing their stress levels. This is in accordance with results reported by Niemantsverdriet, Majoor, Scherpbier, and Van der Vleuten (2004). The students who only used emotion-oriented and/or avoidant coping strategies did not succeed in reducing their stress levels and appeared to pay very little attention to their learning. Although they tried to convince themselves otherwise, they were merely trying to survive by avoiding stressful situations and/or denying their feelings of stress. This attitude also caused them to avoid potential learning experiences. The results of this study confirm the theories and research contending or implying that stress has a detrimental effect on learning (Frijda, 1986; Baumeister, Bratslavsky, Muraven, \& Tice, 1998; Baumeister, DeWall, Ciarocco, \& Twenge, 2005; Baumeister, Twenge, \& Nuss, 2002; Christianson, 1992; Frijda, 1986; Lazarus, 1993a, 1993b; Twenge, Catanese, \& Baumeister, 2002, 2003; Yuille, \& Tollestrup, 1992). Students may be right in saying that a small amount of stress makes them more alert and focuses their attention on the central features of a task, thereby enhancing memory and thus learning (Lazarus, 1993), but there is no denying that when stress levels are too high or the coping strategies used ineffective it is impossible to direct attention to the task in hand.

The results of Studies 4 and 5 show that internships are important for the learning of mental health sciences students. They learn during their internships to become less insecure about their knowledge and skills, which may indicate a growth in confidence through working in professional practice. They also learn to make first attempts at structuring and being in charge of a diagnostic interview. Furthermore, they learn to ask many questions they need to ask in a diagnostic interview and to collect a great deal of information from a client. However, they still have a long way to go before they are on a par with experts in theoretical knowledge and cognitive interviewing skills. The results emphasise the importance of dynamic use of various domains of knowledge, as knowledge of diagnostic interviewing, knowledge about various symptoms and diagnostic categories as described in DSM-IV-tr, knowledge about the working relationship with a client, and knowledge about further treatment. Experts use these various domains of knowledge in an integrated way: diagnostic hypotheses are formulated or rejected on the basis of thoughts about the working relationship or client behaviour, and interpretations in terms of DSM-IV-tr trigger thoughts about maintaining the working relationship. Furthermore, the experts' knowledge clusters are extensive and can be used flexibly and strategically. For example, when an expert is considering depression, the various forms of depression and the diagnostic criteria of depression seem to become activated automatically and the experts systematically asks questions to test them. Furthermore, experts can dynamically plan the interview and adapt their questions to the current information need, the time available and the working relationship with the client.

Students and interns, on the other hand, seem to suffer from a lack of theoretical knowledge and cognitive interviewing skills. Their knowledge of the topics to be covered in the diagnostic interview seems to be quite sufficient, although students 
have to make a conscious effort to activate this knowledge while performing a diagnostic interview and they are very insecure about the quality of their knowledge and skills. During a diagnostic interview they mainly rely on their knowledge of the diagnostic interview (which questions to ask and how to ask these questions). However, when it comes to hypothesis testing the content of the other knowledge clusters seems to be deficient and the various clusters do not seem to be interrelated. They do formulate diagnostic hypotheses during the interview, but their ability to interpret and organise client information in a structured way falls short. As a result they are not able to systematically test and evaluate the hypotheses they formulate. Furthermore, they do not think about a diagnosis until after the interview. And even with the use of the DSM-IV-tr manual their diagnoses are less accurate than those of experts.

The question that arose from the results of our fifth study is whether students possess enough theoretical knowledge about DSM-IV-tr and cognitive interviewing skills to be able to perform a diagnostic interview with a real client without support. This question cannot be answered with sufficient confidence, but the results suggest that many students' and interns' lack sufficient knowledge to be able to perform an acceptable diagnostic interview with a real client independently. During their internships they grow in confidence and have less doubts about their knowledge and skills, but they still have difficulty applying theoretical knowledge and structuring an interview. They may get quite far with their knowledge of which questions to ask and how to ask them, but their insufficient capability to organise and interpret client information impairs their diagnostic reasoning and makes it difficult to form a good representation of a client's problems. The fact that they have to consciously activate their knowledge about the right questions to ask and the correct way to ask them during task performance, may even cause them to pay too little attention to the content of client information.

\section{How do students learn during their internships?}

The results of Study 1 show that students prefer being actively involved in their internships. With active involvement they mean actively performing as many tasks as possible and seeing as great a variety of diseases, cases and/or patients as possible. In this light it seems a paradoxical finding that students seldom self initiate learning activities in which they are expected to take an active role, such as overcoming gaps in knowledge and skills and learning by preparation and evaluation of tasks and task performance. On the one hand students want to actively engage in tasks, but on the other hand they take remarkably little initiatives to achieve active involvement in their learning process. From the students' perspective, active involvement does not seem to have anything to do with active involvement in their learning process, but it seems to be related to active performance of tasks to gain professional knowledge and skills. The results of Study 2 support this conclusion. These results also show that students use almost no self-directed learning skills, such as reflection and formulating learning goals before the start of internships. 
This is supported by research by Dornan, Hadfield, Brown, Boshuizen, and Scherpbier (2005), Van Eekelen, Boshuizen, and Vermunt (2005) and Niemantsverdriet, Van der Vleuten, Majoor, and Scherpbier (2005).

The same paradox seems to hold for organising coaching and support. Students highly value supervisors with whom they can discuss and do things, supervisors who give feedback on their performance and stimulate the learning process by asking questions that challenge students to think. But despite their clear picture of what they value or miss in their supervisors, students hardly ever take steps to obtain the type of coaching and support they value most.

Students' attitude towards learning is rather passive during internships. For active involvement in their learning, they are very dependent on their supervisors. This conclusion is supported by Kilminster and Jolly (2000) and Kilminster, Jolly, and Van der Vleuten (2002). Students' dependence on their supervisors may be associated with the results of Study 3, which show that most students remain rather passive in coping with stressful experiences. They seldom actively engage in efforts to overcome their feelings of stress; instead they resort to trying to avoid stressful situations and/or denying their feelings of stress. This also interferes with their putting effort and attention into their learning process (Baumeister, Bratslavsky, Murraven, \& Tice, 1998; Frijda, 1986; Twenge, Catanese, \& Baumeister, 2002, 2003; Yuille \& Tollestrup, 1992).

These findings show that much of the learning during internships is implicit and incidental. What purposeful learning activities students undertake seem to be limited to learning from books and observing and/or assisting experts performing an interesting procedure they want to learn. Most students show little active involvement in learning, cannot or do not use self-directed learning skills in practice (they may be self-directed when learning from books), and are lacking in successful coping skills. When students are not consciously involved in their learning, do not know what they can expect from learning in practice or how to learn in practice, or are lacking in relevant learning skills or skills to cope with stressful experiences, and when supervisors do not stimulate self-directed learning skills, it seems inevitable that many valuable learning experiences may be wasted.

\section{Critical reflections and further research}

\section{Qualitative research methodology}

Qualitative research gives insight into patterns and dynamics. Because that was the goal of the studies in this thesis, mainly qualitative research methodologies were used. In Studies 1 and 2 students were interviewed using a critical incidents method. Only neutral questions were asked about how and what they learned during their internships. This was considered to be the most appropriate method to explore students' views of learning activities and processes, without steering them in any direction or prompting them to name certain ways of learning. An important result from this study is that students are not very conscious of their learning du- 
ring internships and do not use many self-directed learning strategies. Although only a small group of students was interviewed, these results add to the growing body of evidence from very different areas and with different research methodologies, giving reason to assume that our findings are likely to be valid (i.e. Dornan, Hadfield, Brown, Boshuizen, \& Scherpbier, 2005; Kilminster \& Jolly, 2000; Kilminster, Jolly, \& Van der Vleuten, 2002; Niemantsverdriet, Van der Vleuten, Majoor, \& Scherpbier, 2005; Van Eekelen, Boshuizen, \& Vermunt, 2005).

In Study 3 systematic and in depth interviews were conducted to gain insight into how students cope with stressful experiences during internships. An interview technique from rational emotive therapy (Ellis \& Grieger, 1977) was used because it has the potential to afford detailed insight into a specific situation and in the way it is handled by someone. Because this method asks for very factual and detailed descriptions, it is possible to look at an experience from various perspectives. Despite the small number of participants, these interviews yielded a clear and systematic picture of how students cope with stressful experiences during internships. For generalisability to other research populations, this systematic interview technique is easy to replicate in other student populations. In addition to students with extreme stress levels, it would be interesting to interview students who experienced medium amounts of stress.

A strong feature of Studies 4 and 5 is the use of a real-life task to study differences in expertise in cognitive interviewing skills in mental health care. Although the methodology used is very time-consuming, investigating authentic task performance is the best way to study expertise differences in a reliable manner. Concerning the methodology of stimulated recall, Ericsson and Simon $(1980,1993)$ argued that useful and reliable verbal reports can be obtained when clear probes are used and retrospective reports are elicited directly after the task in question is performed. Furthermore, compared to other studies in which a qualitative and timeconsuming research methodology was used, a relatively large number of counsellors participated in this study, thereby increasing the chance of finding reliable patterns of results. Especially for expertise research in a new domain, like the domain of mental health care, the present study is strong in generating hypotheses about differences in cognitive interviewing skills, which can be studied in depth in further research.

\section{Studying students' views on learning in internships}

The picture that emerges from studies addressing only students' views on learning in internships will be limited. Interviews automatically yield problem descriptions and interpretations from the students' points of view. The viewpoints of other persons involved, such as supervisors, colleagues, patients/clients or the researcher, may differ from that of the students. Attribution theory recognises differences between actors and observers in attributions of causes of behaviour (Jones \& Nisbett, 1972). Students, as actors, will give other explanations for their behaviour than supervisors, as observers, or researchers who try to observe and chart the whole sys- 
tem. Jones and Nisbett found that those involved as actors are inclined to attribute behaviour to situational and external causes, while observers mainly attribute the actor's behaviour to his or her personality (dispositional or personality attributions). Researchers try to chart the whole system and the dynamics within this system. These different viewpoints may be at odds with each other. For example, when students report that it is important for them that their supervisors actively stimulate their learning, they may attribute any problems with this to the supervisors. A researcher, however, may recognise the problem but attribute it partly to students' failure to take responsibility for seeking coaching and support from their supervisors and partly to students' lack of adequate self-directed learning which prevents them from taking that responsibility. So, for research purposes, it seems very important to separate the problem description from the interpretations of the problem and the attributions to causes. Students may be able to report reliably on problems they experience, but there may be differences between researchers and students in their interpretation of the situation and attribution to causes. It is the task of the researcher to separate the attributions and interpretations from the problem. The interview method used in Study 3 may be promising in this respect. Because a rather objective and detailed description of an experience and a student's behaviour is elicited, it is possible to take various perspectives on the experience.

Despite the drawback of a limited point of view, students' views on learning during internships demonstrated that students are not very consciously involved in their learning process. However, this does not necessarily mean that they did not learn a great deal more than they reported. It is possible that they did not recognise their learning, because it may have occurred in a more implicit or incidental way (Eraut, 2000, 2004; Marsick, 2006; Marsick \& Watkins, 1990; Van der Klink \& Streumer, 2004). It seems that asking only neutral questions about the critical incidents students mentioned in the interviews, was not the most suitable method to study implicit learning. This leads to an important question for further research, namely what and how students learn implicitly during internships. This question is especially important in view of the finding that students' learning probably relies mainly on implicit methods. Although we should realise that implicit learning is not an easy process to unravel, it may be worthwhile for researchers to try and detect changes in behaviour that may reflect implicit learning.

\section{Studying reflection}

The results of the studies in this thesis show that students hardly ever use deliberate reflection in order to learn. However, research of reflection is hampered by the difficulty of determining criteria for reflection (see also: Mansvelder-Longayroux, 2006). Reflection involves looking back on experiences and becoming aware of, criticising, and analysing one's ideas, thoughts, feelings, actions, and assumptions relating to that experience. These processes can vary in intensity, which makes it hard to determine when to call something reflection. In the present study rather stringent criteria were used, which may have caused an underestimation of reflec- 
tion. However, this possibility is weakened by other studies on reflection which also found remarkably few indications of reflection (e.g. Niemi, 1997; Rosie \& Murray, 1998).

Another problem in studying reflection is that the research method itself may induce reflection. In many studies reflection is studied by interviewing students or asking them to keep a learning log (e.g. Niemi, 1997, Rosie \& Murray, 1998), both methods which implicit require students to look back on experiences. Reflections elicited in such a research setting, however, do not guarantee that the students did indeed use reflection as a method for learning in and from practice. As a consequence, these methods may lead to overestimation of the use of reflection. This makes it hard to design a study to investigate the role of reflection in learning in practice. To overcome this problem we only asked neutral questions in an interview using the critical incidents method.

\section{Practical implications}

The preceding discussion of the results of the studies in this thesis has revealed several areas of tension concerning learning in internships as well as suggestions for overcoming them.

\section{Learning versus assessment}

Students' concerns about making a good impression and their fear of being judged and making mistakes may be related to the area of tension between learning and assessment. Students know that internships are intended as learning experiences for them but at the same time they think that they are expected to be able to perform tasks independently from day one. They try to reassure themselves by saying that they do not have to know everything yet, but they do not seem to succeed in convincing themselves. Hanging on to the idea that they have to be able to perform independently is not going to help them to learn. As a result, students are experiencing a great deal of stress, which hinders their learning. Furthermore, trying to live up to unrealistic expectations will contribute to their fear of judgement. Fear that their supervisors may see them as incompetent may hold students back from asking their supervisors for help. The other side of the picture, however, concerns the learning environment and supervisors' attitudes and skills. Dornan, Boshuizen, King, and Scherpbier (2007) found that the behaviour of, amongst other people, supervisors has a strong influence on students' participation and learning in clinical practice. Results of Study 2 also showed that a safe learning environment, in which students are allowed to make mistakes, is important for learning to occur.

It may be an important task for supervisors to promote students' learning by helping them to adjust their ideas of what is expected of them. It may be important that supervisors explicitly invite students to reflect on their experiences. Furthermore, supervisors should coach students on how they can learn from their experiences. Observation and feedback should be an obvious and natural part of the internships and thus occur much more frequently than is usually the case. Van der 
Hem-Stokroos, Daelmans, Scherpbier, Van der Vleuten, De Vries, and Haarman (2001) and Van der Hem-Stokroos, Daelmans, Van der Vleuten, Haarman, and Scherpbier (2003) also found that direct observation of and feedback on students' performance by staff did not occur very frequently and emphasised that these are crucial clerkship components that are highly valued by students. It might help when assessment becomes an integral part of internships instead of a big intimidating event at the end (Govaerts, Van der Vleuten, Schuwirth, \& Muijtjens, 2007). Students should receive feedback continuously and should be stimulated to ask for it.

\section{Active involvement in activities versus active involvement in learning}

Somehow, being in charge of their learning process during internships is not something that students really think about. Their main concern appears to be to be engaged in as many activities as possible and to see the greatest possible variety of diseases, cases and patients. Although this stimulates students' active involvement in working and implicitly in gaining professional knowledge and skills, it does not imply that they are actively involved in their learning processes. Thus learning occurs largely in an implicit and incidental way. In light of deliberate practice theory, however, this is an undesirable state of affairs. Deliberate practice theory states that active involvement in learning is a prerequisite for productive learning in practice (Ericsson, 2003; Ericsson, Krampe, \& Tesch-Römer, 1993); deliberate practice is indispensable in acquiring expertise; simply gaining experience is not enough. So students should be taught how to benefit from learning from experience in a new authentic learning environment. Here lies an important task for the educational programme. More attention should be given to preparing students for their internships. First of all, students should become aware of what and how they can learn from practice. In the present situation, they enter internships without a clear idea of how they can benefit and learn from their experiences. Furthermore, students should learn to set and evaluate learning goals and how to organise their learning experiences to reach their learning goals. Finally, reflection should receive more attention early in the curriculum and measures should be taken to achieve a more gradual transition from theory to practice in the undergraduate curriculum. However, reflection is part of most educational programmes, but this does not seem to help in fostering students' independent reflection. Further research is needed to find ways to foster reflection in students and help them to set and evaluate learning goals.

It should be noted on the other hand that the current tendency to improve students' learning by teaching them self-directed learning skills (e.g., Niemantsverdriet, 2007) may lead to underestimation of the strength of implicit and incidental learning and the role of the supervisor in the learning of students.

\section{Supervision versus self-directed learning}

The results of Studies 1, 2, and 3 show the importance of supervisors in fostering reflection and supporting student learning processes in internships. Students ap- 
pear to adopt a dependent attitude towards their supervisors. They know exactly what they want from their supervisors and how their supervisors should behave, but they take no steps to ensure that their supervisors meet their needs. Fear of judgement is likely to play an important role in this. Another possibility is that students may be able to recognise good and poor coaching and support, but do not know how to organise their own coaching and support. This is probably another skill students need to learn. None of the theories described in the introduction of this thesis deny the importance of supervisors for students' learning. Schön (1983, 1990) argued that supervisors play an important role in teaching students how to reflect on their experiences. Vygotsky's (1978) concept of a Zone of Proximal Development can be helpful in this respect. The zone of proximal development is the contrast between assisted performance and unassisted performance. When students need to learn new tasks they need their supervisors to coach and support them in their learning. Initially, supervisors have to teach and coach students how to perform the task in hand. As students become more skilled they should be given less assistance. Gradually, supervisors should hand over the responsibility for learning to the students and eventually withdraw from their task altogether. What was first guided by the supervisor becomes now guided and directed by the students themselves. This concept was later integrated in theories of scaffolding (see Lajoie, 2005 for the state of affairs). At the start of internship supervisors should probably take responsibility for students' learning and reflection and gradually bring students to a level where they can learn independently. Supervisors may play a central role in teaching students to take control over their own learning by gradually stepping back and teaching students to learn independently (see also: Van der Sanden, Streumer, Doornekamp, Hoogenberg, Teurlings, Van der Neut, and Wiekeraad-Stegink, 2001). Nevertheless, supervisors will probably continue to be important for students' learning.

An important prerequisite, however, for successful gradual reduction of external regulation of learning is that supervisors have sufficient knowledge of learning processes and supervision. Supervisors should be educated in supervision skills. Increasing supervisors' knowledge of important principles of learning and teaching may be a very important first step in changing their attitudes. Currently, many supervisors have not been trained in coaching and/or supervising students.

\section{Possessing knowledge and skills versus learning}

This area of tension has a lot in common with the tension between learning and assessment. Internships are meant for students to learn from. However, students should also have a certain amount of knowledge and skills before starting their internships. It is very difficult to determine what entrance level of knowledge and skills is required for internships. The question raised by the studies in this thesis is whether students have enough knowledge and skills to be able to benefit optimally from their internships. In other words: whether there is a discrepancy between what students know and what is expected of them in practice. Although this was not part 
of the research questions addressed in this thesis, the results show that it is an important question given that students appeared to experience massive difficulties in using their theoretical knowledge in performing authentic tasks. Prince, Van de Wiel, Scherpbier, Van der Vleuten, and Boshuizen (2000) reported similar difficulties faced by students who discovered that they lacked practical knowledge when confronted with patient problems in practice. Is this something students start to learn during their internships or should there be more attention for integration of theory and practical knowledge and skills in the undergraduate curriculum? Rote learning will not be the solution to these problems, but students may benefit from more applied knowledge before entering their internships.

Furthermore, the results of the studies in the present thesis show that students in mental health sciences might benefit from training in cognitive interviewing skills. Most educational programmes in therapeutic or diagnostic skills focus on the process skills and the content skills (e.g. Bögels, 1994; Ivey, 1971). Content skills are used to collect appropriate diagnostic, aetiological, and contextual information; process skills comprise interpersonal and communication skills. Cognitive interviewing skills, however, may be very important in enhancing the integration of content and process skills. They include knowledge and govern the thought processes of mental health professionals when diagnosing a client (Bögels, 1999). Cognitive interviewing skills involve attending to and seeking information about self, the client, and the therapeutic relationship, organising and integrating information into viable hypotheses and client conceptualisations, and planning, guiding and evaluating therapeutic interventions (Morran, 1986; Morran, Kurpius, Brack, \& Brack, 1995). The cognitive skills model for counsellor training developed by Morran et al. (1995) may offer a suitable approach to teaching students cognitive interviewing skills.

Finally, the results of Study 3 show that teaching and training of successful coping skills can be relevant to students. Further research is needed on how to develop an effective training programme for this.

\section{Conclusion}

Professional practice is the most authentic learning environment thinkable and therefore is expected to be a very powerful learning environment. However, the studies in the present thesis point to the overall conclusion that current internships suffer from various shortcomings which lessen their power as a learning environment. The current internships sometimes even seem to have a negative effect on the learning of students. The findings of this thesis suggest some important improvements to the current internships.

Students may benefit from better preparation, in the sense that they are informed in advance what to expect from their internships and what and how they can learn from clinical practice. In addition, students may benefit from supervisors who can help them by providing a safe learning environment and stimulating and gradually coaching them to a more self-directed way of learning. This implies that 
supervisors should know about learning processes in practice and have good supervision skills. Finally, observation and feedback should be an obvious and integrated part of internships and thus occur with far greater frequency than is customary in many internships.

\section{References}

American Psychiatric Association. (2000). Diagnostic and statistical manunl of mental disorders (4th edition TR ed.). Washington DC: American Psychiatric Association.

Baumeister, R. F., Bratslavsky, E., Muraven, M., \& Tice, D. M. (1998). Ego depletion: Is the active self a limited resource? Jotrmal of Personality and SocialPsychology, 74, 5, 1252-1265.

Baumeister, R. F., DeWall, C. N., Ciarocco, N. J., \& Twenge, J. M. (2005). Social exclusion impairs self-regulation. Journal of Personality and Social psychology, 88, 4, 589-604.

Baumeister, R. F., Twenge, J. M., \& Nuss, C. K. (2002). Effects of social exclusion on cognitive processes: Anticipated aloneness reduces intelligent thought. Journal of Personality and Social Psychology, 83, 4, 817-827.

Bögels, S. M. (1994). Teaching and assessing dingnostic interviening skills. Maastricht: Universitaire Pers Maastricht.

Bögels, S. M. (1999). Diagnostic interviewing in mental health care: Methods, training and assessment. In E. Memon \& R. Bull (Eds.), Handbook of the psychology of interviezining. Chichester: Wiley.

Christianson, S. A. (1992). Emotional stress and eyewitness memory: A critical review. Psychological Bulletin, 112, 284-309.

Dornan, T., Hadfield, J., Brown, M., Boshuizen, H. P. A., \& Scherpbier, A. J. J. A. (2005). How can medical students learn in a self-directed way in the clinical environment? Design-based research. Medical Education, 39, 356-364.

Dornan, T., Boshuizen, H. P. A. , King, N., \& Scherpbier, A. J. J. A. (2007). Experience-based learning: a model linking the processes and outcomes of medical students' workplace learning. Medical Education, 41, 1, 84-91.

Ellis \& Grieger (1977). Handbook of rational-emotive thernpy. Berlin: Springer.

Eraut, M. (2000). Non-formal learning and tacit knowledge in professional work. Britisch Journal of Educational Psychology, 70, 113-136.

Eraut, M. (2004). Informal learning in the workplace. Studies in Contintuing Education, 26, 2, 247-273.

Ericsson, K. A. (2003). The search for general abilities and basic capacities: Theoretical implications from the modifiability and complexity of mechanisms mediating expert performance. In: R. J. Sternberg and E. L. Grigorenko (Eds.). The psychology of abilities, competencies, and expertise. Cambridge: Cambridge University Press.

Ericsson, K. A., Krampe, R. T., \& Tesch-Römer, C. (1993). The role of deliberate practice in the acquisition of expert performance. Psychological Review, 100, 3, 363-406.

Ericsson, K. A., \& Simon, H. A. (1980). Verbal reports as data. Psychologicnl Review, 87, 3, 215-251.

Ericsson, K. A., \& Simon, H. A. (1993). Protocol analysis: Verbal reports as data. Revised edition. Cambridge MA: Massachusetts Institute of Technology.

Frijda, N. H. (1986). The enotions. Cambridge: Cambrigde University Press.

Govaerts, M. J., Van der Vleuten, C. P. M., Schuwirth, L.W., \& Muijtjens, A. M. (2007). Broadening perspectives on clinical performance assessment: Rethinking the nature of in-training assessment. Advances of Health Sciences Education Theory and Practice, 12, 2, 239-260.

Irby, D. M. (1995). Teaching and learning in ambulatory care settings: A thematic review of the literature. Academic Medicine, 70, 10, 898-931.

Ivey, A. E. (1971). Microcounselling: Innovations in interviewing training. Springfield: Thomas.

Jones, E. E., \& nisbett, R. E. (1972). The actor and the observer: divergent perceptions of the causes of behavior. In E. T. Jones, D. E. Kanouse, H. H. Kelley, R. E. Nisbett, S. Valins, \& B. Weiner (eds.) Attribution: perceiving the causes of behnvior (pp 79-94). Morristown: General Learning Press.

Kilminster, S., \& Jolly, B. (2000). Effective supervision in clinical practice settings: A literature review. Medical Education, 34, 827-840. 
Kilminster, S., Jolly, B., \& Van der Vleuten, C. P. M. (2002). A framework for effective training for supervisors. Medical Tencher, 24, 4, 385-389.

Lajoie, S. P. (2005). Extending the scaffolding metaphor. Instructional Science, 33, 541-557.

Lawrence, S. L., Lindemann, J. C., \& Gottlieb, M. (1999). What students value: Learning outcomes in a required third-year ambulatory primary care clerkship. Academic Medicine, 74, 6, 715-717.

Lazarus, R. S. (1993a). Coping theory and research: Past, present and future. Psychosomatic Medicinte, $55,234-247$.

Lazarus, R. S. (1993b). From psychological stress to the emotions: A history of changing outlooks. Annual Review of Psychology, 44, 1-21.

Mansvelder-Longayroux, D. (2006). The learning portfolio as a tool for stimulating reflection by student teachers. Dissertation. Leiden: Leiden University Graduate School of Teaching.

Mansvelder-Longayroux, D., Beijaard, D., \& Verloop, N. (2002). Het portfolio als reflectieinstrument voor docenten in opleiding (The portfolio as reflection-instrument for student teachers). Pedagogische Studieën, 79, 269-286.

Marsick, V. (2006). Informal strategic learning in the workplace. In: J. N. Streumer (Ed.). Workrelated learning (pp. 51-69). The Netherlands: Springer.

Marsick, V. J., \& Watkins, K. E. (1990). Informal and incidental learning in the workplace. London: Routledge.

Morran, D. K. (1986). Relationship of counselor self-talk and hypothesis formulation to performance level. Journal of Counseling Psychology, 33, 4, 395-400.

Morran, D. K., Kurpius, D. J., Brack, C. J., \& Brack, G. (1995). A cognitive-skills model for counselor training and supervision. Journal of Counseling \& Development, 73, 384-389.

Niemantsverdriet, S., Majoor, G. D., Scherpbier, A. J. J. A., \& Van der Vleuten, C. P. M. (2004). I found myself a down-to-earth Dutch girl: A qualitative study into learning outcomes from interships abroad. Medical Education, 38, 749-757.

Niemantsverdriet, S., Van der Vleuten, C. P. M., Majoor, G. D., \& Scherpbier, A. J. J. A. (2005). An explorative study into learning on international internships; experiential learning processes dominate. Medical Education, 39, 1236-1242.

Niemantsverdriet, S. (2007). Learning from international internships. A reconstruction in the medical domain. Dissertation. Maastricht: University Press Maatricht.

Niemi, P. M. (1997). Medical students' professional identity: self-reflection during the preclinical years. Medical Education, 31, 408-415.

Prince, K. J. A. H., Van de Wiel, M. W. J., Scherpbier, A. J. J. A., Van der Vleuten, C. P. M., \& Boshuizen, H. P. A. (2000). A qualitative analysis of the transition from theory to practice in undergraduate medical training in a PBL-medical school. Advances in Health Sciences Education, 5, 105-116.

Rosie, J., \& Murray, R. (1998). An evaluation of learning on clinical placements in radiography. Medical Teacher, 20, 3, 227-236.

Schön, D. A. (1983). The reflective practitioner: How professionals think in action. London: Temple Smith.

Schön, D. A. (1990). Educaling the reflective practitioner. San Francisco: Jossey-Bass Publishers.

Twenge, J. M., Catanese, K. R., \& Baumeister, R. F. (2002). Social exclusion causes self-defeating behavior. Journal of Personality and Social Psychology, 83, 3, 606-615.

Twenge, J. M., Catanese, K. R., \& Baumeister, R. F. (2003). Social exclusion and the deconstructed state: Time perception, meaninglessness, lethargy, lack of emotion, and self-awareness. Journal of Personality and Social Psychology, 85, 3, 409-423.

Van der Hem-Stokroos, H. H., Daelmans, H. E. M., Scherpbier, A. J. J. A., Van der Vleuten, C. P. M., De Vries, H., \& Haarman, H. J. Th. M. (2001). How effective is a clerkship as a learning environment, Medical Teacher, 23, 608-613.

Van der Hem-Stokroos, H. H., Daelmans, H. E. M., Van der Vleuten, C. P. M., Haarman, H. J. Th. M., \& Scherpbier, A. J. J. A. (2003). A qualitative study of constructive clinical learning experiences, Medical Teacher, 25, 120-126.

Van der Klink, M., \& Streumer, J. (2004). De werkplek als leersituatie (The workplace as learning environment). In: J. Streumer, \& M. Van der Klink (Eds.) Leren op de werkplek (Learning at the workplace). Den Bosch: Reed Business Information. 
Van der Sanden, J. J. M., Streumer, J. N., Doornekamp, B. G., \& Teurlings, C. C. J. (2001). Botrustenen voor vernieunend voorbereidend middelbar beropssonderwijs IBuilding blocks for renewed and preparatory secondary education]. Utrecht: APS.

Van Eekelen, I. M., Boshuizen, H. P. A., \& Vermunt, J. D. (2005). Self regulation in higher education teacher learning. Higher Educntion, 50, 3, 447-471.

Vygotsky, L. S. (1978) Mind in Society: The development of higher osychological. Cambridge, MA: Harvard University Press

Yuille, J. C., \& Tollestrup, P. A. (1992). A model of the diverse effects of emotion on eyewitness memory. In S. A. Christianson (Ed.), Handbook of memory and emotion: Theory, research and practice (pp. 201-215). Hillsdale: Erlbaum. 


\section{Appendix}

\section{Thought clusters and categories}

\begin{tabular}{|c|c|}
\hline $\begin{array}{l}\text { Clusters (A-G) and categories } \\
(1-38)\end{array}$ & Description \\
\hline \multicolumn{2}{|l|}{ A. Metacognition } \\
\hline $\begin{array}{l}1 \text { Thoughts and/or doubts about } \\
\text { (lack of) knowledge and skills }\end{array}$ & $\begin{array}{l}\text { "I have to pay attention to asking open-ended questions", "I'm } \\
\text { asking a lot of yes/no questions", "I'm not sure how to formulate } \\
\text { this question", "I shouldn't have asked this", "I don't know } \\
\text { whether I should continue this line of questioning", "I don't } \\
\text { know whether this information is relevant", "I don't know all the } \\
\text { DSM-IV-TR criteria" }\end{array}$ \\
\hline $\begin{array}{l}2 \text { Using prior knowledge and/or } \\
\text { skills }\end{array}$ & $\begin{array}{l}\text { Using general prior knowledge relating to the diagnosis or pos- } \\
\text { sible explanations for the complaints ("This is often consistent } \\
\text { with...") Thoughts about other clients with similar complaints }\end{array}$ \\
\hline \multicolumn{2}{|c|}{ B. Regulation of the diagnostic interview } \\
\hline 3 Planning and structuring & $\begin{array}{l}\text { Indicating that certain information should be obtained and for } \\
\text { that purpose wanting to return to a particular issue and in doing } \\
\text { so commenting on the general structuring of the interview, plan- } \\
\text { ning the interview, deliberately postponing questions about } \\
\text { certain issues ("I am asking about his complaints first", "I will } \\
\text { not pursue this, because it's not important for now", "If his fa- } \\
\text { ther was an alcoholic, he may also drink too much. I will have to } \\
\text { ask him later on") }\end{array}$ \\
\hline 4 Lack of structure & $\begin{array}{l}\text { Remarks about lack of structure ("This interview totally lacks } \\
\text { structure", "I'm asking things in a very unstructured way") or ad } \\
\text { hoc structuring ("I'm going to ask about the relationship with } \\
\text { his wife now") }\end{array}$ \\
\hline $\begin{array}{l}5 \text { Finding it difficult to let go of } \\
\text { the planned structure }\end{array}$ & $\begin{array}{l}\text { Difficulties in diverging from the planned structure; Rigidly } \\
\text { sticking to the planned structure, even if the client's answers do } \\
\text { not fit the planned line of questioning or the client is telling } \\
\text { something else; Being unable to flexibly adjust the interview to } \\
\text { the client's story }\end{array}$ \\
\hline 6 Time & $\begin{array}{l}\text { Thoughts about the available time ("I feel rushed because of the } \\
\text { limited time", "I think I'm going to finish the interview now } \\
\text { because I don't know what else to ask.") }\end{array}$ \\
\hline $\begin{array}{l}7 \text { Adjusting the interview to the } \\
\text { limited available time }\end{array}$ & $\begin{array}{l}\text { Thoughts about adjusting the interview to the limited time avail- } \\
\text { able; Deciding not to ask about certain topics because there isn't } \\
\text { enough time }\end{array}$ \\
\hline $\begin{array}{l}8 \text { Inability to estimate the } \\
\text { amount of time left }\end{array}$ & $\begin{array}{l}\text { "I don't know how long I've been interviewing", "Do I still have } \\
\text { time?" }\end{array}$ \\
\hline
\end{tabular}


Appendix

\begin{tabular}{|c|c|}
\hline $\begin{array}{l}\text { Clusters }(A-G) \text { and categories } \\
(1-38)\end{array}$ & Description \\
\hline $\begin{array}{l}9 \text { Saying/asking what one is } \\
\text { thinking }\end{array}$ & $\begin{array}{l}\text { Saying what one is doing or asking at a certain moment without } \\
\text { explaining why the information is important, just thinking what } \\
\text { the question is going to be ("I'm going to ask how old he was } \\
\text { when his father died") and asking the question immediately after } \\
\text { that }\end{array}$ \\
\hline 10 Strategic thoughts & $\begin{array}{l}\text { Giving reasons for asking specific questions or performing cer- } \\
\text { tain actions; A clear reason for asking a question or performing } \\
\text { an action; Deliberately inducing a silence to see whether the } \\
\text { client keeps talking or waits for another question; asking open- } \\
\text { ended questions for a specified reason; thoughts about ways of } \\
\text { formulating the question, asking things in a certain way, or using } \\
\text { certain words; The content of the thought is also categorised } \\
\text { (Some strategies are concerned with building a working relation- } \\
\text { ship) }\end{array}$ \\
\hline \multicolumn{2}{|l|}{ C. Diagnostic reasoning } \\
\hline $\begin{array}{l}11 \text { Formulating diagnostic hy- } \\
\text { potheses }\end{array}$ & $\begin{array}{l}\text { Formulating diagnostic hypotheses in DSM-IV-TR terms ("I } \\
\text { think he has recurrent depression") }\end{array}$ \\
\hline 12 Testing diagnostic hypotheses & $\begin{array}{l}\text { Testing the DSM-IV-TR hypotheses ("I'm testing whether he has } \\
\text { depression with psychotic features") }\end{array}$ \\
\hline $\begin{array}{l}13 \text { Evaluating diagnostic hy- } \\
\text { potheses }\end{array}$ & $\begin{array}{l}\text { Evaluating the DSM-IV-TR hypotheses during the interview or } \\
\text { recognising new information as evidence in support of a certain } \\
\text { hypothesis ("Fatigue and loss of appetite are consistent with } \\
\text { depressive disorder") }\end{array}$ \\
\hline $\begin{array}{l}14 \text { Formulating diagnostic hy- } \\
\text { potheses not found in DSM-IV- } \\
\text { TR }\end{array}$ & $\begin{array}{l}\text { Formulating diagnostic hypotheses not found in DSM-IV-TR } \\
\text { "This man is expressing his problems somatically", or describ- } \\
\text { ing hypochondria without naming the disorder) }\end{array}$ \\
\hline $\begin{array}{l}15 \text { Testing diagnostic hypotheses } \\
\text { not found in DSM-IV-TR }\end{array}$ & $\begin{array}{l}\text { Testing diagnostic hypotheses not found in DSM-IV-TR ("I'm } \\
\text { testing whether his disorder consists of fear of suffering from } \\
\text { various diseases") }\end{array}$ \\
\hline $\begin{array}{l}16 \text { Evaluating diagnostic hy- } \\
\text { potheses not found in DSM-IV- } \\
\text { TR }\end{array}$ & Evaluating diagnostic hypotheses not found in DSM-IV-TR \\
\hline 17 Differential diagnosis & $\begin{array}{l}\text { Thoughts about the differential diagnosis ("This is serious. It } \\
\text { might be bipolar disorder or depression with psychotic fea- } \\
\text { tures.") }\end{array}$ \\
\hline 18 Etiology & $\begin{array}{l}\text { Factors that are important in the origin of the complaints, pre- } \\
\text { cipitating factors, predisposing factors ("I ask this question to get } \\
\text { information about important issues at that time", "I'm looking } \\
\text { for a possible cause of his complaints", "I think quitting his job } \\
\text { affected his complaints") }\end{array}$ \\
\hline
\end{tabular}




\begin{tabular}{|c|c|}
\hline $\begin{array}{l}\text { Clusters }(A-G) \text { and categories } \\
(1-38)\end{array}$ & Description \\
\hline \multicolumn{2}{|c|}{ D. Content of the diagnostic interview } \\
\hline 19 Exploration of complaint & $\begin{array}{l}\text { "O.k., he says he has headaches, then I want to know what } \\
\text { causes them and for how long he's had them"; Further specifica- } \\
\text { tion of the complaint; Asking about DSM-IV-TR critcria without } \\
\text { having formulated the diagnosis (Asking about suicide without } \\
\text { formulating depression as a possible diagnosis) }\end{array}$ \\
\hline 20 Further treatment & $\begin{array}{l}\text { Thinking about possible treatment "This client doesn't seem } \\
\text { eligible for psychotherapy, because he doesn't talk much of his } \\
\text { own accord" }\end{array}$ \\
\hline 21 Functional analysis & $\begin{array}{l}\text { Thoughts about situations in which the symptoms occur, the } \\
\text { client's feelings and thoughts in relation to symptoms, client's } \\
\text { behavior when symptoms occur and consequences ("I'm trying } \\
\text { to make a functional analysis", "I want to know what his } \\
\text { thoughts were in that situation") }\end{array}$ \\
\hline 22 Client's request for help & $\begin{array}{l}\text { Thoughts about why the client seeks treatment now ("I want to } \\
\text { ask why he seeks treatment for his complaints now", "I want to } \\
\text { know what he sees as the main problem") }\end{array}$ \\
\hline $\begin{array}{l}23 \text { Client's motivation to receive } \\
\text { mental health care }\end{array}$ & $\begin{array}{l}\text { Thoughts about whether this client would be motivated to re- } \\
\text { ceive mental health care, taking into account his focus on physi- } \\
\text { cal complaints ("Clients with physical complaints are often not } \\
\text { motivated to receive psychological care, so I want to know what } \\
\text { he thinks of talking to a psychologist") }\end{array}$ \\
\hline $\begin{array}{l}24 \text { Interconnectedness of com- } \\
\text { plaints }\end{array}$ & $\begin{array}{l}\text { Thoughts about the interconnectedness of the various symp- } \\
\text { toms/complaints. Are the physical complaints consistent with } \\
\text { depression or with hypochondria. Thinking about primary and } \\
\text { secondary diagnoses. }\end{array}$ \\
\hline $\begin{array}{l}25 \text { Asking about issues that are } \\
\text { normally covered in a diagnostic } \\
\text { interview }\end{array}$ & $\begin{array}{l}\text { Asking questions about issues that are normally covered in a } \\
\text { diagnostic interview, such as social environment, youth, psychi- } \\
\text { atric history, relationships, medication }\end{array}$ \\
\hline \multicolumn{2}{|c|}{ E. Client counselor relation and communication } \\
\hline 26 Working relationship & $\begin{array}{l}\text { Thoughts about building a working relationship with the client. } \\
\text { Thoughts about how this client with these complaints should be } \\
\text { treated in order to build or strengthen the working relationship } \\
\text { and/or collect relevant information. "I must not use words that } \\
\text { are too difficult for this client (otherwise he won't understand } \\
\text { me)", "I think it's wise to let the client talk freely", "Is the client } \\
\text { open to questions about other things than just his physical com- } \\
\text { plaints?" }\end{array}$ \\
\hline $\begin{array}{l}27 \text { Counselor's emotional reac- } \\
\text { tion to the client's story or com- } \\
\text { plaints }\end{array}$ & $\begin{array}{l}\text { "I'm relieved he tells something of his own accord", "I'm } \\
\text { amazed, he's doing it", being shocked by the client's plans to } \\
\text { commit suicide or being surprised about something the client } \\
\text { says. }\end{array}$ \\
\hline
\end{tabular}


Appendix

\begin{tabular}{|c|c|}
\hline $\begin{array}{l}\text { Clusters }(A-G) \text { and categories } \\
(1-38)\end{array}$ & Description \\
\hline 28 Countertransference & $\begin{array}{l}\text { Feelings that the client's behavior or attitude (speech, tone of } \\
\text { voice, vagueness of answers) evokes in the therapist, such as } \\
\text { compassion, irritation, concern. "This client is very irritating, } \\
\text { because he doesn't answer my question", "I'm thinking, come on } \\
\text { man be more precise in your answers (in a tone of voice that } \\
\text { clearly marks irritation)" }\end{array}$ \\
\hline 29 Miscommunication & $\begin{array}{l}\text { Misunderstanding or failing to understand what the client is } \\
\text { saying or why the client is saying something in response to the } \\
\text { counselor's probing. "I didn't understand what he was saying, } \\
\text { but I'm hesitant to ask him again" }\end{array}$ \\
\hline \multicolumn{2}{|l|}{ F. Client } \\
\hline 30 Thoughts about the client & $\begin{array}{l}\text { Thoughts about the client's person or attitude, his nonverbal } \\
\text { behavior, his way of presenting complaints. Noticing that the } \\
\text { client does not respond to reflection of feelings or that the client } \\
\text { is taking literally everything the counselor says }\end{array}$ \\
\hline 31 Wondering about the client & I.e. "I wonder whether the client...", "I wonder why he..." \\
\hline \multicolumn{2}{|l|}{ G. Miscellaneous } \\
\hline 32 Using a technique & $\begin{array}{l}\text { Using a technique or asking a question because that is what the } \\
\text { counselor has learned to do. "Good moment for a reflection of } \\
\text { feelings" }\end{array}$ \\
\hline $\begin{array}{l}33 \text { Describing the interview } \\
\text { process }\end{array}$ & $\begin{array}{l}\text { Thoughts that say something about the way the participant in- } \\
\text { terviews the client. "What I'm doing here, and I do that more } \\
\text { often, is ..." }\end{array}$ \\
\hline $\begin{array}{l}34 \text { Pursuing certain issues in } \\
\text { more detail. }\end{array}$ & $\begin{array}{l}\text { Pursuing an issue the client has brought up in greater detail. } \\
\text { "This may be the vagueness of an alcoholic, I have to ask more } \\
\text { detailed questions", "I don't trust his answer, I have to ask for } \\
\text { more details" }\end{array}$ \\
\hline 35 Simulated client & $\begin{array}{l}\text { Thoughts about interviewing a simulated client rather than a real } \\
\text { client, thoughts about the simulated client's performance ("This } \\
\text { is typical behavior of a simulated client", "He's playing his role } \\
\text { very realistically") }\end{array}$ \\
\hline 36 Irrelevant thoughts & $\begin{array}{l}\text { Letting one's attention wander, thinking about a shopping list, } \\
\text { etc }\end{array}$ \\
\hline 37 Experiment & Feeling self-conscious in front of the camera, etc \\
\hline 38 Not categorized & Thoughts that were too vague to be categorized.. \\
\hline
\end{tabular}




\section{Summary}

\section{Problem definition}

Professional practice is the most authentic learning environment thinkable and therefore is expected to be a very powerful learning environment. Most academic educational programs include an internship period in which students work on a research project or in a professional setting. These internships aim at various educational goals, including learning from experience, learning to apply and enrich theoretical knowledge and skills in practice, and tuning knowledge and skills to practice. Learning in internships, however, might be difficult for students, because the workplace learning environment, which is new for them and not specifically designed for learning, requires a new learning attitude and new learning skills. For many students, internships may be the first time they have to take so much responsibility for their own learning process. They have to (at least partly) choose their own learning experiences, set their own learning goals, seek out coaching and support, and apply self-directed learning skills such as reflection to learn from their experiences.

Research has been done on various aspects that influence learning in academic internships, e.g. the clinical teacher, stress level, the learning environment, and learning goals. Remarkably little research has been done on how students learn in their internships and what they learn, the learning processes and the learning results. Therefore, exploration of what and how students learn during their internships is the central focus of this thesis. More specifically, we focus on how and what individual students learn in the context of their internships. The context of our research into internships is students in undergraduate mental health sciences and medical training programmes of Maastricht University.

\section{Main results and overview of the thesis}

The present thesis consists of seven chapters. Chapter 1 contains the theoretical background to the studies and the research questions. Chapter 2 till 6 describe the various studies that aim at answering the research questions. In chapter 7 the answers to the research questions are given and a general conclusion is drawn. The starting point for the present thesis was Study 1, that focussed on the first two broad research questions, namely how and what students learn during their internships. On the basis of this first exploratory study, the following studies focussed on more specific factors that influence learning in internships and on how these factors influence learning. Every chapter has been written to read independently which inevitably leads to overlap across the chapters. 


\section{Chapter 1}

Chapter 1 includes an overview of relevant theories, namely experiential learning theories, self-directed learning theories, theories of workplace learning, theories of expertise development, and theories of learning and emotions. These theories describe different aspects of learning in practice and function as theoretical background for the various studies in the present thesis. Furthermore, chapter 1 describes the specific research questions and the research methods that were used to answer these questions. The research questions were:

1. What do students learn during their internships?

2. How do students learn during their internships?

3. What factors contribute to or impede learning in internships?

\section{Chapter 2}

In chapter 2 the first study is described. This study focused on the first two broad research questions, namely what and how students learned during their internships. This was an exploratory study, which was not aimed at testing a previously formulated hypothesis. Students in mental health sciences and medicine were interviewed about important learning experiences in their internships. They described several important learning experiences and answered questions about what was instructive, what was less instructive, which difficulties they came across, and how they learned from these experiences.

The results showed that many students entered internships with the broad but unspecified idea that they will learn as much as possible about professional knowledge and skills. Many students were not aware that they could learn other important things, such as learning about personal growth and learning about working. They did not learn these things - or were not aware that they did so until they were faced with difficult experiences that forced them to learn about personal growth or working. Furthermore, students preferred to be actively involved in their internships. With active involvement they mean actively performing as many tasks as possible and seeing as great a variety of diseases, cases and/or patients as possible.

In this light it seems a paradoxical finding that students seldom self initiated learning activities in which they were expected to take an active role, such as overcoming gaps in knowledge and skills and learning by preparation and evaluation of tasks an task performance. From the students' perspective, active involvement did not seem to have anything to do with active involvement in their learning process and using self-directed learning skills. Instead, active involvement seemed to be related to active performance of tasks to gain professional knowledge and skills.

Another important, but unexpected, result was that students in medicine reported spontaneously that they experienced a lot of stress during their internships, while students in mental health sciences did not report anything about feelings of stress. 


\section{Chapter 3}

Chapter 3 describes a study that focussed more specifically on how students used self-directed learning skills during their internships. The self-directed learning theories and experiential learning theories were used as theoretical background. The research questions were: 1) Do students use reflection in their learning, and, if so, in what way? 2) In what way do students learn from coaching and support and does this involve self-directed learning? 3) Do students formulate learning goals before starting their internships?

The results showed that very few interviewed students used deliberate reflection for their learning. Furthermore, supervisors appeared to play a crucial role in learning, but the majority of the students did not actively seek coaching and support. Students were rather dependent on their supervisors for learning and reflection. Finally, most students did not formulate learning goals before entering internship.

\section{Chapter 4}

The study described in Chapter 4 was inspired by an unexpected but important result of study 1 , namely that medical students spontaneously reported to experience a lot of stress during their internships, while students in mental health sciences did not spontaneously report about feelings of stress. This study aimed to augment our understanding of how students cope with stressful experiences during internships and the effects of stress on their learning. The theories about learning and emotion were the background to this study.

Medical and mental health sciences students with very high and very low selfreported stress levels were interviewed about stressful experiences and how they impacted their learning. An interviewing technique from the rational emotive therapy was used. Students described a stressful situation as lively and concretely as possible, and answered structured questions to explicate their thoughts, feelings, and behaviours in that situation. In this way a complete picture of the coping process and of the function of various coping strategies was obtained.

Situations that students frequently described as stressful were those in which they were anxious to make a good impression, afraid of making mistakes or being judged, or insecure about their skills.

Students with high stress levels used mainly emotion-oriented and/or avoidant coping strategies. They tried to reassure themselves and to carry on doing their work instead of confronting their stress. Students with low reported stress levels could be divided into a group using mostly avoidant coping strategies and a group using mostly task-oriented and emotion-oriented coping.

Concerning the influence of stress on learning, a remarkable discrepancy was found between what students reported and what the results showed. Many of the interviewed students said that feelings of stress had a positive influence on their learning, whereas many interviews revealed that feelings of stress hindered learning. An important factor that seemed to mediate the influence of stress on 
learning appeared to be the coping strategy used by students to handle stressful experiences. Students who used task-oriented coping strategies, were the only students who were successful in reducing their stresslevels. The students who only used emotion-oriented and/or avoidant coping strategies did not succeed in reducing their stress levels and appeared to pay very little attention to their learning. They were mainly trying to survive by avoiding stressful situations and/or denying their feelings of stress. This attitude also caused them to avoid potential learning experiences.

\section{Chapter 5}

In chapter 5 a study is described that focussed more specifically on what students learned during their internships. The goal of the study was to improve our knowledge of cognitive diagnostic interviewing skills that counselors use during diagnostic interviewing and of any differences between beginning and experienced counselors in the use of these skills. The study regarded all cognitive processes during a diagnostic interview. The following research questions were formulated: 1 ) What do counselors of various experience levels think during a diagnostic interview? 2) What are the differences between beginning and experienced counselors' cognitive processes? In addition we wanted to know: 3) Do beginning and experienced counselors differ in diagnostic accuracy?

Diagnostic accuracy was seen as an important indicator of the quality of cognitive interviewing skills. Results showed that experts made more accurate diagnoses than students and interns. The results of the analysis of cognitive processes in diagnostic interviewing showed that beginning and experienced counselors have a common understanding of the content to be covered in the diagnostic interview and of the way to do that. This common core of cognitive processes, shared by all groups, involves: understanding the client, his complaints and the way these complaints are expressed, the etiology, hypothesis generation, testing and evaluation, and their own emotional reactions. However, the novices' cognitive processes were accompanied by many thoughts expressing doubts about their knowledge and skills in the present situation. A similar situation applied to the intermediates, although to a considerably lesser extent. This may indicate a growth in confidence through working in professional practice. They also seemed to have learned to make first attempts at structuring and being in charge of a diagnostic interview. Furthermore, they had learned to ask many questions they needed to ask in a diagnostic interview and to collect a great deal of information from a client. Experts, on the other hand, were able to pay attention to many things at the same time, like diagnostic reasoning, structuring and planning of the interview and adjusting the interview to the limited time available, building and maintaining the working relationship with the client, and thinking about further treatment. Furthermore, experts' questions and actions were guided by clear goals and explicit strategies for obtaining important client information. They were able to ask client information in various ways. 


\section{Chapter 6}

In this chapter the second part of the study in chapter 5 is described. The aim of study 5 was to gain insight into differences between beginning and experienced counselors in the quality of their cognitive processes during diagnostic interviewing. Additionally, this study investigated possible indications of knowledge restructuring that may be related to differences in cognitive processes.

The results show qualitative differences between cognitive processes in the three groups on three levels: overall structure of the interview protocols (planning of the interview and adjustments during the interview), the way and extent to which control was exercised over the interview, and the subsequent steps in the diagnostic reasoning process (information detection, interpretation of the information, drawing conclusions or taking action on the basis of interpretations, and evaluation). Furthermore, indications for knowledge restructuring were found. Knowledge and skills in diagnostic interviewing appear to become automated with experience. Knowledge about the DSM-IV-tr categories appears to expand with experience, can be activated by multiple cues and its application becomes automated. Knowledge clusters become interrelated.

\section{Chapter 7}

In chapter 7 the research questions are answered, the studies were critically reflected on, and an overall conclusion is drawn. Furthermore, ideas for further research and implications of the results for practice were given.

\section{Conclusion}

Practice is the most authentic learning environment thinkable and therefore should be a very powerful learning environment. However, the studies in the present thesis lead to the overall conclusion that current internships suffer from various shortcomings, which lessen their power as a learning environment. The current internships sometimes even seem to have a negative effect on the learning of students. The findings of this thesis suggest some important improvements to the current internships. 


\section{Samenvatting}

\section{Doel van dit proefschrift}

De professionele beroepspraktijk is de meest authentieke leeromgeving denkbaar. De meeste universitaire studies omvatten een stageperiode waarin studenten werken in de beroepspraktijk of aan een onderzoeksproject. Leren tijdens een stage kan voor studenten best lastig zijn. Het verschilt in veel opzichten van leren in de voorgaande studiejaren en vraagt dan ook hele andere studievaardigheden van studenten. Als studenten stage gaan lopen, maken ze vaak voor het eerst kennis met de latere beroepspraktijk. Vaak is het ook voor het eerst dat studenten zoveel verantwoordelijkheid dragen voor hun eigen leerproces. Ze moeten, in ieder geval deels, hun eigen leerervaringen kiezen en/of creëren, en ze moeten zich andere manieren van leren eigen maken.

Gepubliceerde onderzoeken over leren tijdens universitaire stages betreffen vooral de coschappen van geneeskunde en richten zich veelal op specifieke aspecten die leren in deze stages beïnvloeden, zoals bijvoorbeeld de supervisor, stress, de leeromgeving en leerdoelen. Opmerkelijk is dat er tot op heden weinig onderzoek is gedaan naar hoe studenten leren in hun stage en wat ze leren. Dit is daarom de centrale vraag in dit proefschrift. Leren in de praktijk is lastig te onderzoeken omdat de praktijk een complexe omgeving is waarin veel verschillende factoren een rol spelen. Verder is het leren in een dergelijke situatie vaak impliciet, spontaan, en afhankelijk van de specifieke context.

Dit proefschrift richt zich op de vragen hoe en wat individuele studenten leren in de context van hun stage. Dit onderzoek is gedaan onder studenten geestelijke gezondheidskunde en studenten geneeskunde van de Universiteit Maastricht.

\section{Belangrijkste resultaten en opbouw van dit proefschrift}

Dit proefschrift bestaat uit zeven hoofdstukken. Hoofdstuk 1 bevat de theoretische achtergrond van het onderzoek en de onderzoeksvragen. Hoofdstuk 2 tot en met 6 beschrijven de verschillende onderzoeken die zijn gedaan om deze vragen te beantwoorden. In hoofdstuk 7 wordt antwoord gegeven op de onderzoeksvragen en wordt een algemene conclusie getrokken. Dit proefschrift start met een zo breed mogelijk onderzoek naar hoe en wat studenten leren in hun stage. Op basis van dit onderzoek wordt in de volgende hoofdstukken ingezoomd op specifiekere factoren die een rol spelen bij het leren in de stage en hoe deze factoren een rol spelen. Ieder hoofstuk staat op zichzelf en kan dus onafhankelijk van de andere worden gelezen. Hierbij moet echter rekening worden gehouden met de onvermijdelijke overlap tussen de hoofdstukken. 
Samenvatting

\section{Hoofdstuk 1}

Hoofdstuk 1 omvat een korte beschrijving van een aantal theorieën, namelijk theorieën over ervaringsleren ('experiential learning'), over zelfgestuurd leren, over leren op de werkplek, over expertise ontwikkeling, en over leren en emoties. Deze theorieën zeggen allemaal iets over verschillende aspecten van leren in de praktijk en fungeren als theoretische achtergrond voor de verschillende onderzoeken. Verder staan in hoofdstuk 1 de specifieke onderzoeksvragen beschreven en de onderzoeksmethoden die gebruikt zijn om deze vragen te beantwoorden. De onderzoeksvragen waren:

1. Wat leren studenten tijdens hun stage?

2. Hoe leren studenten tijdens hun stage?

3. Welke factoren dragen bij aan het leren tijdens de stage of belemmeren juist dit leren?

\section{Hoofdstuk 2}

In hoofdstuk 2 wordt het eerste onderzoek beschreven. Dit onderzoek richt zich op de eerste twee brede onderzoeksvragen, namelijk wat en hoe leren studenten tijdens hun stage. Studenten geestelijke gezondheidskunde en geneeskunde werden geïnterviewd over belangrijke leerervaringen tijdens hun stage. Ze beschreven een aantal belangrijke leerervaringen, en beantwoordden vragen over wat leerzaam was, wat minder leerzaam was, wat ze moeilijk vonden, en hoe ze leerden van deze ervaringen.

De resultaten laten zien dat studenten veelal aan hun stage beginnen met het brede, niet specifieke idee om zoveel mogelijk professionele kennis en vaardigheden op te doen. Veel studenten zijn zich niet bewust van het feit dat je van een stage ook andere belangrijke dingen kunt leren, zoals leren werken en leren op het gebied van persoonlijke ontwikkeling. Hierover leerden ze pas dingen, of waren ze er zich pas bewust van deze te leren, op het moment dat ze geconfronteerd werden met moeilijke situaties waarin ze min of meer gedwongen werden om hier aandacht voor te hebben.

Verder gaven studenten aan het meest te leren van het zelfstandig uitvoeren van taken en het zien van een zo gevarieerd mogelijk scala aan verschillende ziektes en/of patiënten. Dit impliceert dat studenten het belangrijk vinden een actieve rol te hebben tijdens hun stage. Opmerkelijk was echter dat studenten weinig leeractiviteiten vertonen waarin ze een actieve rol hebben, zoals bijvoorbeeld voorbereiden en evalueren van taken. Als studenten spraken over actief zijn bedoelden ze zoveel mogelijk taken doen en dingen zien. Dit heeft echter weinig te maken met actief leren en het gebruik van zelfgestuurde leervaardigheden. Een ander belangrijk, maar onverwacht, resultaat was dat studenten geneeskunde spontaan aangaven hun stages als stressvol te ervaren, terwijl studenten geestelijke gezondheidskunde hier niets over opmerkten. 


\section{Hoofdstuk 3}

Hoofdstuk 3 beschrijft een onderzoek dat meer specifiek ingaat of en hoe studenten gebruik maken van zelfgestuurde leervaardigheden tijdens hun stages. De theorieen over zelfgestuurd leren en ervaringsleren werden gebruikt als theoretische achtergrond. De onderzoeksvragen waren: 1) Gebruiken studenten reflectie als leeractiviteit, en, zo ja, hoe?, 2) Hoe leren studenten van supervisie en omvat dit zelfgestuurd leren?, en 3) Formuleren studenten leerdoelen voordat ze beginnen aan hun stage?

De resultaten laten zien dat weinig studenten doelgericht reflecteren als leerstrategie. Verder werd duidelijk dat supervisoren een cruciale rol spelen in het leren van studenten, maar dat de meerderheid van de studenten weinig initiatief toont om de supervisie te krijgen die ze wensen of noodzakelijk achten. De meeste geïnterviewde studenten stellen zich voor hun leren en reflecteren veelal afhankelijk op van hun supervisor. Tenslotte formuleren de meeste studenten geen leerdoelen voordat ze beginnen aan hun stage.

\section{Hoofdstuk 4}

Hoofstuk 4 beschrijft een ander onderzoek dat direct geïnspireerd is op de resultaten van de eerste studie. Het feit dat geneeskundestudenten spontaan vertelden hun stages als erg stressvol te ervaren, gaf aanleiding tot een meer specifiek onderzoek naar de invloed van stress en de manier waarop studenten daarmee omgaan (coping) op leren.

Studenten geneeskunde en geestelijke gezondheidskunde die een erg hoog of een erg laag stressniveau rapporteerden, werden geïnterviewd over stressvolle ervaringen tijdens hun stage, over hoe ze daarmee omgingen, en over hoe deze ervaringen hun leren beïnvloedden. Om een gedetailleerd beeld te krijgen van de stressvolle situaties en van hoe studenten omgingen met deze situaties, werd een interviewtechniek gebruik uit de rationeel emotieve therapie. Studenten beschreven een stressvolle situatie zo helder en levendig mogelijk, waarna ze gestructureerde vragen beantwoordden over hun gedachten, gevoelens, en gedrag in die situatie. Zo werd een compleet beeld gekregen van het copingproces en het doel van de gebruikte copingstrategieën.

De meeste stressvolle situaties die studenten beschreven, hadden betrekking op het willen maken van een goede indruk, de angst om fouten te maken en/of beoordeeld te worden, of onzekerheid over hun vaardigheden.

Studenten die een hoge mate van stress rapporteerden bleken veelal emotiegerichte en/of vermijdende copingstrategieën te gebruiken. Ze probeerden zichzelf gerust te stellen en bleven doorwerken in plaats van te proberen invloed uit te oefenen op de stressbronnen. Studenten die weinig stress rapporteerden vielen uiteen in twee groepen. De ene groep maakte veelal gebruik van vermijdende copingstrategieën en de andere groep van taakgerichte, al dan niet in combinatie met emotiegerichte, copingstrategieën. 
Wat betreft de invloed van stress op leren werd een opvallende discrepantie gevonden tussen wat studenten rapporteerden en wat de resultaten lieten zien. Veel van de geïnterviewde studenten rapporteerden dat stress een positief effect had op leren, terwijl uit de meeste interviews bleek dat het tegendeel het geval was. De gebruikte copingstrategieën leken een belangrijke mediërende factor te zijn. De studenten die gebruik maakten van taakgerichte copingstrategieën bleken als enige succesvol in het verlagen van het stressniveau. De studenten die alleen gebruik maakten van emotiegerichte en/of vermijdende copingstrategieën slaagden er niet in hun stressniveau te laten dalen en bleken weinig aandacht te hebben voor leren. Zij leken meer gericht op overleven door het zoveel mogelijk vermijden van stressvolle situaties en/of op het ontkennen van het ervaren van stress. Deze houding leek er ook voor te zorgen dat ze potentieel leerzame situaties/ervaringen vermeden.

\section{Hoofdstuk 5}

In hoofdstuk 5 wordt een onderzoek beschreven dat meer specifiek gericht was op wat studenten leren tijdens hun stage. Het onderzoek richtte zich op de vraag hoe goed studenten voor en na hun stage een diagnostisch interview konden uitvoeren en een diagnose konden stellen. Het onderzoek was gericht op alle cognitieve processen gedurende het interview. De onderzoeksvraag was: Wat denken therapeuten van verschillende ervaringsniveaus allemaal tijdens een diagnostisch interview? Welke verschillen bestaan er in cognitieve processen tussen beginnende en ervaren therapeuten? Een extra onderzoeksvraag was of beginnende en ervaren therapeuten verschilden in diagnostische accuraatheid.

Diagnostische accuraatheid werd gezien als belangrijke indicator van de kwaliteit van de cognitieve interviewvaardigheden. Resultaten lieten zien dat experts accuratere diagnoses stelden dan studenten en stagiaires. Uit analyse van de cognitieve processen bleek dat de cognitieve processen van beginnende en ervaren therapeuten dezelfde kern bevatten. Deze gemeenschappelijke kern bestond uit gedachten over begrijpen van de cliënt, de klachten van de cliënt, de etiologie van de klachten, formuleren van diagnostische hypothesen, testen van deze hypothesen, evalueren van de hypothesen, en de eigen emotionele reacties op de cliënt. Daarnaast rapporteerden de beginnende therapeuten veel twijfels over hun kennis en vaardigheden. Hetzelfde geldt voor stagiaires, alhoewel in mindere mate. Dit zou kunnen wijzen op een groei in vertrouwen door het werken in de beroepspraktijk. Stagiaires zetten ook de eerste stappen in het structureren van het interview en het uitoefenen van controle over het gesprek. Verder leerden ze veel vragen stellen en informatie verzamelen van de cliënt, hoewel ze deze informatie niet goed konden interpreteren. Ervaren psychotherapeuten daarentegen waren in staat tegelijkertijd aandacht te besteden aan veel verschillende dingen, zoals diagnostisch redeneren, structureren en plannen van het interview en het interview aanpassen aan de tijd, opbouwen en onderhouden van een werkrelatie met de cliënt en alvast denken aan toekomstige behandeling. Verder hadden experts veel helderder doelen en meer expliciete strategieën voor het verkrijgen van belangrijke informatie van de cliënt. 
Ze hadden verschillende manieren van uitvragen van informatie van de cliënt, die ze nodig hadden voor het stellen van een diagnose.

\section{Hoofdstuk 6}

In dit hoofdstuk wordt het tweede deel van het onderzoek in hoofdstuk 5 beschreven. Het doel van studie 5 was meer inzicht verwerven in de verschillen tussen beginnende en ervaren therapeuten in de kwaliteit van de cognitieve processen tijdens het diagnostisch interview. Daarbij werd in deze studie onderzocht of er mogelijk indicaties bestonden voor kennisherstructurering, die gerelateerd konden worden aan de verschillen tussen de groepen in cognitieve processen.

De resultaten lieten verschillen zien tussen de cognitieve processen van de drie groepen op drie niveaus: de algemene structuur van het interviewprotocol (planning van het interview en aanpassen daarvan tijdens het interview), de manier en mate waarin controle werd uitgeoefend op het gesprek, en de opeenvolgende stappen in het diagnostisch redeneerproces (informatie selecteren, interpretatie van deze informatie, trekken van conclusies of acties ondernemen op basis van de interpretaties, en evaluatie).

\section{Hoofdstuk 7}

In hoofdstuk 7 wordt antwoord gegeven op de onderzoeksvragen, wordt het onderzoek kritisch beschouwd, en wordt een algemene conclusie getrokken. Verder worden aanbevelingen gedaan voor vervolgonderzoek en worden implicaties beschreven die de onderzoeken in dit proefschrift hebben voor stages.

\section{Algemene conclusie}

De beroepspraktijk is de meest authentieke leeromgeving denkbaar en zou een zeer krachtige leeromgeving zijn. Echter, de onderzoeken zoals beschreven in dit proefschrift leiden tot de algemene conclusie dat de huidige stages nog veel tekortkomingen bevatten die ertoe leiden dat ze momenteel functioneren als een minder optimale en krachtige leeromgeving dan ze zouden kunnen zijn. De huidige stages lijken soms zelfs een negatief effect te hebben op het leren van studenten. Dit proefschrift geeft een aantal mogelijke verbeteringen voor de huidige stages. 


\section{Curriculum Vitae}

Agnes Wagenaar was born on the 6th of september 1973 in Burgum, The Netherlands. In 1990 she finished secondary education at the Drachtster Lyceum in Drachten, after which she studied at nursing school for one year at the Noordelijke Hogeschool in Leeuwarden. From 1991 until 1997 she studied clinical psychology at the University of Groningen (Rijksuniversiteit Groningen). During these years she combined therapeutical work with research activities and she gained experience in teaching activities. From 1998 until 2005 Agnes was a PhD student at the Department of Educational Development and Research at Maastricht University where she investigated what and how students learn in internships. She also worked as a tutor and trainer and supervised students with their master thesis. From april 2005 until januari 2006 Agnes worked as a psychologist at Stichting De Hoop, an organisation for addiction care. From april 2006 she did a postgraduate education programme training as a health psychologist at Accare Child Psychiatry in Groningen. She graduated in april 2008. She is currently working as a health psychologist at Verslavingszorg Noord Nederland, addiction care.

Agnes Wagenaar werd geboren op 6 september 1973 in Burgum. In 1990 slaagde ze voor haar HAVO examen op het Drachtster Lyceum in Drachten, waarna ze in 1991 haar propedeuse haalde van de $\mathrm{HBO}-\mathrm{V}$ aan de Noordelijke Hogeschool in Leeuwarden. Van 1991 tot en met 1997 studeerde ze klinische psychologie aan de Rijksuniversiteit Groningen. Tijdens haar studie heeft ze onderzoek en therapeutisch werk gecombineerd en deed ze ervaring op in het geven van onderwijs. Vanaf 1998 tot en met 2005 werkte Agnes als promovendus bij Onderwijsontwikkeling en Onderwijsresearch aan de Universiteit Maastricht. Gedurende haar promotietraject gaf ze veel onderwijs als tutor en trainer en begeleidde ze studenten bij het schrijven van hun afstudeerscriptie. Vanaf april 2005 tot en met januari 2006 werkte Agnes tevens als psycholoog / behandelcoördinator in de verslavingszorg bij Stichting De Hoop. Daarna heeft ze de opleiding tot gezondheidszorgpsycholoog gedaan bij Accare kinder- en Jeugdpsychiatrie in Groningen. In april 2008 heeft ze deze opleiding afgerond. Momenteel werkt Agnes als GZ-psycholoog bij Verslavingszorg Noord Nederland. Daar werkt ze onder andere mee aan het opzetten van internetbehandelingen voor verslaving en een comorbide depressie of angststoornis. 